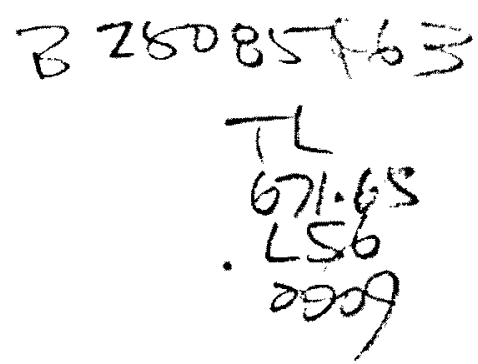

COMPUTATIONAL AERO ACOUSTICS

ANALYSIS OF AN AIRCRAFT CLIMATE CONTROL SYSTEM

\author{
by \\ Lin, Arthur Kar Leung, \\ Bachelor of Aerospace Engineering, \\ Ryerson University, 2007
}

\author{
A thesis \\ presented to Ryerson University \\ in partial fulfillment of the \\ requirements for the degree of \\ Master of Applied Science \\ in the Program of \\ Aerospace Engineering
}

Toronto, Ontario, Canada, 2009

(C) Arthur Kar Leung Lin, 2009 


\section{Author's declaration}

I hereby declare that I am the sole author of this thesis.

I authorize Ryerson University to lend this thesis to other institutions or individuals for the purpose of scholarly research.

I further authorize Ryerson University to reproduce this thesis by photocopying or by other mcans, in total or in part, at the request of other institutions or individuals for the purpose of scholarly research. 


\title{
COMPUTATIONAL AERO ACOUSTICS ANALYSIS OF AN AIRCRAFT CLIMATE CONTROL SYSTEM
}

\author{
Arthur Kar Leung Lin \\ Master of Applied Science, Aerospace Engineering, 2009 \\ Aerospace Engineering \\ Ryerson University
}

\begin{abstract}
With a higher standard of living and education, engineers are paying more attention on how the surrounding environment affects the public's comfort. Aircraft cabin noise is one of the main concerns for most airlines with surveys done to understand what customers feel and research to understand how noise can be modeled with state-of-the-art aero acoustic theories. In this work, computational aero acoustics was performed to simulate flow through a duct with an orifice plate as part of an aircraft environmental control system and to compare the results with experimental data. Experimental results of a low velocity flow with large orifice demonstrated better agreement than a high velocity flow with a small orifice plate. The numerical solution and experimental results were found to agree within $10 \%$ for broadband noise. Further research is required for better computational results for flow through a small orifice plate.
\end{abstract}




\section{Acknowledgements}

I would like to express my gratitude to all those who gave me the possibility to complete this thesis. I want to thank the Department of Core Engineer of Bombardier Aerospace Toronto for giving me permission to commence this thesis in the first instance, to do the necessary research work and to use departmental data. I have furthermore to thank my focal, Mr. George Waller.

I am deeply indebted to my supervisor Professor Jeffrey Yokota, Ph.D., Associate Professor and Graduate Program Director of the Department of Aerospace Engineering, Ryerson University, whose help, stimulating suggestions and encouragement helped me in all the time of research for and writing of this thesis.

Especially, I would like to give my special thanks to my parents for their support which enabled me to complete this work. 


\section{Table of Contents}

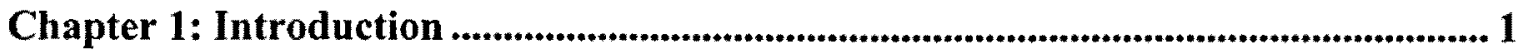

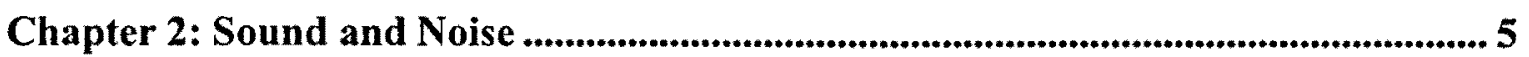

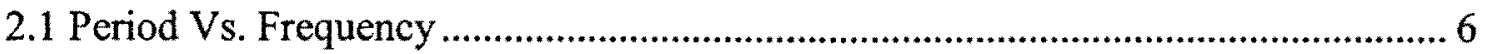

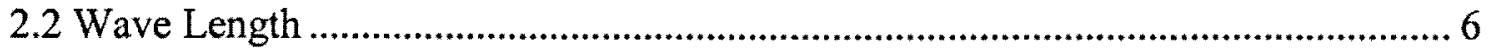

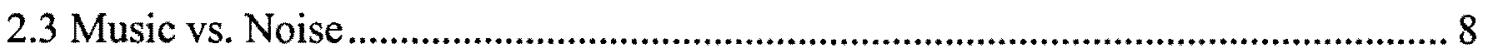

2.4 Spectrum

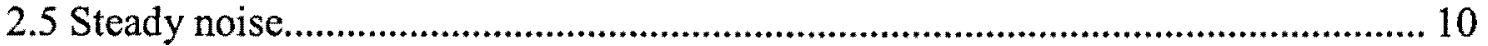

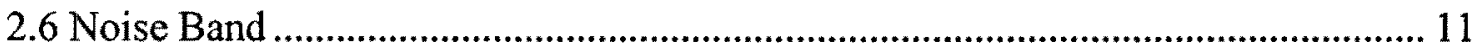

2.7 Decibels and Weighted Decibels Scale ...................................................................... 13

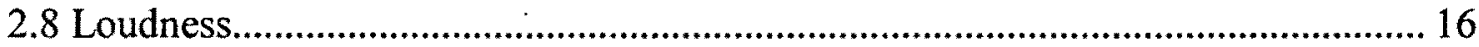

2.9 Aircraft noise

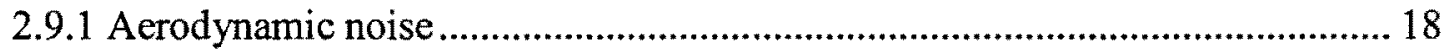

2.9.2 Engine and other mechanical noise …......................................................... 19

2.9.3 Noise from aircraft systems ............................................................................. 19

Chapter 3: Environmental Control System and Pipe Theory ........................................ 20

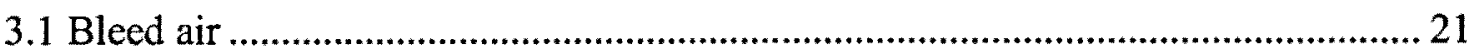

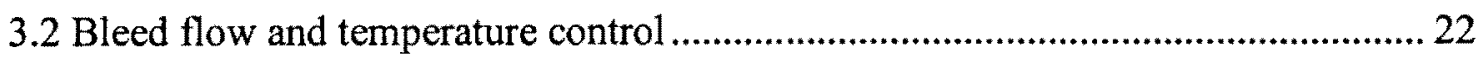

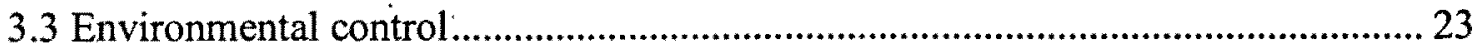

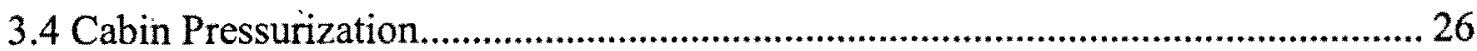

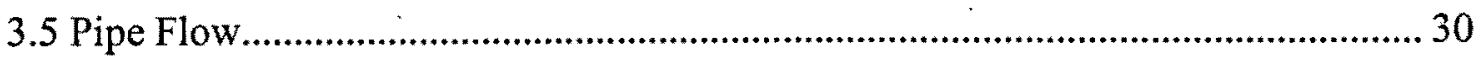

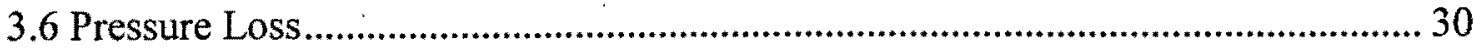

Chapter 4: Computational Theory ......................................................................................34

4.1 Theoretical (Analytical) Solution.............................................................................. 35

4.2 Computational Fluid Dynamic (Numerical) Solution ...............................................36

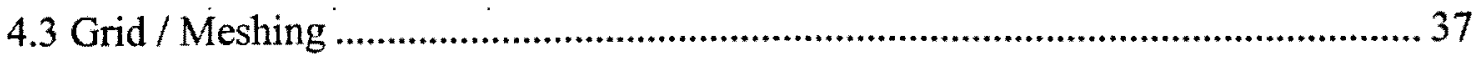

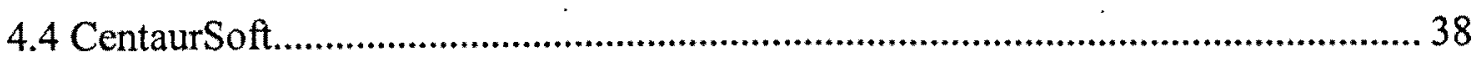

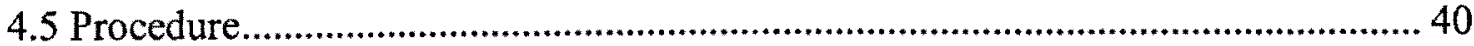

Chapter 5: CFD Result .......................................................................................................... 49 


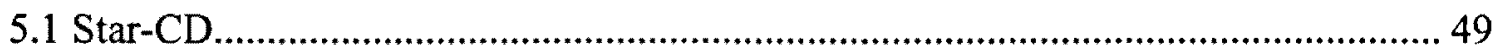

5.2 Boundary Conditions and Flow Properties ....................................................... 50

5.3 Grid Refinement and Accuracy Check.............................................................. 58

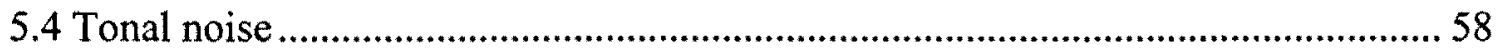

Chapter 6: Summary and conclusions ................................................................... 60

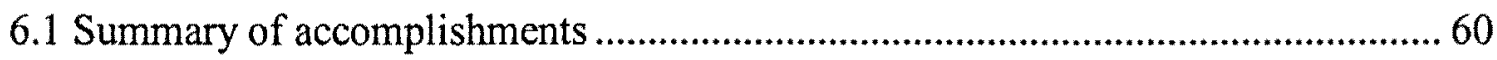

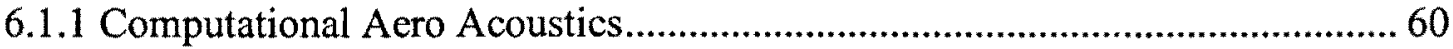

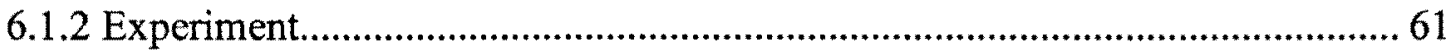

6.1.3 Comparison between computation and experimental result .......................... 62

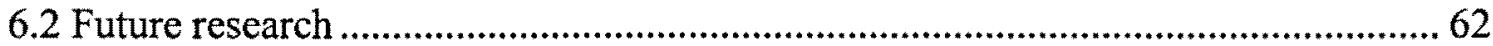

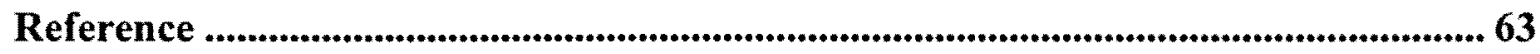




\section{List of Tables}

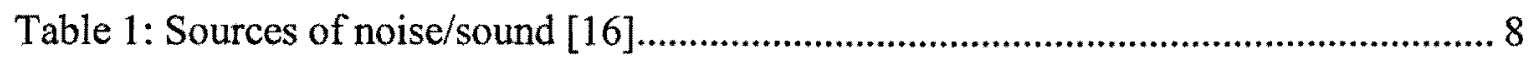

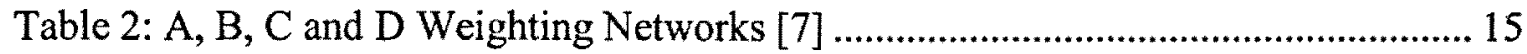

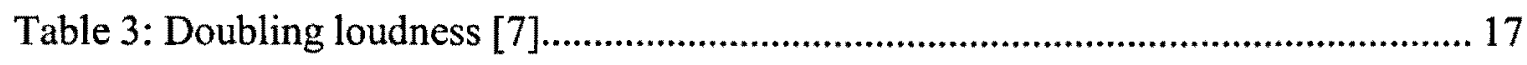

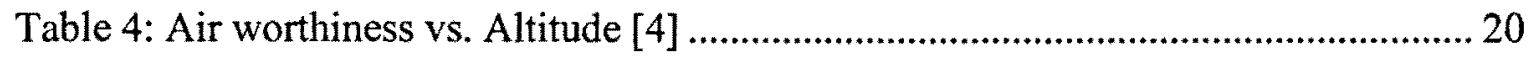

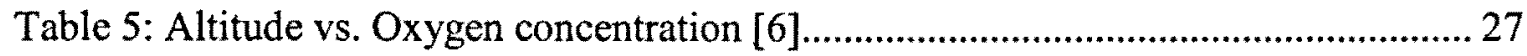

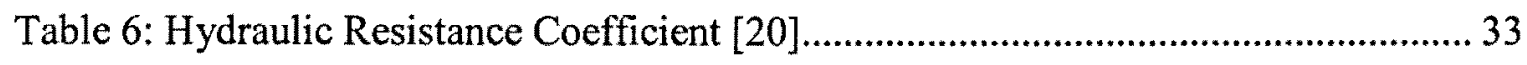
] 


\section{List of Figures}

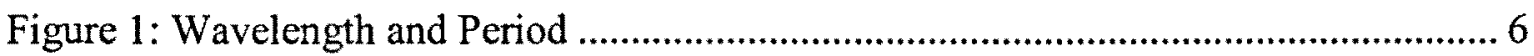

Figure 2: Wavelength and Frequency [15] ..................................................................

Figure 3: Example of Discrete Frequency noise [15] ................................................ 10

Figure 4: Example of Broad Band Noise [15] .............................................................. 11

Figure 5: Example of Different Frequency Band [15] ............................................... 12

Figure 6: Sensitivity of human ear at different SPL with respect to different frequency

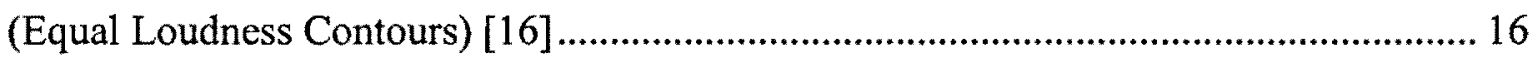

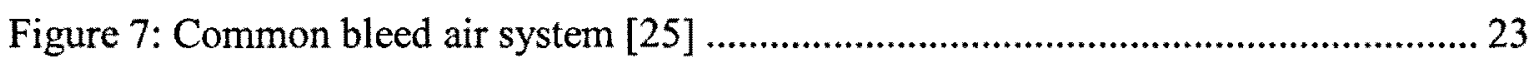

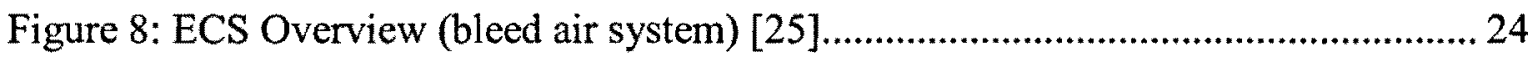

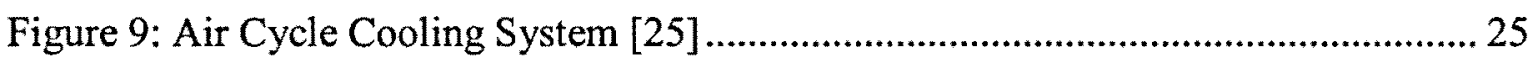

Figure 10: ECS of large airplane cabin temperature control [25] .................................... 26

Figure 11: ECS Overview (pressurization system) [25] ................................................... 28

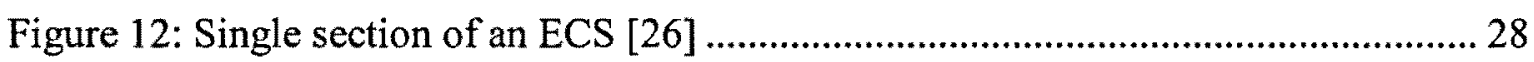

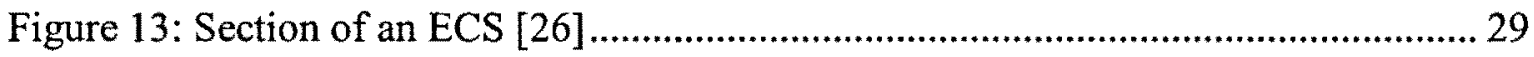

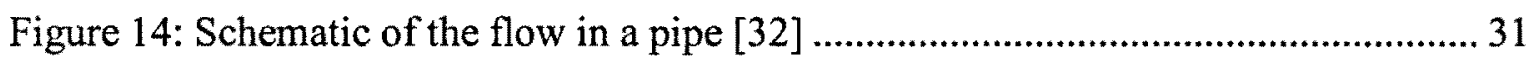

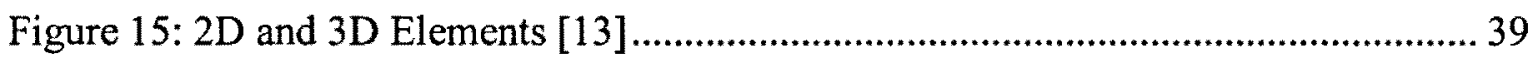

Figure 16: Use of source function [13] ......................................................................... 42

Figure 17: Source function is used behind the orifice plate............................................... 43

Figure 18: Curved Pull Back example [13] ..................................................................... 44

Figure 19: Curve pull back angle is set to be true............................................................ 45

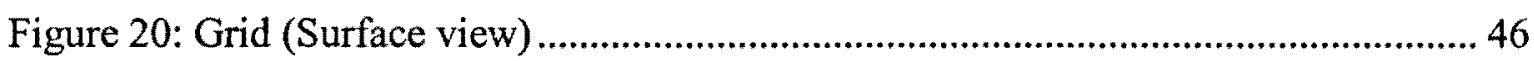

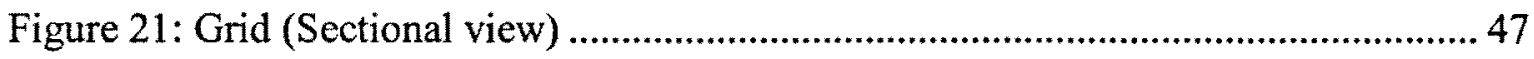

Figure 22: Grid (Sectional view, zoom in at inlet) ......................................................... 48

Figure 23: Experiment Geometry ................................................................................... 50

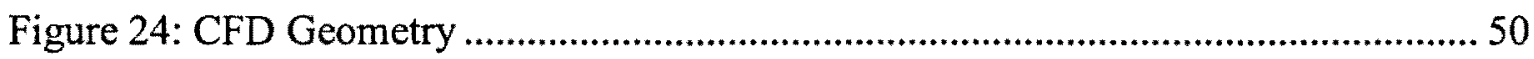

Figure 25: Flow coming in at all direction, flow separation at inlet................................. 52

Figure 26: CFD inlet is setup similar to the experiment.................................................. 52

Figure 27: Flow coming in smoothly, no flow separation at inlet..................................... 53 
Figure 28: Total pressure contour graph ..................................................................... 55

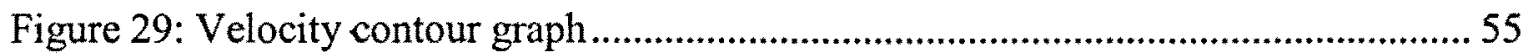

Figure 30: Velocity contour graph behind orifice plate.................................................... 56

Figure 31: Velocity vector graph behind orifice plate ...................................................56

Figure 32: Result from CAA and Experiment .............................................................. 57

Figure 33: Result from CAA and Experiment ................................................................59 


\section{Nomenclature}

\begin{tabular}{|c|c|}
\hline $\mathrm{D}$ & Pipe Diameter [m] \\
\hline e & Energy $[\mathrm{J}]$ \\
\hline $\mathrm{F}, \mathrm{f}$ & Force $[N]$ \\
\hline $\mathrm{L}$ & Pipe Length [m] \\
\hline $\mathrm{P}$ & Pressure $[\mathrm{Pa}]$ \\
\hline Q & Heat Energy [ $\mathrm{J}]$ \\
\hline $\mathrm{R}, \mathrm{r}$ & Radius \\
\hline $\operatorname{Re}_{\mathrm{D}}$ & Reynolds Number \\
\hline $\mathrm{S}$ & Area $\left[\mathrm{m}^{2}\right]$ \\
\hline SPL & Sound Pressure Level \\
\hline $\mathrm{t}$ & Time $[\mathrm{s}]$ \\
\hline$u, v, w$ & Velocity $[\mathrm{m} / \mathrm{s}]$ \\
\hline V & Velocity $[\mathrm{m} / \mathrm{s}]$ \\
\hline W & Work $[\mathrm{J}]$ \\
\hline $\mathrm{x}, \mathrm{y}, \mathrm{z}$ & Rectangular Coordinate \\
\hline$\lambda$ & Pipe Friction \\
\hline$\mu$ & Absolute Viscosity $\left[\mathrm{kg} / \mathrm{s}^{*} \mathrm{~m}\right]$ \\
\hline$v$ & Kinematic Viscosity $\left[\mathrm{m}^{2} / \mathrm{s}\right]$ \\
\hline$\rho$ & Density $\left[\mathrm{kg} / \mathrm{m}^{3}\right]$ \\
\hline$\tau$ & Shear Stress $\left[\mathrm{N} / \mathrm{m}^{2}\right]$ \\
\hline$\varsigma$ & Hydraulic Resistance Coefficien \\
\hline
\end{tabular}




\section{Chapter 1: Introduction}

As transportation in general, and air travel in particular, has become more common and more advance, passenger comfort expectations have increased. For example, ten years ago, heaters were the only standard feature in the climate control system of most European cars, however since the 1990s, mobile air conditioning has become one of the standard climate control feature in most European vehicles as well. [14] As transportation usage increases, passenger comfort expectations now demand air conditioning as a standard feature in both private and public vehicles. For example, the Toronto Transit Commission included air conditioning in subways as early as 1977 , model H5 [37], and has had air conditioning in buses since 1991, model OBI Orion V.[38]

Clearly, environmental control systems are very important because they help customers feel comfortable. Furthermore, airplane environmental control systems are more sophisticated than the simple air conditioning systems found in cars, buses, and ships. [25] The environmental control systems found in airplanes must control not just temperature, but also pressure, density and humidity. As airplanes fly at different altitudes, the outside air temperatures, pressures and densities are significantly different than the environmental conditions found inside the passenger cabins. For example, if the airplane is flying at $2000 \mathrm{~m}$ above sea level, the outside air pressure is $80 \mathrm{kPa}$, temperature is $2.0^{\circ} \mathrm{C}$, and density is $1.0 \mathrm{~kg} / \mathrm{m}^{3}$ [4], however, for passenger comfort, conditions inside the cabin must be maintained close to sea level standard, $101.2 \mathrm{kPa}, 20$ ${ }^{0} \mathrm{C}$ and $1.2 \mathrm{~kg} / \mathrm{m}^{3}$, correspondingly.

In aircraft, the performance of the environmental control system is interconnected with many other sub systems. The proper operation of the jet engine, the avionics system, the electrical systems, and the power generator all affect the overall performance of the environmental control system. Furthermore, varying environmental conditions in one section of a cabin will alter the temperatures and pressures throughout the aircraft. 
Clearly, these varying environmental conditions will affect passenger comfort and equipment performance. For example, since the cabin needs to be pressurized, the fuselage must not buckle under this pressure difference. The environmental control system itself is made up of many different structures. These structures include the pipes, junctions, valves, and orifice plates that are required to deliver the conditioned air to the various part of the cabin. Pipes are the metal tubes that the air flows through and junctions are used as connectors between multiple pipes. Valves control the direction of the flow while orifice plates control the flow rate within the piping system. [31] The overall climate control system is constructed from a number of combinations of these four basic components. Each of these combinations are grouped to define a specific sub system. Examples of these sub system include the cabin cooling pack heat exchanger, and the bleed air manifold. These sub systems are combined to form the basic infrastructure of the entire environmental control system. [40]

Increasingly, to lower operating costs, airlines are requiring manufacturers to reduce aircraft weight. This can be achieved by using lighter materials such as carbon fibre and light weight alloys, or by minimizing the number and size of as many parts as possible. For instance, the pipes used to construct the environmental control systems are often reduced to the smallest diameter possible. [36] The weight of the environmental control system is significant, and thus any reduction in the sizes of the pipes, the junctions, the valves and the orifice plates would significantly reduced the overall weight of the aircraft. However, any reduction in the weight and size of the environmental control system cannot compromise its overall performance. In particular, while a change in the dimensions of the aircraft environmental control system might help reduce its overall weight, it often results in other significant problems. For example, the benefits of reduced pipe diameters are offset by the problems associated with the increased flow velocities and the noise that is generated across orifice plates. [36] When high velocity flows crosses orifice plates, the flows become vortical and thus create significant amount of noise. Therefore, flow generated noise has become significant. [2]

Identifying acceptable levels of noise are difficult because there are no standards for how quiet are "good" or how noisy are "bad". [3] Music to one person could be noise to another. However, in general, sound that causes human discomfort and fatigue is more 
easily defined as noise. [15] High power or high intensity sound can lead to permanent hearing damage. [16] However, as found in several Boeing surveys, zero cabin noise is also not desirable. [33] If the background cabin noise is reduced to zero, or close to zero, conversations between seatmates can be heard several rows away; noises such as toilet flushing could be heard throughout the cabin; and private conversation would be nonexistent. Thus, total silence is not desirable. Currently, manufacturers like Boeing are looking for the optimal customers' cabin conditions. With existing technologies the noise generate outside the cabin can be reduced. However, noise generated within the cabin is not as easily controlled.

However, the best way to avoid a significant noise problem is to be aware of all the potential sources of noise and to minimize them throughout the design. Currently, externally generated noise can be controlled by mechanical noise reduction systems. However, since internally generated noise is fluid dynamic in nature, it cannot be reduced by these existing mechanical noise reduction systems. Currently the modeling of internal noise is not well established and requires high computational power. [36]

While significant knowledge and understanding of fundamental aero acoustics has been established $[1,2,24,25,35,36]$, an understanding of internal cabin noise is complicated by the interactions between the flow and the various components of the environmental control system When investigating the source of internal cabin noise the flow through the environmental control system, is modeled by its simplest form; the flow through pipe and an orifice.

In this work we will simulate the flows through the ducts and orifice plates of an aircraft environmental control system and then compare these results with experimental data provided by Bombardier Aerospace. The numerical flow simulations were obtained using the Star-CD program which is also provided by Bombardier Aerospace.

First, steady state simulations were conducted to verify appropriate grid resolution, to obtain the correct inflow boundary conditions needed to produce the required velocity profile crossing the orifice plate, and to ensure that the average pressure drop across the orifice plate matched experimentally verified values. 
Then, transient simulations were conducted to obtain total pressure distributions at various locations behind the orifice plate. These total pressure values were then processed through a Discrete Fourier Transform to obtain sound pressures which were then plotted vs. sound frequency.

Finally, these results were compared to experimental data which showed that the noise level predicted by the computational simulation were within $10 \%$ of the experimental result.

This work demonstrated that with the proper grid resolution, the proper inflow boundary conditions needed to produce fully developed flow in front of the orifice plate, and the correct combination of inflow and outflow boundary condition needed to create the average pressure drop across the orifice plate, one can reasonably predict the noise level generate by the orifice plate in a pipe. And once again, the orifice plate in a pipe combination is the basic building block of any aircraft environmental control system. 


\section{Chapter 2: Sound and Noise}

Sound can be defined as any pressure variation in an elastic medium in the form of sound waves from the sound source to the receptor. [3] These pressure waves can travel in air, water, or others from the sources to human ears or microphones. If these pressure waves are too slow or the changes are too gradual, human ear might not be able to detect the pressure variation. Pressure changes could be caused by any vibrating object which alternately compresses and expands the air surrounding the vibrator. Pressure waves of lower and higher pressure are sent out in all directions from the source. The sound waves change from the lower to higher pressure that is detected by the ear drum is what expresses as sound. [15] 


\subsection{Period Vs. Frequency}

One cycle of the pressure change is called a period, express in unit of time. [26] The measure of the rapidity of alterations of a periodic signal per unit time is called frequency, expressed in cycles per second or Hertz (Hz). [15] Therefore, frequency is also called the reciprocal of period or vice or versa, and is given as follows:

$\operatorname{Period}[s]=\frac{1}{\text { frequency }[\mathrm{Hz}]}$

\subsection{Wave Length}

As shown in Figure 1, period is one complete cycle from one peak to the next peak on the graph, in unit of time. And wavelength is the distance a sound wave travel in one complete cycle in unit of distance.

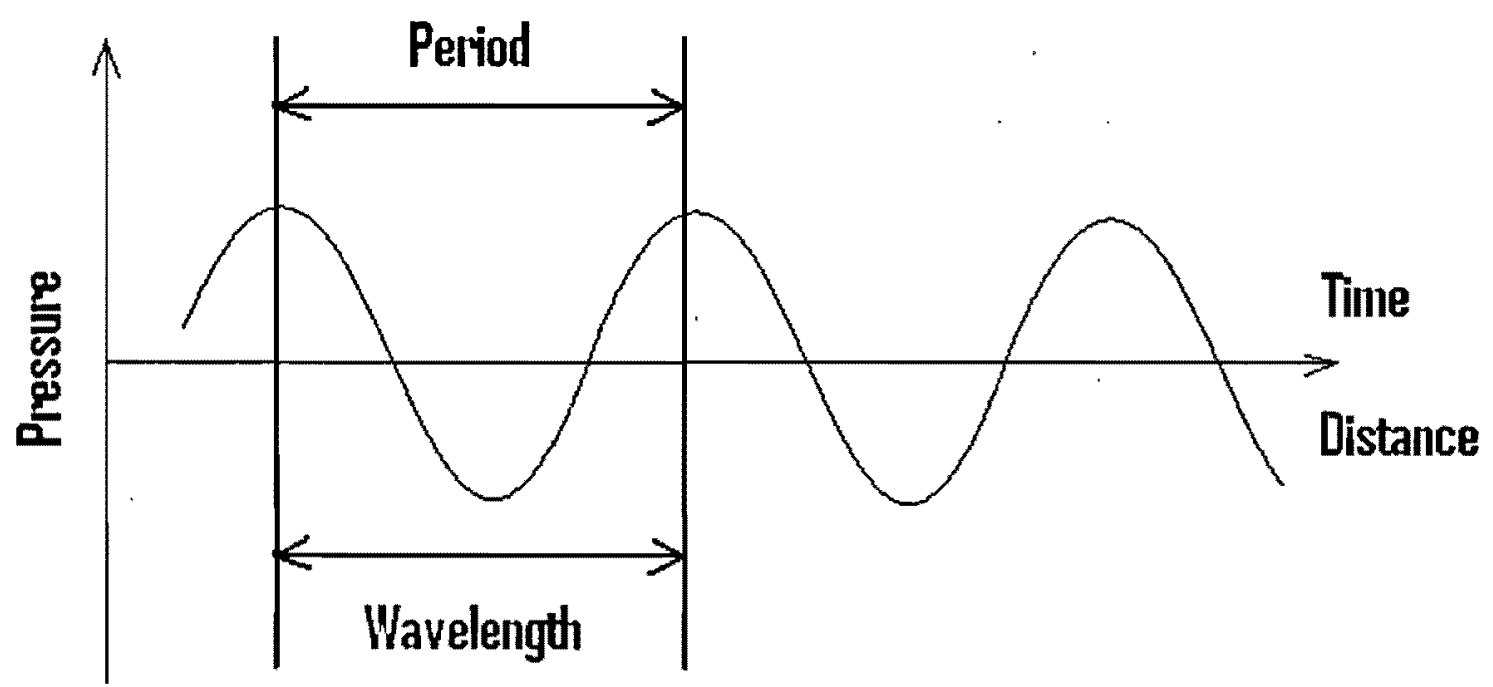

Figure 1: Wavelength and Period 
Speed of sound is the speed of the sound wave traveling through a medium. Speed of sound varies with the properties of the medium, for example, density of the medium, temperature of the medium, etc. [5] For purpose of sound measurement, the speed of sound in air is expressed as $340 \mathrm{~m} / \mathrm{s}$ or $372 \mathrm{yard} / \mathrm{s}$ at sea level and $15^{\circ} \mathrm{C}$ atmospheric temperature.

Wavelength can be calculated with,

$$
\text { wavelength }=\frac{\text { speed of sound }}{\text { frequency }}
$$

In general low frequency has large wavelength, and high frequency has small wavelength. [15] Figure 2 shows the relationship between wavelengths at three different frequency levels. An object in the sound path must be larger than a wavelength in order to significantly disturb the sound.
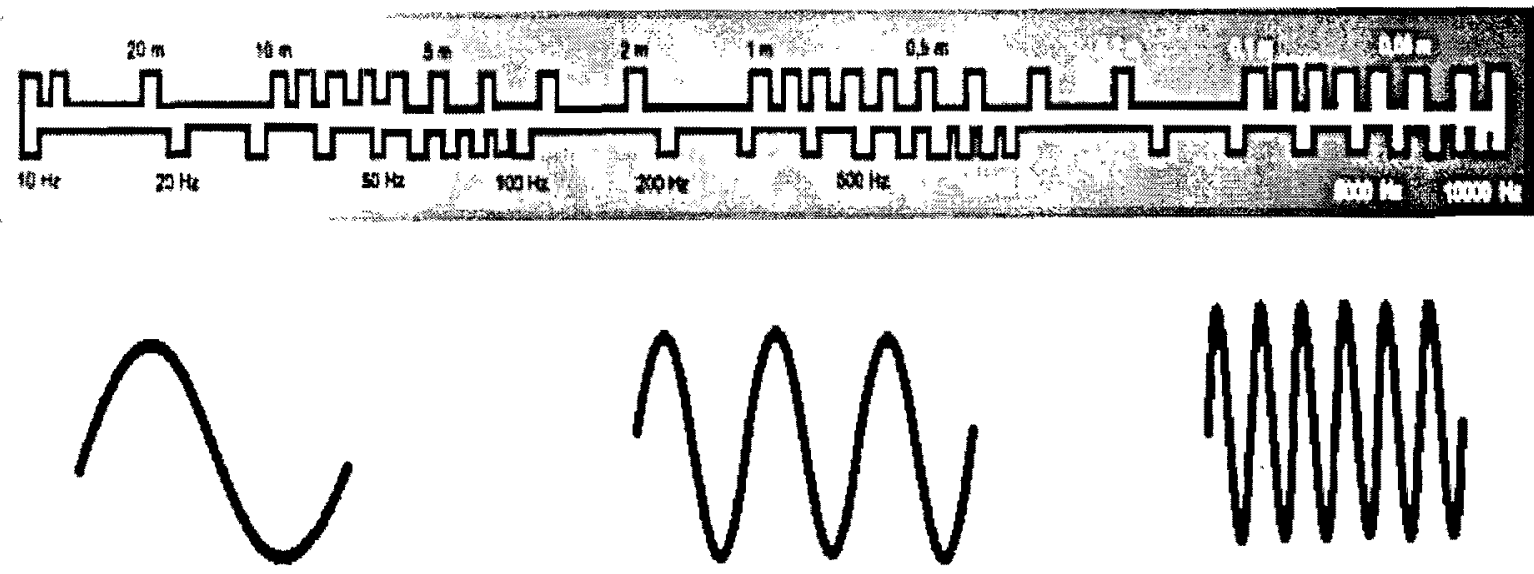
Low Frequency
Mid Frequency
High Frequency

Figure 2: Wavelength and Frequency [15] 
Speed of sound is the speed of the sound wave traveling through a medium. Speed of sound varies with the properties of the medium, for example, density of the medium, temperature of the medium, etc. [5] For purpose of sound measurement, the speed of sound in air is expressed as $340 \mathrm{~m} / \mathrm{s}$ or $372 \mathrm{yard} / \mathrm{s}$ at sea level and $15{ }^{\circ} \mathrm{C}$ atmospheric temperature.

Wavelength can be calculated with,

wavelength $=\frac{\text { speed of sound }}{\text { frequency }}$

In general low frequency has large wavelength, and high frequency has small wavelength. [15] Figure 2 shows the relationship between wavelengths at three different frequency levels. An object in the sound path must be larger than a wavelength in order to significantly disturb the sound.
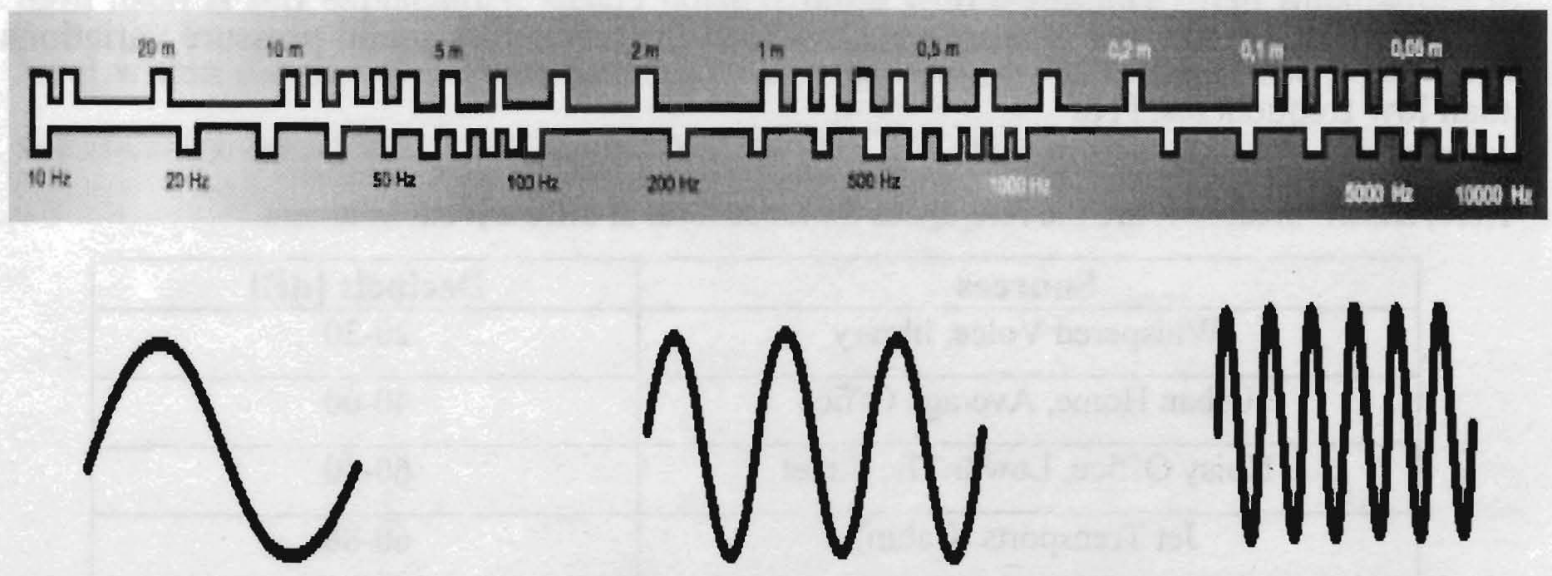
Low Frequency
Mid Frequency
High Frequency

Figure 2: Wavelength and Frequency [15] 


\subsection{Music vs. Noise}

The two main families of sound are music and noise. However, what is the difference between noise and music? For example, when rock music is played, people who like it might think it is music, but people who do not appreciate it, might think it is noise. And again, people who like classical music verses people do not. A German poet and humorist Wihelm Busch once mocked: "Music is always noise - related - and often not appreciated." [29] Therefore, sound/noise is a very difficult to define. In general and widely accepted definition for noise is sound that average people do not appreciated and find irritable. [16] Sound that does not carry useful information is also called noise. [10] When exposed to noise for long periods of time, it would cause human discomfort and fatigue. [16]

The lowest pressure change that normal adult can detect is 20 micro-Pascal of a pure tone at $1000 \mathrm{~Hz}$, which is equivalent to $0 \mathrm{~dB}$. Decibel $(\mathrm{dB})$ is a logarithmic scale to measure pressure change, it was devised to make calculations of noise levels manageable. The human ear's range starts at the threshold of hearing, $0 \mathrm{~dB}$, and ends at the threshold of pain, $140 \mathrm{~dB}$. Human ear is more sensitive to high frequencies sound pressure variations than low frequencies. [16]

Here, shown in table 1, are the references for noise level at different environment.

\begin{tabular}{|c|c|}
\hline Sources & Decibels [dB] \\
\hline Whispered Voice, library & $20-30$ \\
\hline Urban Home, Average Office & $40-60$ \\
\hline Noisy Office, Low traffic Street & $60-80$ \\
\hline Jet Transports (Cabin) & $60-88$ \\
\hline Public Address System & $90-100$ \\
\hline Busy City Street & $80-100$ \\
\hline Single Rotor Helicopter & $80-102$ \\
\hline Power Lawn Mower & $100-110$ \\
\hline Rock Concert & $115-120$ \\
\hline Jet aircraft at takeoff & $130-140$ \\
\hline
\end{tabular}

Table 1: Sources of noise/sound [16] 
Cabin noise is around $60-88 \mathrm{~dB}$, which is equivalent to a noisy office. It is necessary to reduce cabin noise, but in a public area, it might not be a good to reduce the noise level to a threshold of hearing. If the cabin is as quite as a library, flight attendants and passengers might need to move very carefully or slowly, in order not to make noise to disturb the others, which might make the passenger even more uncomfortable. Noise level in a public area might not be a case of "the lower the better"; it is good enough to reduce the cabin noise level to urban home or average office noise level.

\subsection{Spectrum}

As known, light is made up of different colours called the colour spectrum which can be seen when light passes through a transparent prism. Similarly sound can be analyzed with a noise spectrum, as sound is made up of different frequencies. Therefore, frequency is used as an independent variable for most of the sound analysis application.

Noise can be classified into two main families, steady noise and non-steady noise. The term itself is self explanatory, steady noise is noise with negligibly small fluctuations of level within the period of observation, and non-steady noise is noise whose level varies significantly during the period of observation. [31] 


\subsection{Steady Noise}

Discrete frequency noise is steady noise with audible discrete tones, this type of noise often has the pure tone over a number of frequencies. Each pressure level jump at various frequencies in Figure 3 is a discrete tone. Discrete frequency noise is the most common noise found in industry and it can caused by rotating parts of machines such as fans, internal combustion engines, transformers and pumps. [7]

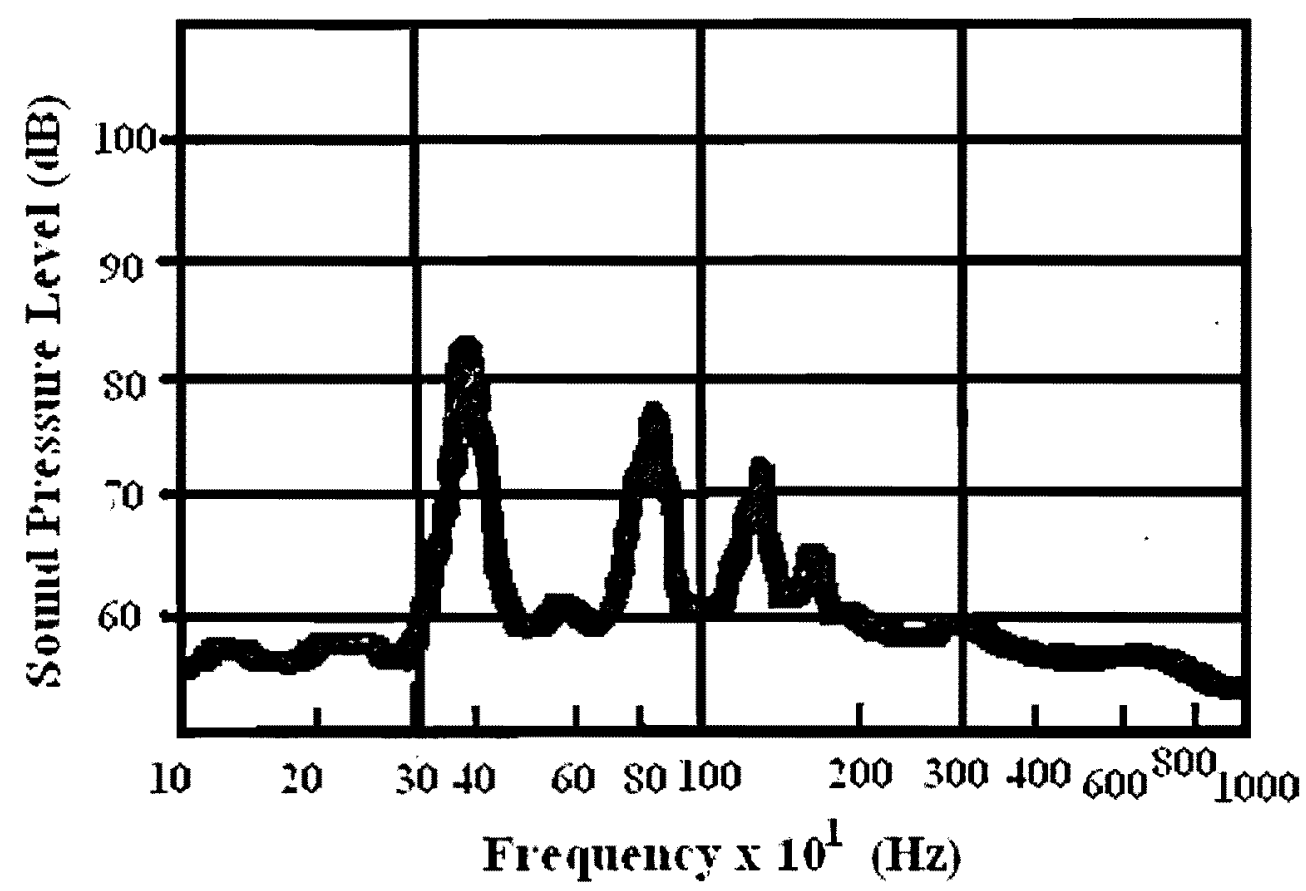

Figure 3: Exampie of Discrete Frequency noise [15]

Broad band noise is steady noise whose sound pressure level distribution over the frequency spectrum has no dominant peaks, varying smoothly with frequency. [15] Acoustical energy might be heavily concentrated in one or more area of the sound spectrum. Pink noise is, when noise level is up in the low frequency, and down in the high frequency in a board band noise, an example of a pink broad band noise is shown in Figure 4. [7] Pink is analogous to the pink light at the lower frequencies of the colour spectrum. [15] 


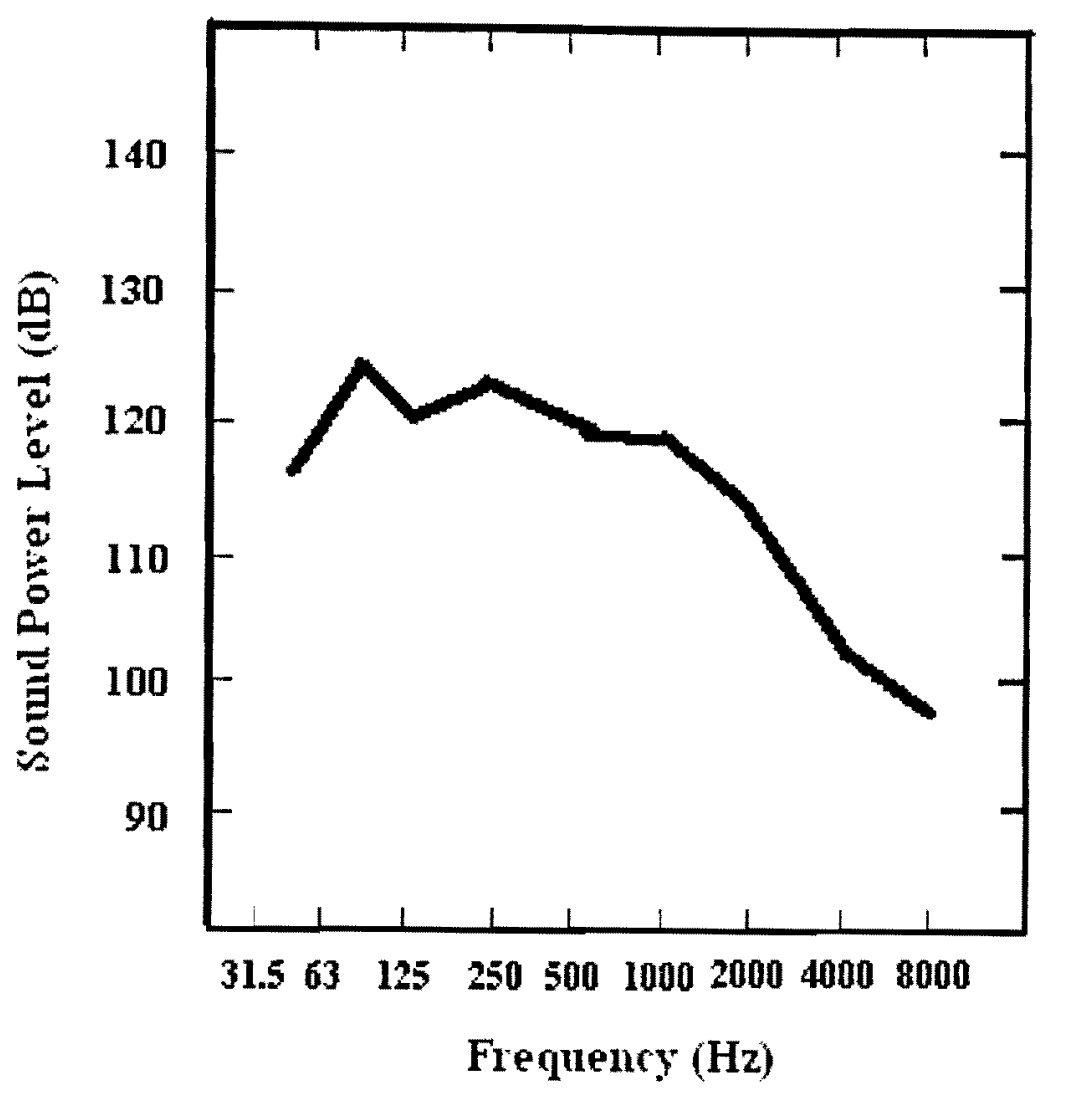

Figure 4: Example of Broad Band Noise [15]

\subsection{Noise Band}

A band is a range of frequencies between two limits. [7] Similar to measuring speed of an object, one can measure the distance the object traveled in each second, or every minute ( 60 second), or every hour ( 3600 second), depends on how frequently the speed changed. Obviously, if measuring with the same period of time, the smaller the scale, the more data needed to be collected. When studying a noise spectrum, it is not practical to examine the acoustic energy generated at every frequency at the same time, massive amounts of data would be generated. The three most common types of frequency scales that were used to measure sound are, narrow band, one-third octave band and octave band, listing from the most detail to least. [7] The scale is done by dividing the frequency range into a set of broader ranges, each containing less information. 
Octave band just like the octaves on a piano, each set of frequency is exactly double of the previous set of frequency. [15] Nine octave bands are the most often used when measuring industrial noise, starting from $31.5 \mathrm{~Hz}$, then doubling to $63 \mathrm{~Hz}$, then $125 \mathrm{~Hz}$, $250 \mathrm{~Hz}, 500 \mathrm{~Hz}, 1000 \mathrm{~Hz}, 2000 \mathrm{~Hz}, 4000 \mathrm{~Hz}$, and end at $8000 \mathrm{~Hz}$. [7] For example, the $500 \mathrm{~Hz}$ octave band is centered at $500 \mathrm{~Hz}$ and it will extends from mid-point between 250 $\mathrm{Hz}$ to $500 \mathrm{~Hz}$, and mid-point between $500 \mathrm{~Hz}$ to $1000 \mathrm{~Hz}$. It can be calculated by,

Starting: $\frac{(\log 250 \mathrm{~Hz}+\log 500 \mathrm{~Hz})}{2}=353 \mathrm{~Hz}$

Ending: $\frac{(\log 500 \mathrm{~Hz}+\log 1000 \mathrm{~Hz})}{2}=706 \mathrm{~Hz}$

Figure 5 shows the three most common bands that were used in measuring noise, from most detail on the left to the least on the right.

In this project, one-third octave band was used to measure the noise generated by an orifice plate in the experiment. Even though the octave band did provide a sufficient level of detail, a couple sound pressure levels were concentrated in different frequency, and one-third octave band can capture these tonal noise.

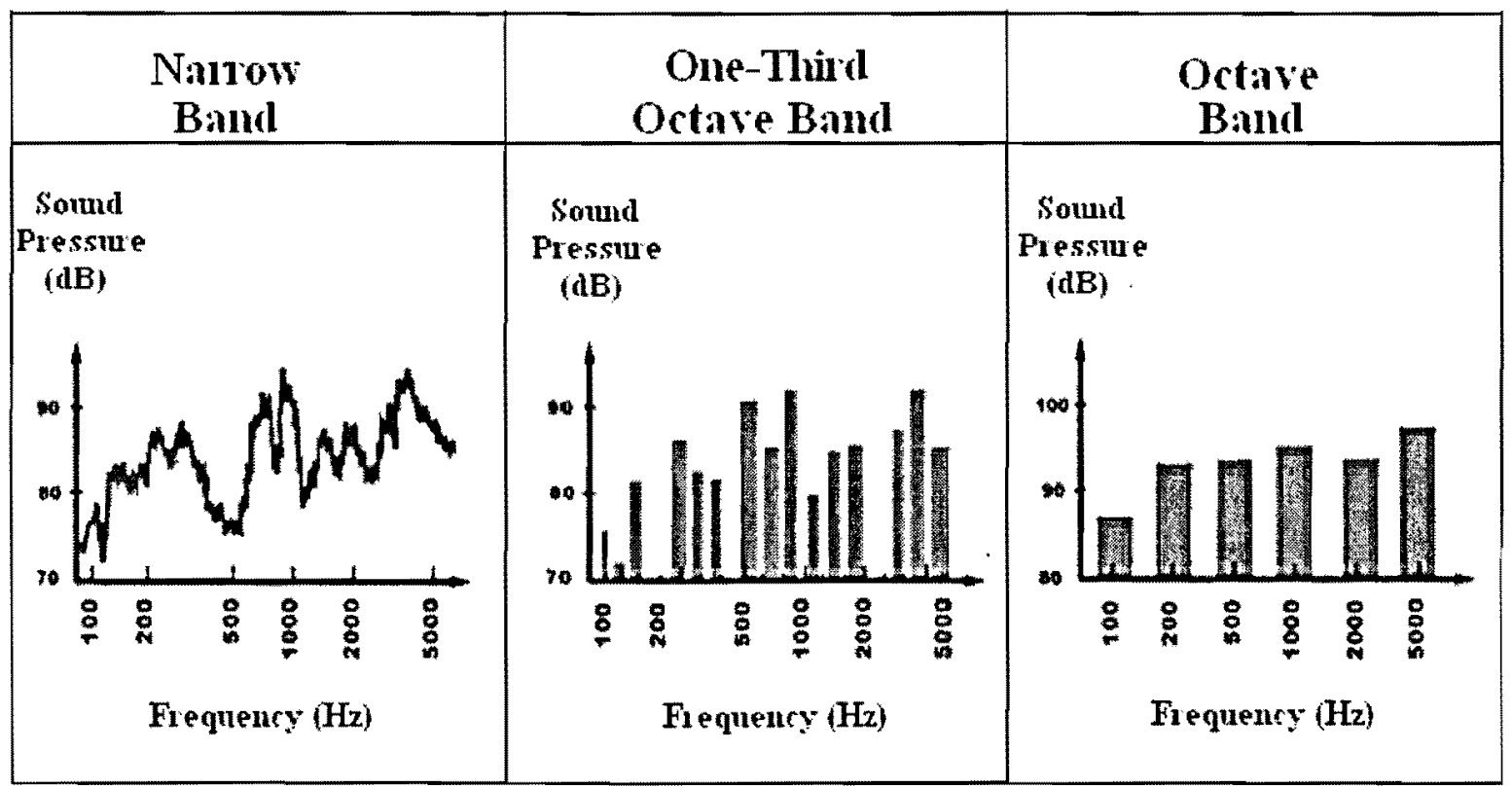

Figure 5: Example of Different Frequency Band [15] 
Octave band just like the octaves on a piano, each set of frequency is exactly double of the previous set of frequency. [15] Nine octave bands are the most often used when measuring industrial noise, starting from $31.5 \mathrm{~Hz}$, then doubling to $63 \mathrm{~Hz}$, then $125 \mathrm{~Hz}$, $250 \mathrm{~Hz}, 500 \mathrm{~Hz}, 1000 \mathrm{~Hz}, 2000 \mathrm{~Hz}, 4000 \mathrm{~Hz}$, and end at $8000 \mathrm{~Hz}$. [7] For example, the $500 \mathrm{~Hz}$ octave band is centered at $500 \mathrm{~Hz}$ and it will extends from mid-point between 250 $\mathrm{Hz}$ to $500 \mathrm{~Hz}$, and mid-point between $500 \mathrm{~Hz}$ to $1000 \mathrm{~Hz}$. It can be calculated by,

Starting: $\frac{(\log 250 \mathrm{~Hz}+\log 500 \mathrm{~Hz})}{2}=353 \mathrm{~Hz}$

Ending: $\frac{(\log 500 \mathrm{~Hz}+\log 1000 \mathrm{~Hz})}{2}=706 \mathrm{~Hz}$

Figure 5 shows the three most common bands that were used in measuring noise, from most detail on the left to the least on the right.

In this project, one-third octave band was used to measure the noise generated by an orifice plate in the experiment. Even though the octave band did provide a sufficient level of detail, a couple sound pressure levels were concentrated in different frequency, and one-third octave band can capture these tonal noise.

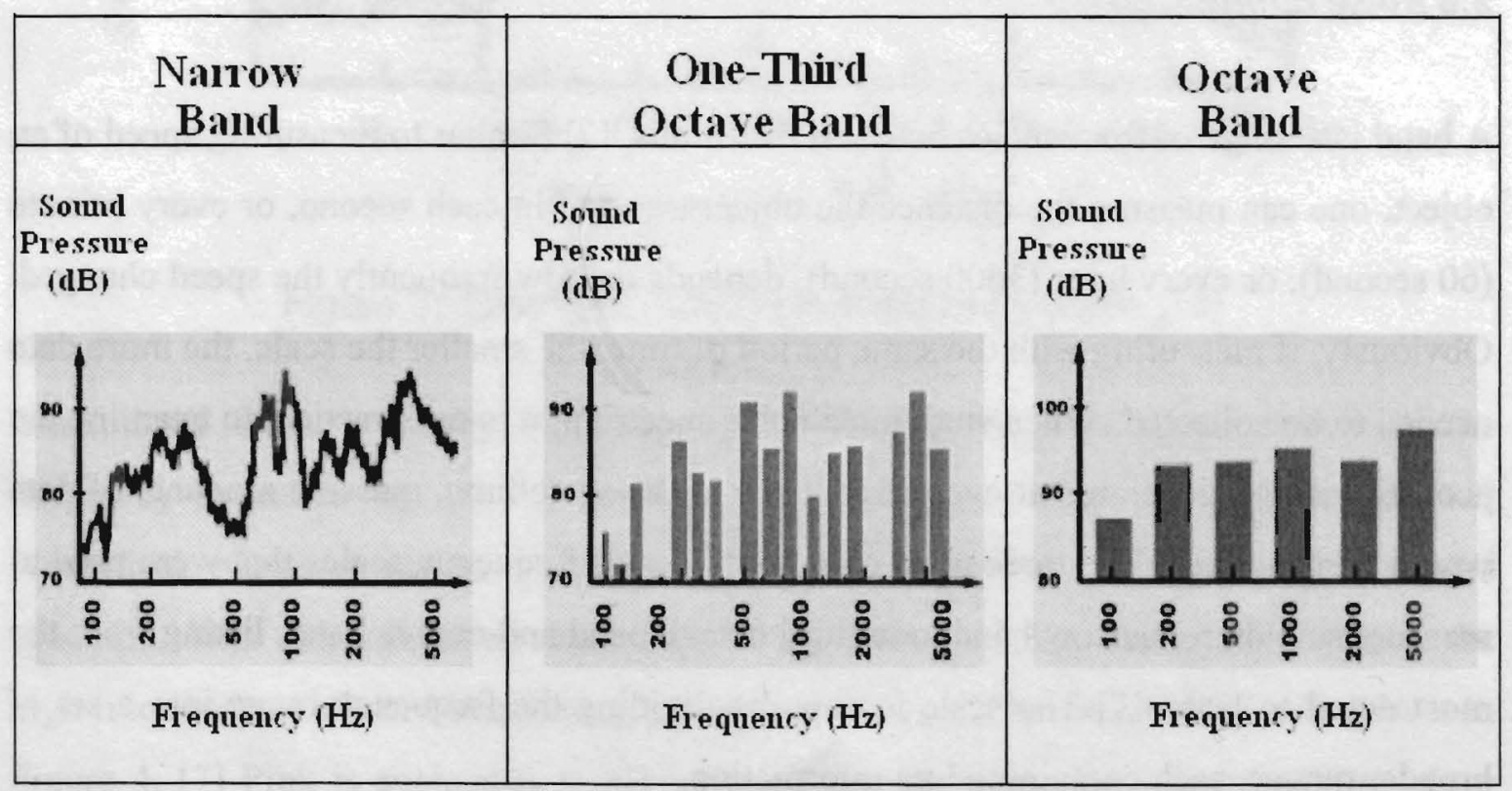

Figure 5: Example of Different Frequency Band [15] 


\subsection{Decibels and Weighted Decibels Scale}

As explain in the previous section, Music vs. Noise, decibel is a logarithmic scale to measure the size or amplitude of pressure change. The lowest sound pressure change that normal adult can detect is 20 micro-Pascal of a pure tone at $1000 \mathrm{~Hz}$, in which the normal atmospheric pressure is 101 kilo-Pascal. [16] A pressure change of the lowest sound pressure change that normal adult can detect is equivalent to five billion times less than atmospheric pressure. Since the range of sound pressure in a standard atmosphere is huge, to the order of billionths, using the Pascal scale to measure is hard to manage. Sound Pressure Level (SPL) unit Decibel (dB) is a logarithmic scale to help measure pressure change, and it was devised to make calculations of noise levels manageable. [3]

$$
S P L=10 \log _{10}\left(\frac{P^{2}}{P_{0}^{2}}\right)[d B]
$$

Or

$$
S P L=20 \log _{10} P+94 \quad[d B]
$$

Where:

$$
\begin{aligned}
& \mathrm{SPL}=\text { Sound Pressure Level } \\
& \mathrm{P}=\text { root-mean-square sound pressure }[\mathrm{Pascal}] \\
& \mathrm{P}_{0}=\text { international reference pressure of } 2.0 \times 10^{-5} \text { [Pascal] }
\end{aligned}
$$

The human ear's range starts at the threshold of hearing, $0 \mathrm{~dB}$, and ends at the threshold of pain, 140dB. [16] The human ear is able to react to exponential changes in sound pressure, and decibel scale is a closer approximation to the sounds heard by the human ear than the Pascal scale. However, human ear is more sensitive to high frequencies sound pressure variations than low frequencies. [16] The range from 1,000 to $5,000 \mathrm{~Hz}$ is the frequencies where human ear is most sensitive to sound. [15] Therefore, a correction factor is created to quantify the sensitivity of humans to sound. 
There are four weighting networks, A-weighted decibel dBA, B-weighted decibel dBB, C-weighted decibel $\mathrm{dBC}$, and D-weighted decibel $\mathrm{dBD}$. [7] To quantify the sensitivity of humans to sound the A-weighted decibel is applied, it can reflect adjusted sound volume perceived by the human ear in different frequency. B-weighted decibel emphasizing middle frequencies; $\mathrm{C}$-weighted decibel were used to attenuate low frequencies much less than the other weightings; D-weighted decibel were used for very high frequencies like those emitted from jet engines. [7]

For purpose of noise control, A-weighted decibel is the most common weighting network in use defined in the International standard IEC61672:2003. [7] For example, most of the time machine manufacturers would provide noise levels of a machine in $\mathrm{dB}$, whereas the regulation of community noise requirement is stated in $\mathrm{dBA}$. It is necessary to convert from $\mathrm{dB}$ to $\mathrm{dBA}$ or sometimes vice versa. The various national standards relating to the measurement of sound pressure level, as opposed to actual sound pressure as shown in Table 2. C weightings are used because they attenuate low frequencies much less than the other weightings. D weightings are used when very high frequencies and $\mathrm{B}$ weightings emphasis on the middle frequencies which are no longer in use.

For example, a $100 \mathrm{~dB}$ sound in the $31.5 \mathrm{~Hz}$ band has a correction factor of -39.4 . Subtract 39.4 from $100 \mathrm{~dB}$ (i.e., $100 \mathrm{~dB}-39.4=60.6 \mathrm{dBA}$ ). The answer is $60.6 \mathrm{dBA}$, which is how "loud" the $100 \mathrm{~dB}$ sound is perceived by the human ear in the $31.5 \mathrm{~Hz}$ band. By contrast, the same $100 \mathrm{~dB}$ sound is perceived by the human ear exactly as 100 $\mathrm{dBA}$ when frequencies are in the $1000 \mathrm{~Hz}$ band (i.e., $100 \mathrm{~dB}-0=100 \mathrm{dBA}$ ). [3]

Figure 6 shows the equal loudness contours, these equal loudness curves show the relative lack of sensitivity of the human ear to low frequency. 


\begin{tabular}{|c|c|c|c|c|}
\hline $\begin{array}{c}\text { Frequency } \\
(\mathrm{Hz})\end{array}$ & Curve A dB & Curve B dB & Curve C dB & Curve $D \mathrm{~dB}$ \\
\hline 10 & -70.4 & -38.2 & -14.3 & -26.5 \\
\hline 12.5 & -63.4 & -33.2 & -11.2 & -24.5 \\
\hline 16 & -56.7 & -28.5 & -8.5 & -22.5 \\
\hline 20 & -50.5 & -24.2 & -6.2 & -20.5 \\
\hline 25 & -44.7 & -20.4 & -4.4 & -18.5 \\
\hline 31.5 & -39.4 & -17.1 & -3 & -16.5 \\
\hline 40 & -34.6 & -14.2 & -2 & -14.5 \\
\hline 50 & -30.2 & -11.6 & -1.3 & -12.5 \\
\hline 63 & -26.2 & -9.3 & -0.8 & -11 \\
\hline 80 & -22.5 & -7.4 & -0.5 & -9 \\
\hline 100 & -19.1 & -5.6 & -0.3 & -7.5 \\
\hline 125 & -16.1 & -4.2 & -0.2 & -6 \\
\hline 160 & -13.4 & -3 & -0.1 & -4.5 \\
\hline 200 & -10.9 & -2 & 0 & -3 \\
\hline 250 & -8.6 & -1.3 & 0 & -2 \\
\hline 315 & -6.6 & -0.8 & 0 & -1 \\
\hline 400 & -4.8 & -0.5 & 0 & -0.5 \\
\hline 500 & -3.2 & -0.3 & 0 & 0 \\
\hline 630 & -1.9 & -0.1 & 0 & 0 \\
\hline 800 & -0.8 & 0 & 0 & 0 \\
\hline 1000 & 0 & 0 & 0 & 0 \\
\hline 1250 & 0.6 & 0 & 0 & 2 \\
\hline 1600 & 1 & 0 & -0.1 & 5.5 \\
\hline 2000 & 1.2 & -0.1 & -0.2 & 8 \\
\hline 2500 & 1.3 & -0.2 & $-0 . \overline{3}$ & 10 \\
\hline 3150 & 1.2 & -0.4 & -0.5 & 11 \\
\hline 4000 & 1 & -0.7 & -0.8 & 11 \\
\hline 5000 & 0.5 & -1.2 & -1.3 & 11 \\
\hline 6300 & -0.1 & -1.9 & -2 & 10 \\
\hline 8000 & -1.1 & -2.9 & -3 & 8.5 \\
\hline 10000 & -2.5 & -4.3 & -4.4 & 6 \\
\hline 12500 & -4.3 & -6.1 & -6.2 & 3 \\
\hline 16000 & -6.6 & -8.4 & -8.5 & -4 \\
\hline 20000 & -9.3 & -11.1 & -11.2 & -7.5 \\
\hline
\end{tabular}

Table 2: A, B, C and D Weighting Networks [7] 


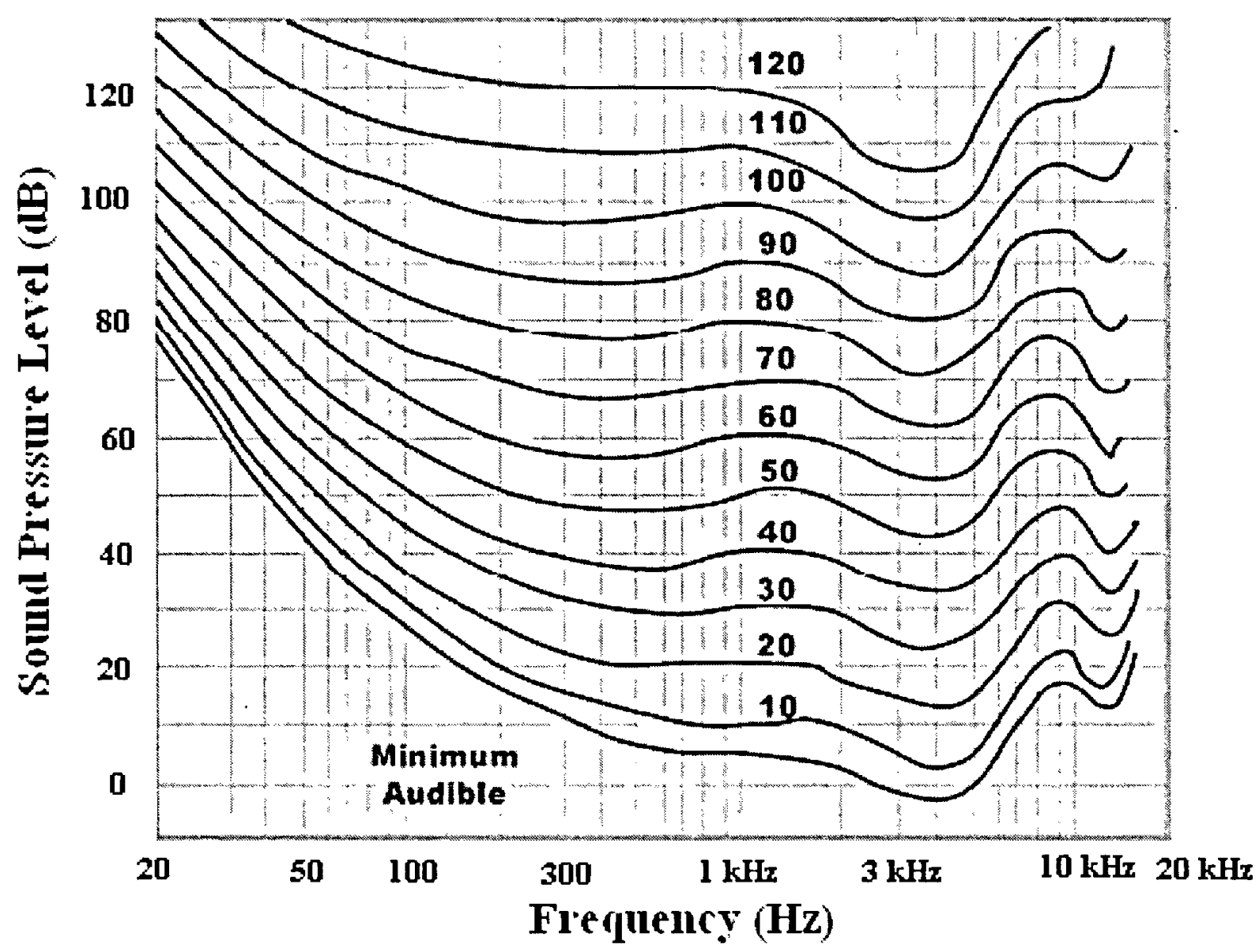

Figure 6: Sensitivity of human ear at different SPL with respect to different frequency (Equal Loudness Contours) [16]

\subsection{Loudness}

Loudness is very subjective, it varies from one person to another. What is interpreted as loud noise by one individual may not be loud or noise to the other person. That is the reason why loudness is rarely used to describe the situation in noise control.

From a mathematical point of view, a $10 \mathrm{~dB}$ increase in sound pressure is equivalent to doubling in the loudness of the sound occurs. [8] Similarly, for each $10 \mathrm{~dB}$ decrease in sound pressure, the loudness is cut in half. [3] Doubling the loudness does not mean doubling the noise source. As stated, doubling the loudness means $10 \mathrm{~dB}$ increase in sound pressure, however, sound pressure is in logarithmic scale, doubling sound pressure, 


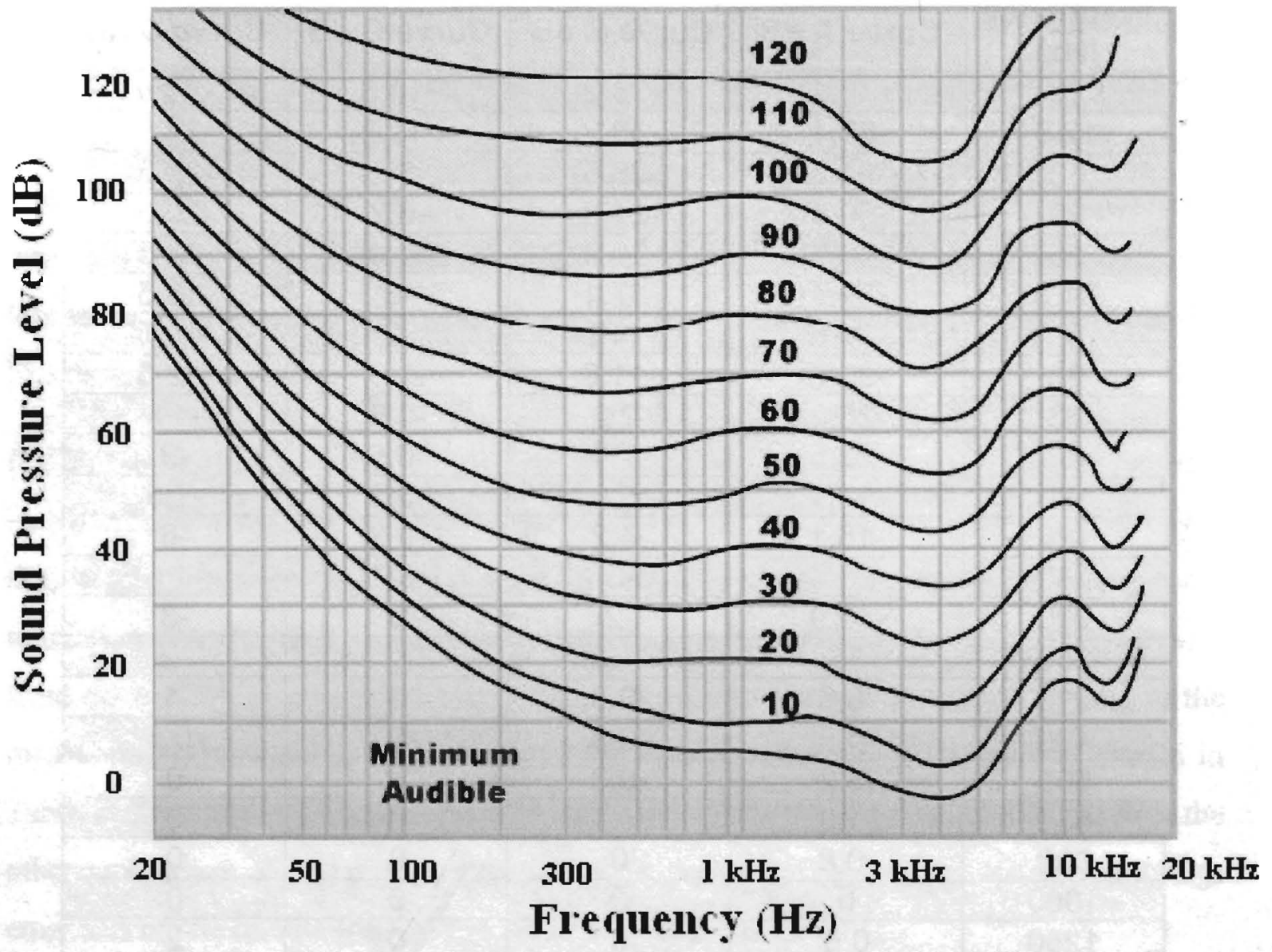

Figure 6: Sensitivity of human ear at different SPL with respect to different frequency (Equal Loudness Contours) [16]

\subsection{Loudness}

Loudness is very subjective, it varies from one person to another. What is interpreted as loud noise by one individual may not be loud or noise to the other person. That is the reason why loudness is rarely used to describe the situation in noise control.

From a mathematical point of view, a $10 \mathrm{~dB}$ increase in sound pressure is equivalent to doubling in the loudness of the sound occurs. [8] Similarly, for each $10 \mathrm{~dB}$ decrease in sound pressure, the loudness is cut in half. [3] Doubling the loudness does not mean doubling the noise source. As stated, doubling the loudness means $10 \mathrm{~dB}$ increase in sound pressure, however, sound pressure is in logarithmic scale, doubling sound pressure, 
is just equivalent to increase of $3 \mathrm{~dB}$. This only applied when the added noise source is identical to the original one.

For example, adding two $85 \mathrm{~dB}$ sources yields:

$$
85 d B+85 d B=10^{\frac{85}{10}}+10^{\frac{85}{10}}=10^{*} \log (632455532)=88 d B
$$

Therefore, in order to double the loudness, increase by $10 \mathrm{~dB}$,

\begin{tabular}{|c|c|}
\hline Noise Source & Noise Level \\
\hline 1 & $120 \mathrm{~dB}$ \\
\hline 2 & $123 \mathrm{~dB}$ \\
\hline 4 & $126 \mathrm{~dB}$ \\
\hline 8 & $129 \mathrm{~dB}$ \\
\hline
\end{tabular}

Table 3: Doubling loudness [7]

8 identical noise sources are needed. Engine noise produced by an aircraft with four identical jet engines, does not make twice as much noise than an aircraft with two identical engines, if and only if identical engines mounted on both aircrafts. The human ear's ability to hear logarithmic changes in sound pressure also explains why loudness increases $10 \mathrm{~dB}$ but the noise level from identical sources increases by only $3 \mathrm{~dB}$. [7] 


\subsection{Aircraft noise}

Aircraft noise is defined as sound produced by the aircraft in different stages of a flight mission; during run-up, taxiing, take-off, cruising, and landing. [27] Especially during takeoff and landing, aircraft noise needs to be controlled, in order to not affect the neighbourhood of about $100 \mathrm{~km}^{2}$ around the airport. [17] When in the take-off stage, aircrafts generally produce an average sound level of more than $100 \mathrm{~dB}$ at ground level. [27]

Landing usually begins at 60 meters above roof level where a sound level of $100 \mathrm{dBA}$ can be realized.[17] Aircraft noise is the second largest (after roadway noise) source of environmental noise. [27] This is just half of the problem; aircraft noise can be separated in to two main sources, external and internal noise.

Any object moving through air would cause compression and rarefaction, producing motion of the air molecules. This movement of the air will generate pressure waves. If these pressure waves were strong enough and propagate within an audible frequency spectrum, sound would be detected by human hearing sensation. Aircrafts are moving through air in high speeds, climate controlling systems constantly adjust pressure and temperature inside the cabin which will compress and expand the air.[25] The change in pressure difference would generate noise in different frequencies, intensities, and noise levels; and the audible noise will be propagated into the passengers' ears.

Three main contributions to the total noise level originate from aerodynamic noise, engine and other mechanical noise, and noise from aircraft systems.[27]

\subsubsection{Aerodynamic noise}

Aerodynamic noise arises from the airflow around the aircraft fuselage and control surfaces. This type of noise increases with aircraft speed and also at low altitudes due to the density of the air. [27] Jet-powered aircrafts create intense noise from aerodynamics, which is typically broadband. [15] Aerodynamic noise would vibrate the skin of the aircraft, and then transfer to the internal wall of the cabin. [10] Noise generated by this source would not be very significant, cabin sound levels may be controlled in civilian commercial airliners due to added sound attenuating material. [19] Exposure to this noise 
in long period of time can lead to damage, since hearing loss is cumulative. [16] In a long haul flight mission, this noise may continue for more than 10 hours. The shape of the nose, windshield or canopy of an aircraft can greatly affect the sound produced. Much of the noise of a propeller aircraft is of aerodynamic origin due to the flow of air around the blades. This type of aerodynamic noise is mostly low frequency determined by the rotor speed. [19]

\subsubsection{Engine and other mechanical noise}

Much of the noise in propeller aircraft comes equally from the propellers and aerodynamics. [1] The mechanical sources produce narrow band high intensity peaks relating to the rotational speed and movement of the moving parts. [7] Noise is propagated through the skin to passengers' ears as the aerodynamic noise. In computational aero acoustics terms, noise from a moving aircraft can be treated as a line source. [25] Also with the new technologies, this noise can be reduced before it is transferred into the cabin. [8]

\subsubsection{Noise from aircraft systems}

Cabin pressurization and conditioning systems are often a major contributor to noise within cabins of civilian aircrafts. [25] In order to reduce operational cost, the weight and dimension of the different systems inside the aircraft are being scaled down to minimize the total aircraft weight. [36] In a constant decreasing in the dimension of the pipe in the environmental control system, air mass flow rate is increasing. More noise is generated by the air flowing in narrower pipes with a higher mass flow rate. Most of the commercial aircraft have a gasper above each passenger's seats; noise from the environmental control system is propagated directly to their ears. This noise is generated through fluid movement. Thus, it is harder to control than noise generated by mechanical vibration. [7] This is the reason why a computational model is needed to simulate the flow and monitor noise propagation. 


\section{Chapter 3: Environmental Control System and Pipe Theory}

When an aircraft is in service, no matter if it is on the ground or in the air, the pilots, flight attendants, and passengers must be kept in an adequate environment. The environment cannot be too hot or too cold, crew members and passengers must have air to breathe, and the atmospheric humidity and pressure conditions must be able to keep people aboard in the aircraft comfortable. [25] Temperature usually kept in between 18 ${ }^{\circ} \mathrm{C}\left(65^{\circ} \mathrm{F}\right)$ and $24^{\circ} \mathrm{C}\left(75^{\circ} \mathrm{F}\right)$. Due to cabin pressurization, pressure would be lower than sea level condition, and normal passenger cabin pressure is around $77.22 \mathrm{kPa}(11.2 \mathrm{psia})$. [40] Air in high attitude, for example $12.19 \mathrm{~km}(40,000 \mathrm{ft})$, is not as dense as at ground level, and has less oxygen, lower temperature, and lower pressure. [4] Table 4 is the comparison between different air properties in two different altitudes.

\begin{tabular}{|c|c|c|}
\hline & Ground level & High Altitude $12.19 \mathrm{~km}(40,000 \mathrm{ft})$ \\
\hline Temperature & $15.01{ }^{\circ} \mathrm{C}\left(59.02^{\circ} \mathrm{F}\right)$ & $-56.34^{\circ} \mathrm{C}\left(-69.68^{\circ} \mathrm{F}\right)$ \\
\hline Pressure & $101,325 \mathrm{~Pa}(14.696 \mathrm{psi})$ & $18,799 \mathrm{~Pa}(2.73 \mathrm{psi})$ \\
\hline Density & $1.225 \mathrm{~kg} / \mathrm{m}^{3}\left(0.0764 \mathrm{lb} / \mathrm{ft}^{3}\right)$ & $0.30229 \mathrm{~kg} / \mathrm{m}^{3}\left(0.01887 \mathrm{lb} / \mathrm{ft}^{3}\right)$ \\
\hline
\end{tabular}

Table 4: Air worthiness vs. Altitude [4]

The mass (amount) of the gases contained in a given volume of air is directly related to the amount of pressure (compression) applied. As oxygen is a gas in the air, the mass of oxygen in a given volume of air is affected by atmospheric pressure. At a higher atmospheric pressure (lower altitude) there is more oxygen in a given volume (e.g. in a given breath) than at low atmospheric pressure (higher altitude). [12]

Therefore, the environmental control system needs to work with widely differing temperature conditions, it must be able to extract moisture and provide air with optimum 
humidity, last but not least, it must ensure that the air in the aircraft always contains a sufficient concentration of oxygen. [25]

The environmental control system is not just for the passengers and the crew members. The system must also provide the right environment for the instruments and equipment to operate accurately and efficiently. For example the computer system in the cockpit generates heat and needs cool air to lower its temperature in order to remain working. The lubrication oil between different mechanism on the aircraft needs to be maintained in a certain temperature range in order to smooth the motion. [23] Therefore, the main purpose of the environmental control system is to provide safe and comfortable conditions for each fare-paying passengers. [25]

With the high operational speed, aircraft in used now have more emphasis on cooling systems, because hot air can be bled from the engines to provide heat for the aircraft air conditioning system. Rather, heat rejection is a more important issue in modern civil jet transportation. The three key elements of an environmental control system are provision of bleed air, environmental control and cabin pressurization. [25]

\subsection{Bleed air}

When the engines are running, hot air can be bled from the intermediate- or high-pressure compressors to provide adequate environment for people in the passenger cabin. In modern civil aircraft engine bleed air is the main source of conditioning air and it is also used to provide cabin pressurization. [25]

Open loop and closed loop bleed air systems are the two most common bleed air systems. Both systems bleed hot air from engine, refrigerate the air to a reasonable working temperature, and then use it to cool the passengers and crew members, as well as equipment. For closed loop system, air will be collect after it has been used for cabin conditioning. Warm air will be refrigerated again and recycle it to be used. In this way, bleed air is used only to provide pressurization, a low venting air supply, and sufficient flow to compensate for leaks in the closed loop system. However, open loop system bleed which large amounts of air from the engines, use it once and then rejected it, use more 
bleed air than the closed loop system and therefore have a correspondingly larger effect on the engine. On the other hand, constantly changing air will provided a healthier and more comfortable environment for the passengers, and it can effectively reduced risk and infection from airborne viruses. [25]

For example a Boeing $737-800$, with a $100 \%$ passenger capacity (176 passenger), the environmental control system requirements usually include a total flow rate of 0.5663 cubic meter per minute (20 cubic feet per minute) per passenger. Air supplied to cabin should be 50\% fresh air and 50\% re-circulated air, for most modern environmental control. Complete cabin air exchange is done every 2.5 minutes. For this specific aircraft, supplied air is comprised of 49.83 cubic meter per minute ( 1,760 cubic feet per minute) of re-circulated air and 24.92 cubic meter per minute ( 880 cubic feet per minute) of fresh air per cooling pack (aircraft model has two cooling packs.) [40]

\subsection{Bleed flow and temperature control}

At different stages of the operation of a Boeing 737-800, outside air temperature can changes significantly. At ground level on a hot day, outside air can reach $49^{\circ} \mathrm{C}\left(120^{\circ} \mathrm{F}\right)$. [40] However, at high altitudes in frigid locations, outside air can be dropped to $-82^{\circ} \mathrm{C} \mathrm{(-}$ $\left.115^{\circ} \mathrm{F}\right)$. The cabin temperature was designed to be between $18^{\circ} \mathrm{C}\left(65^{\circ} \mathrm{F}\right)$ and $24^{\circ} \mathrm{C}(75$ ${ }^{\circ} \mathrm{F}$ ). [40] Opinions of tolerable limits can vary.

When bleed air enters, hot air is needed to refrigerate entering air at a workable pressure of about $650 \mathrm{kPa}$ absolute $(6.5 \mathrm{~atm})$ and high temperature air of about $100{ }^{\circ} \mathrm{C}$ is needed to provided sufficient system flow and for services such as rapid demisting and anti-icing. [25] Tapping air from the low pressure compressor stage can provide the right temperature and pressure for environmental control system used, however, it will lower the engine performance. [4] Therefore, on many civil aircraft, air is tapped from intermediate- and high-pressure compressor stages, even air often at higher pressures and temperatures than required, while bleed tapping can be adjusted depending on the engine speed. [25] Figure 7 is a schematic view of how a common bleed air system looks like. 


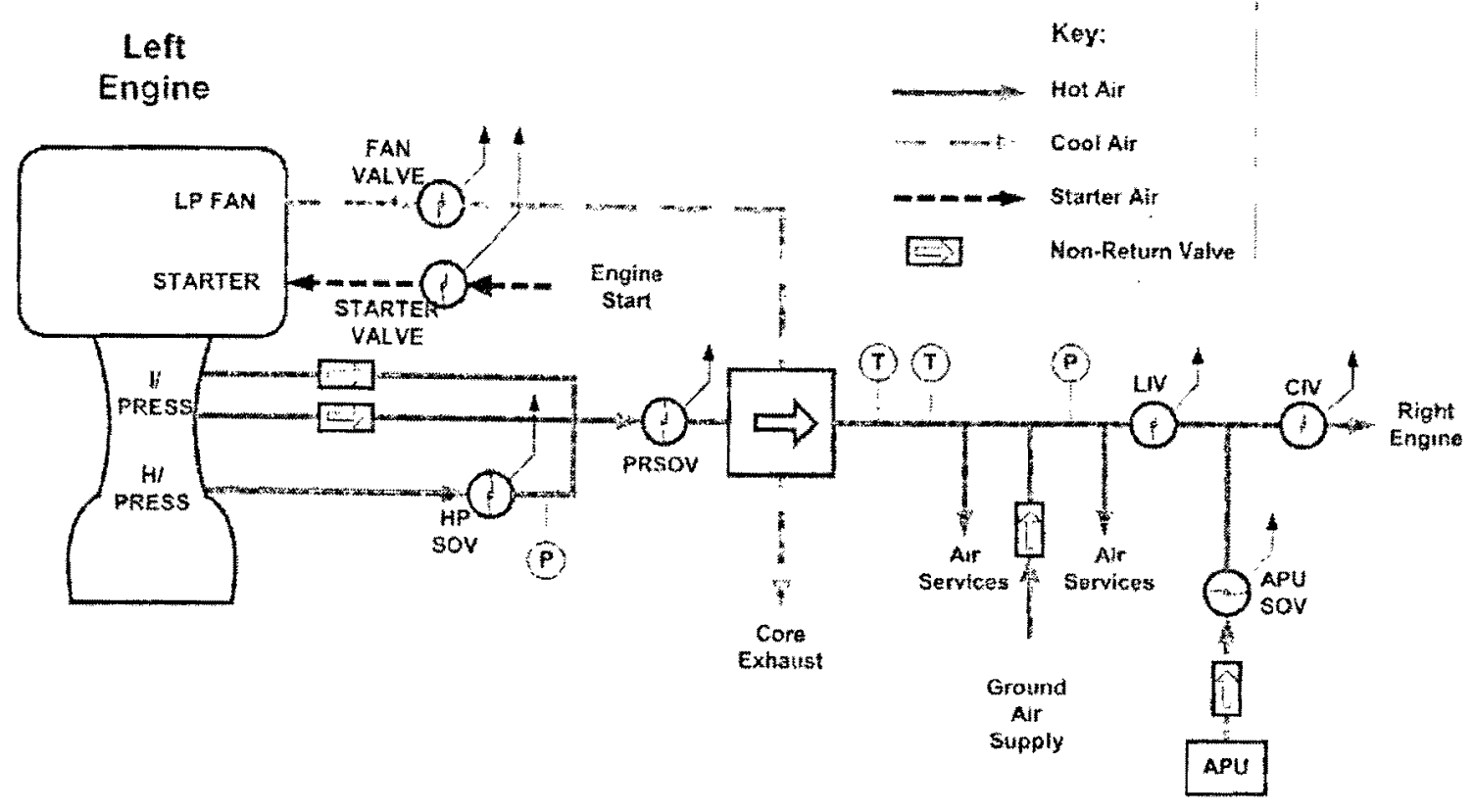

Figure 7: Common bleed air system [25]

To make sure the air serviced is in the pre-design pressure, a Pressure Reducing Shut-Off Valve (PRSOV) is used. [25] Once design pressure is reached, temperature needs to be reduced. Low pressure air from the core exhaust is used usually as heat exchangers to reject unwanted heat to a cooling medium. [22]

\subsection{Environmental control}

Before bleed air gets into the mixing chamber, bleed air passes through two air conditioning packs that cool the bleed air as shown in the top view of the environmental control system in Figure 8. This figure places more emphasis on the bleed air system from the environmental control system viewpoint. The most common Air Conditioning pack (A/C pack) for cooling the bleed air is to use ram air from outside the aircraft together with an Air Cycle Machine (ACM). Then, air is fed to different zones around the aircraft from the mixing chamber where each zone has its own individual temperature level. [25] This will keep passengers in comfortable environment as well as providing designed environment for avionic equipments. 


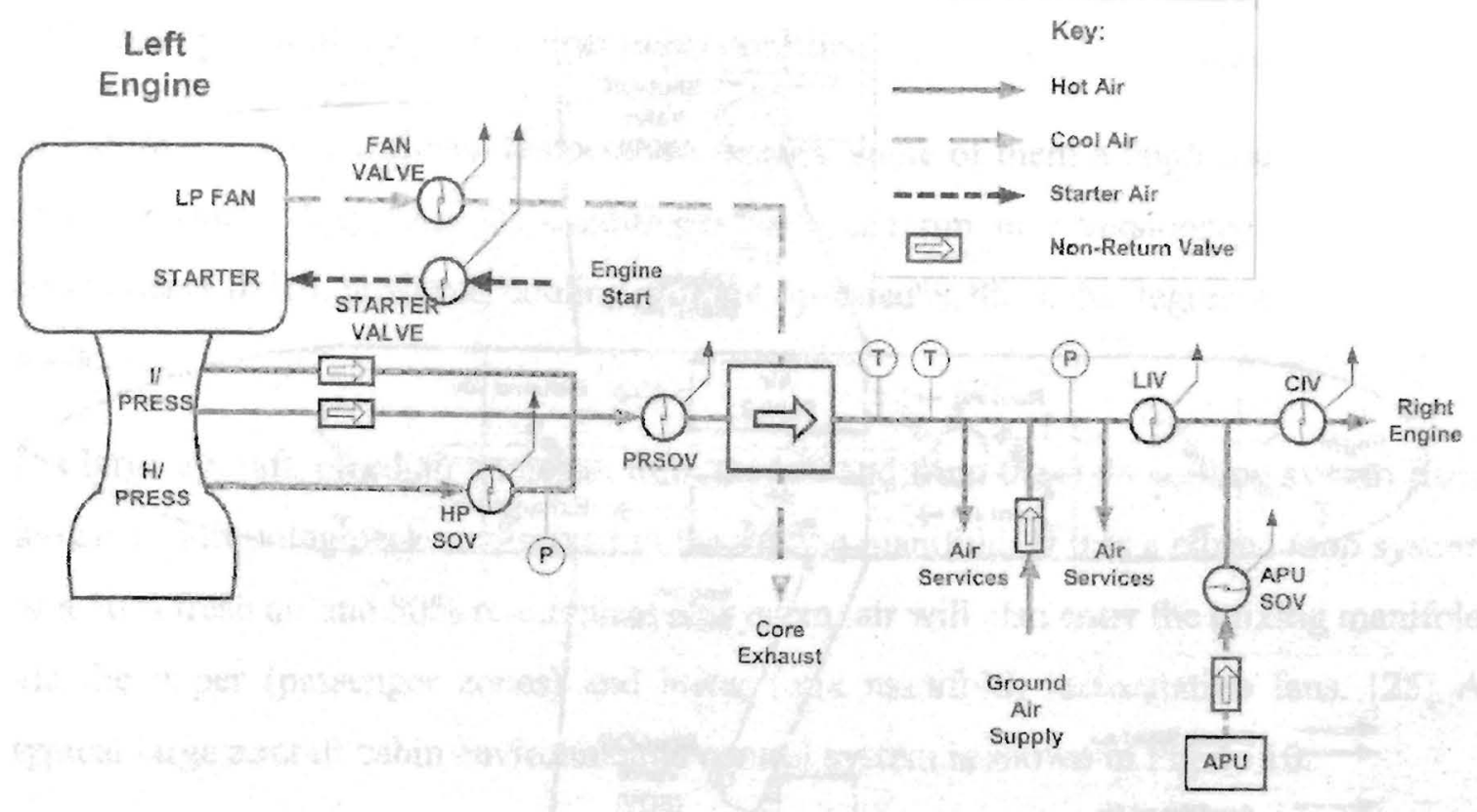

Figure 7: Common bleed air system [25]

To make sure the air serviced is in the pre-design pressure, a Pressure Reducing Shut-Off Valve (PRSOV) is used. [25] Once design pressure is reached, temperature needs to be reduced. Low pressure air from the core exhaust is used usually as heat exchangers to reject unwanted heat to a cooling medium. [22]

\subsection{Environmental control}

Before bleed air gets into the mixing chamber, bleed air passes through two air conditioning packs that cool the bleed air as shown in the top view of the environmental control system in Figure 8. This figure places more emphasis on the bleed air system from the environmental control system viewpoint. The most common Air Conditioning pack (A/C pack) for cooling the bleed air is to use ram air from outside the aircraft together with an Air Cycle Machine (ACM). Then, air is fed to different zones around the aircraft from the mixing chamber where each zone has its own individual temperature level. [25] This will keep passengers in comfortable environment as well as providing designed environment for avionic equipments. 


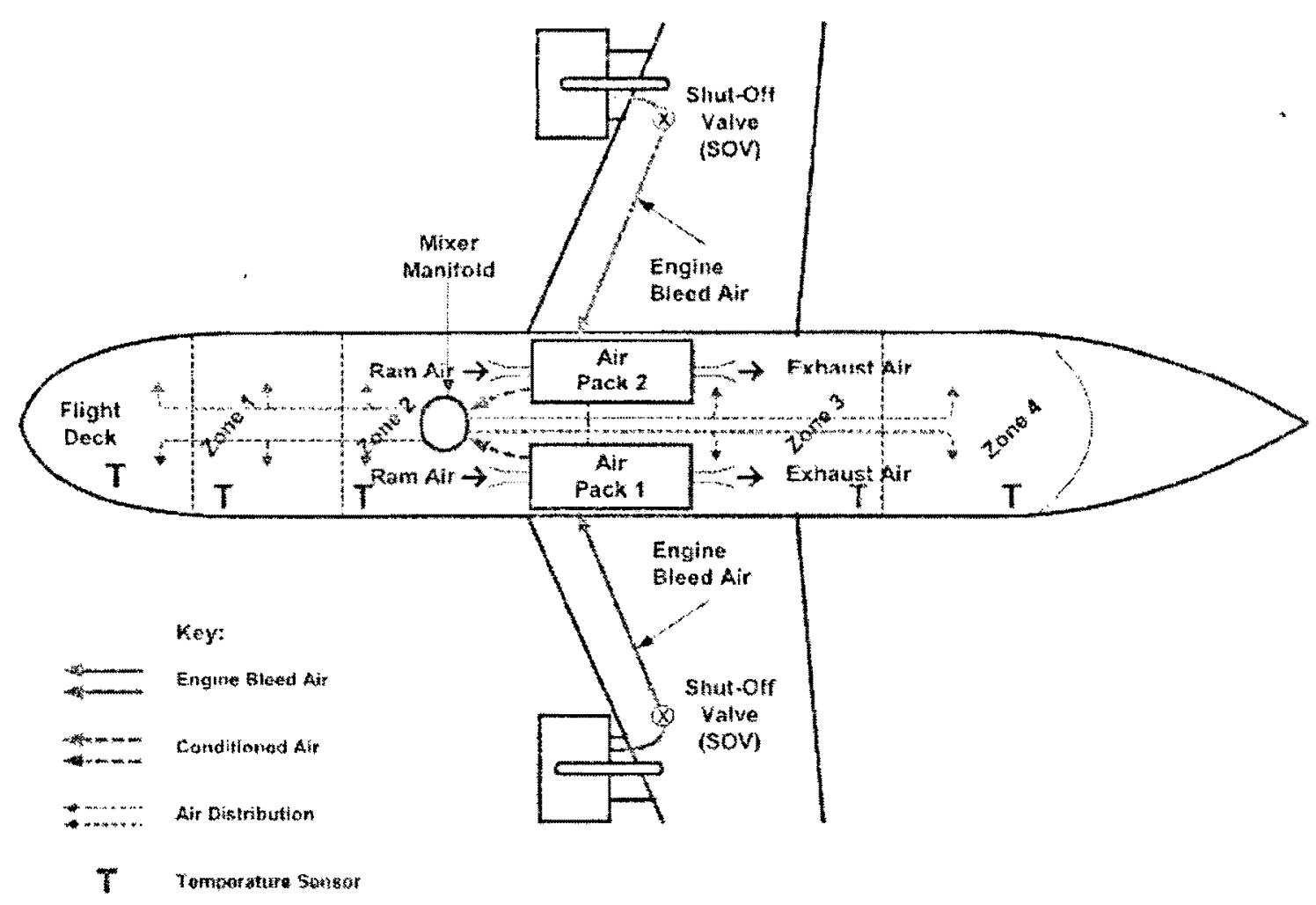

Figure 8: ECS Overview (bleed air system) [25]

For Boeing 737-800, cooling pack uses engine bleed air for supply keeping pressure at $206.84 \mathrm{kPa}$ (30 psia). Bleed air temperature ranges between $177^{\circ} \mathrm{C}-288^{\circ} \mathrm{C}\left(350^{\circ} \mathrm{F}-\right.$ $550^{\circ} \mathrm{F}$ ); depending on the flight stage. At cruise altitude, bleed air supply temperature is approximately $204{ }^{\circ} \mathrm{C}\left(400{ }^{\circ} \mathrm{F}\right)$. [40] And it is similar for different aircraft with similar size.

A common Air Cycle Machine (ACM) with three rotors is used on majority of passenger aircraft as shown in Figure 9. [25] Bleed air will go into the ACM through a primary heat exchanger operated with cool ram air. After certain amount of heat is taken out, then the air will go through the compressor in the $\mathrm{ACM}$, which will raise the air temperature. Hot air will go through the secondary heat exchanger, which is also cooled by ram air. Part of the resulting air is fed through a re-heater and condenser before being applied to the first of the ACM turbine. Afterwards, air is passed through the second ACM turbine to adjust to a designed temperature before passing to the ECS mixing chamber. Output 


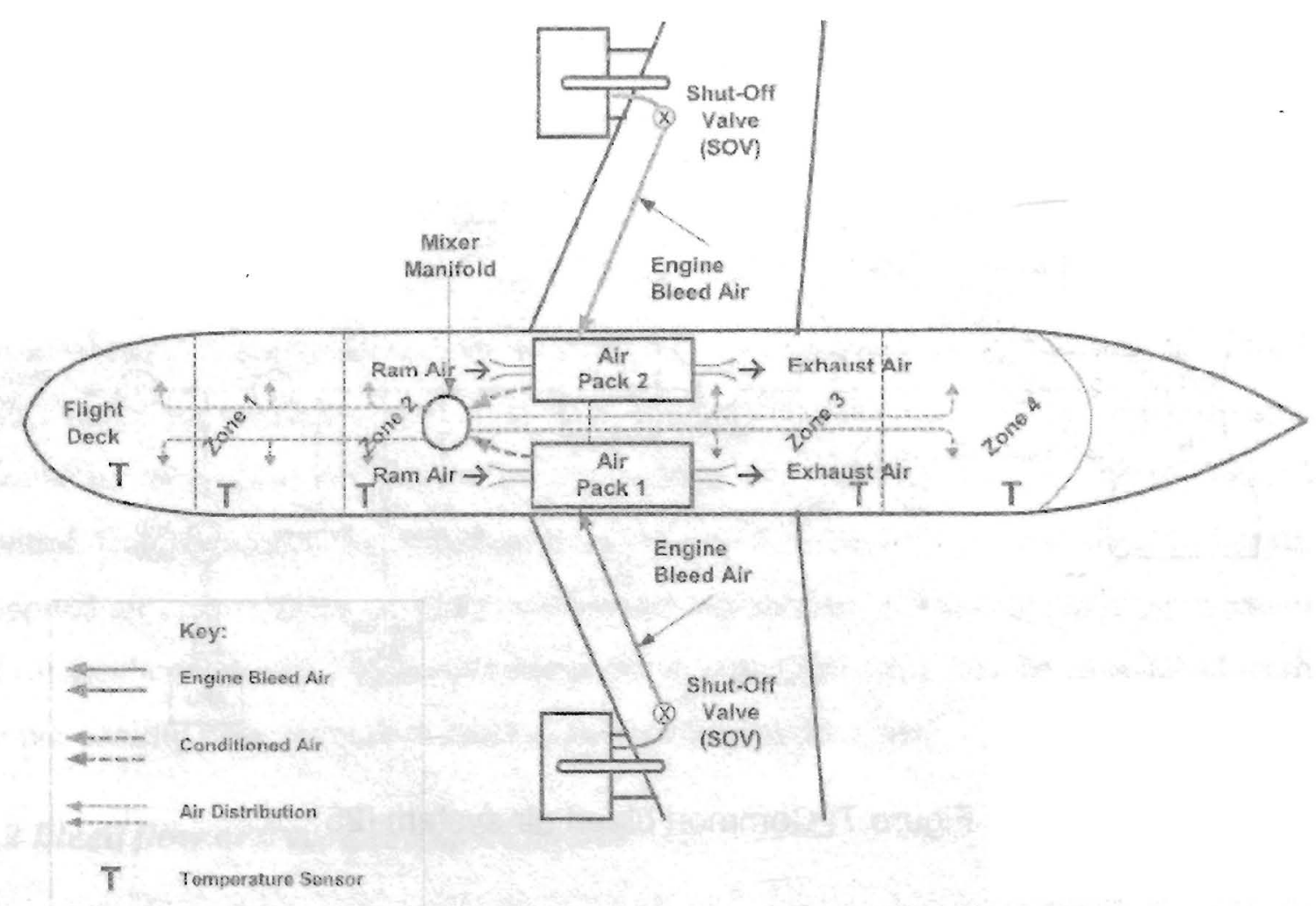

Figure 8: ECS Overview (bleed air system) [25]

For Boeing 737-800, cooling pack uses engine bleed air for supply keeping pressure at $206.84 \mathrm{kPa}(30 \mathrm{psia})$. Bleed air temperature ranges between $177^{\circ} \mathrm{C}-288^{\circ} \mathrm{C}\left(350{ }^{\circ} \mathrm{F}-\right.$ $550^{\circ} \mathrm{F}$ ); depending on the flight stage. At cruise altitude, bleed air supply temperature is approximately $204{ }^{\circ} \mathrm{C}\left(400{ }^{\circ} \mathrm{F}\right)$. [40] And it is similar for different aircraft with similar size.

A common Air Cycle Machine (ACM) with three rotors is used on majority of passenger aircraft as shown in Figure 9. [25] Bleed air will go into the ACM through a primary heat exchanger operated with cool ram air. After certain amount of heat is taken out, then the air will go through the compressor in the ACM, which will raise the air temperature. Hot air will go through the secondary heat exchanger, which is also cooled by ram air. Part of the resulting air is fed through a re-heater and condenser before being applied to the first of the ACM turbine. Afterwards, air is passed through the second ACM turbine to adjust to a designed temperature before passing to the ECS mixing chamber. Output 
temperature is monitor by combination of a series of actuators and valves that operate under the control of the pack temperature controller.

In Figure 9, there are eleven temperature sensors, some of them a duplicated for reasons of redundancy. Also, this air conditioner pack can run in reversionary mode if key components failed, however, cooling will not operated at the same degree as the primary mode. [25]

For large aircraft, bleed air comes in from the left and from the right cooling system from the air conditioning pack, and mixed in the mixing manifold. If it is a closed loop system or a $50 \%$ fresh air and $50 \%$ re-circulate air system, air will also enter the mixing manifold via the upper (passenger zones) and lower (mix manifold) recirculation fans. [25] A typical large aircraft cabin environmental control system is shown in Figure 10.

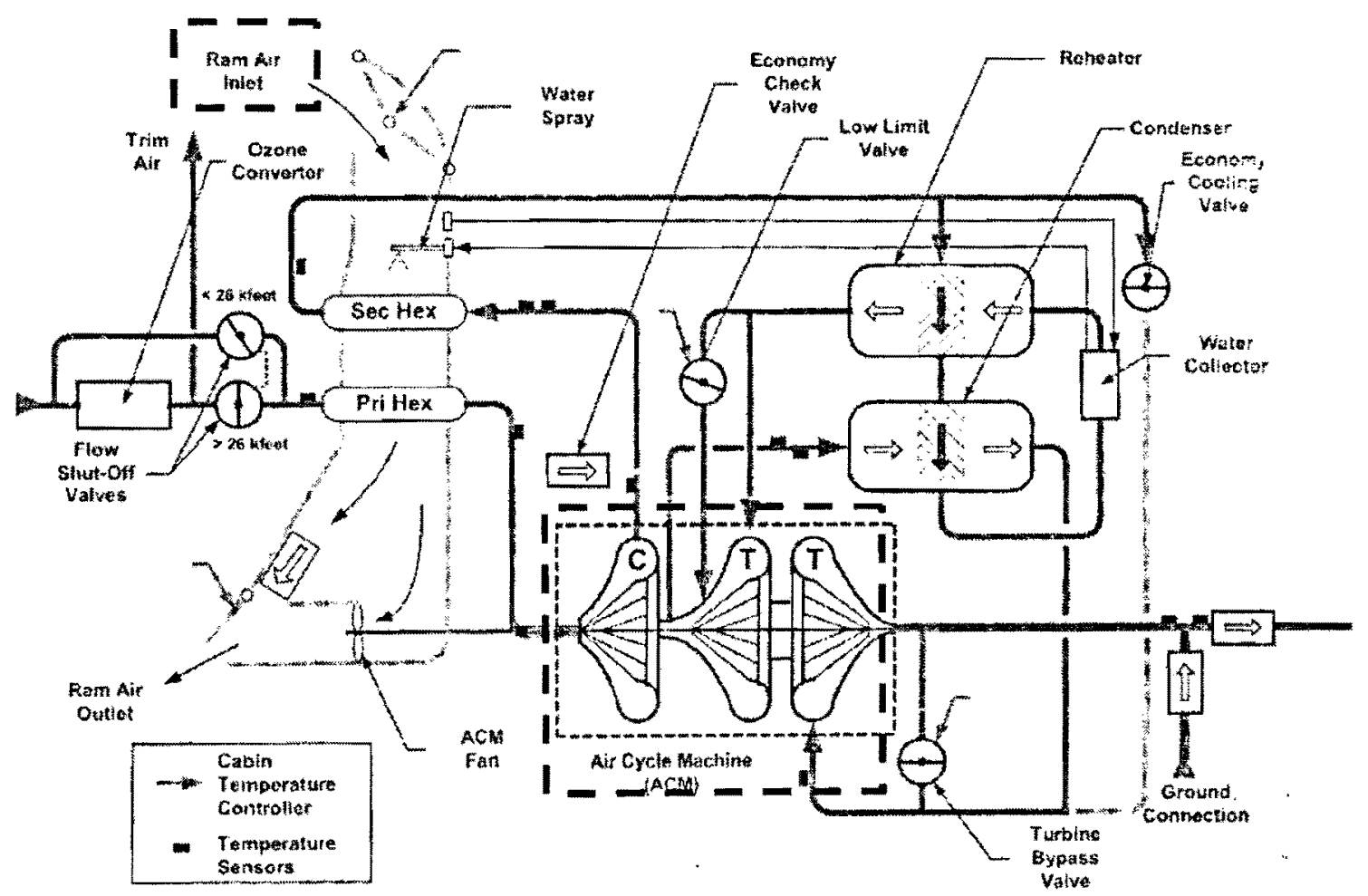

Figure 9: Air Cycle Cooling System [25] 
temperature is monitor by combination of a series of actuators and valves that operate under the control of the pack temperature controller.

In Figure 9, there are eleven temperature sensors, some of them a duplicated for reasons of redundancy. Also, this air conditioner pack can run in reversionary mode if key components failed, however, cooling will not operated at the same degree as the primary mode. [25]

For large aircraft, bleed air comes in from the left and from the right cooling system from the air conditioning pack, and mixed in the mixing manifold. If it is a closed loop system or a $50 \%$ fresh air and $50 \%$ re-circulate air system, air will also enter the mixing manifold via the upper (passenger zones) and lower (mix manifold) recirculation fans. [25] A typical large aircraft cabin environmental control system is shown in Figure 10.

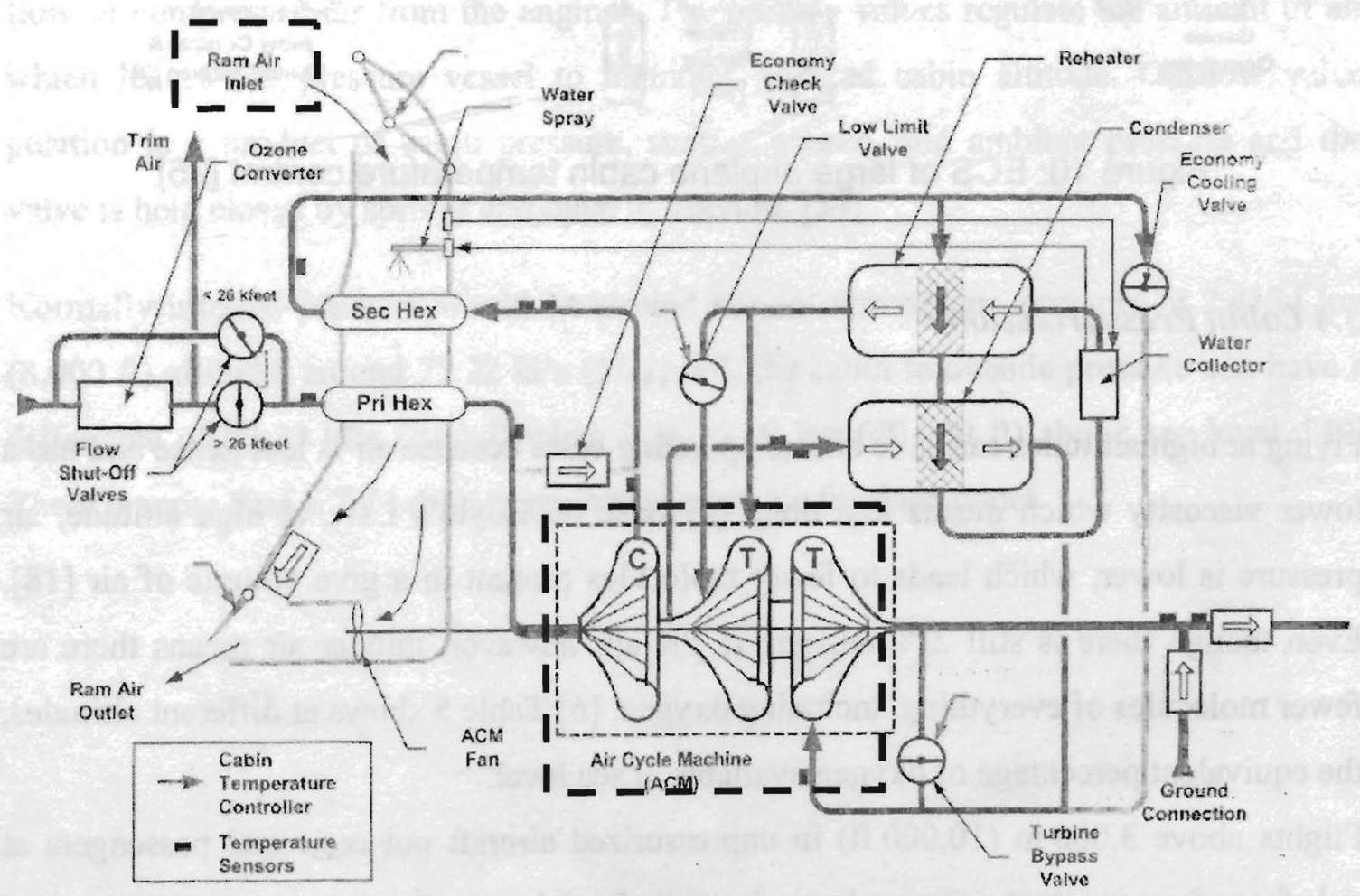

Figure 9: Air Cycle Cooling System [25] 


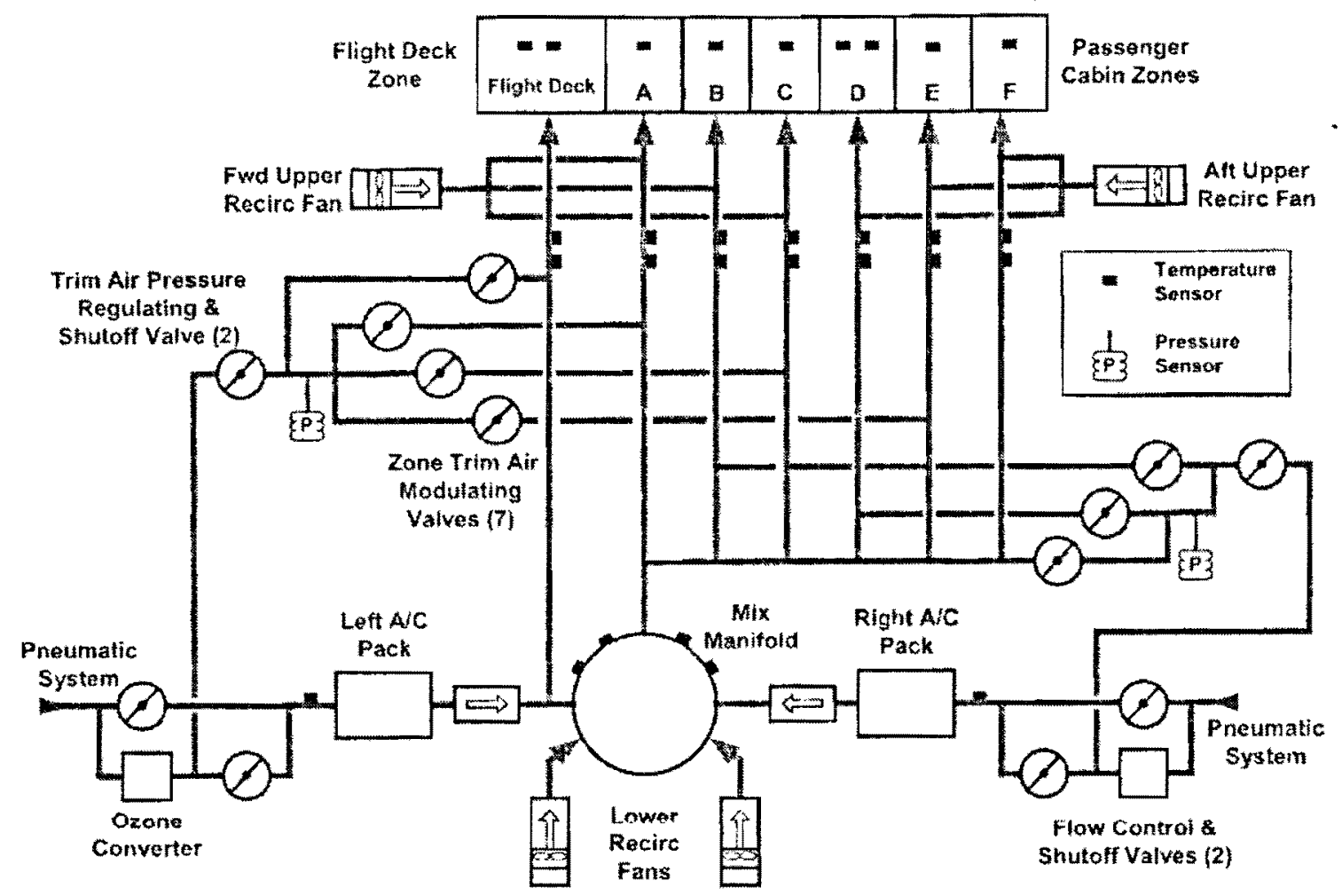

Figure 10: ECS of large airplane cabin temperature control [25]

\subsection{Cabin Pressurization}

Flying at high altitudes can save airline operating costs because air is less dense and has a lower viscosity which means less drag. [4] Base on Boyle's Law, at high altitude, air pressure is lower, which leads to fewer molecules present in a give volume of air [18]. Even though there is still $21 \%$ oxygen in the air, however, thinner air means there are fewer molecules of everything, including oxygen. [6] Table 5 shows at different altitudes, the equivalent percentage of oxygen available at sea level.

Flights above $3,000 \mathrm{~m}(10,000 \mathrm{ft})$ in unpressurized aircraft put crew and passengers at risk from four separate sources, hypoxia, altitude sickness, decompression sickness and barotraumas. [21] Therefore, cabin pressurization systems maintain a cabin altitude lower than the actual flight altitude. This allows for flight at high altitude without the need to wear oxygen masks. 


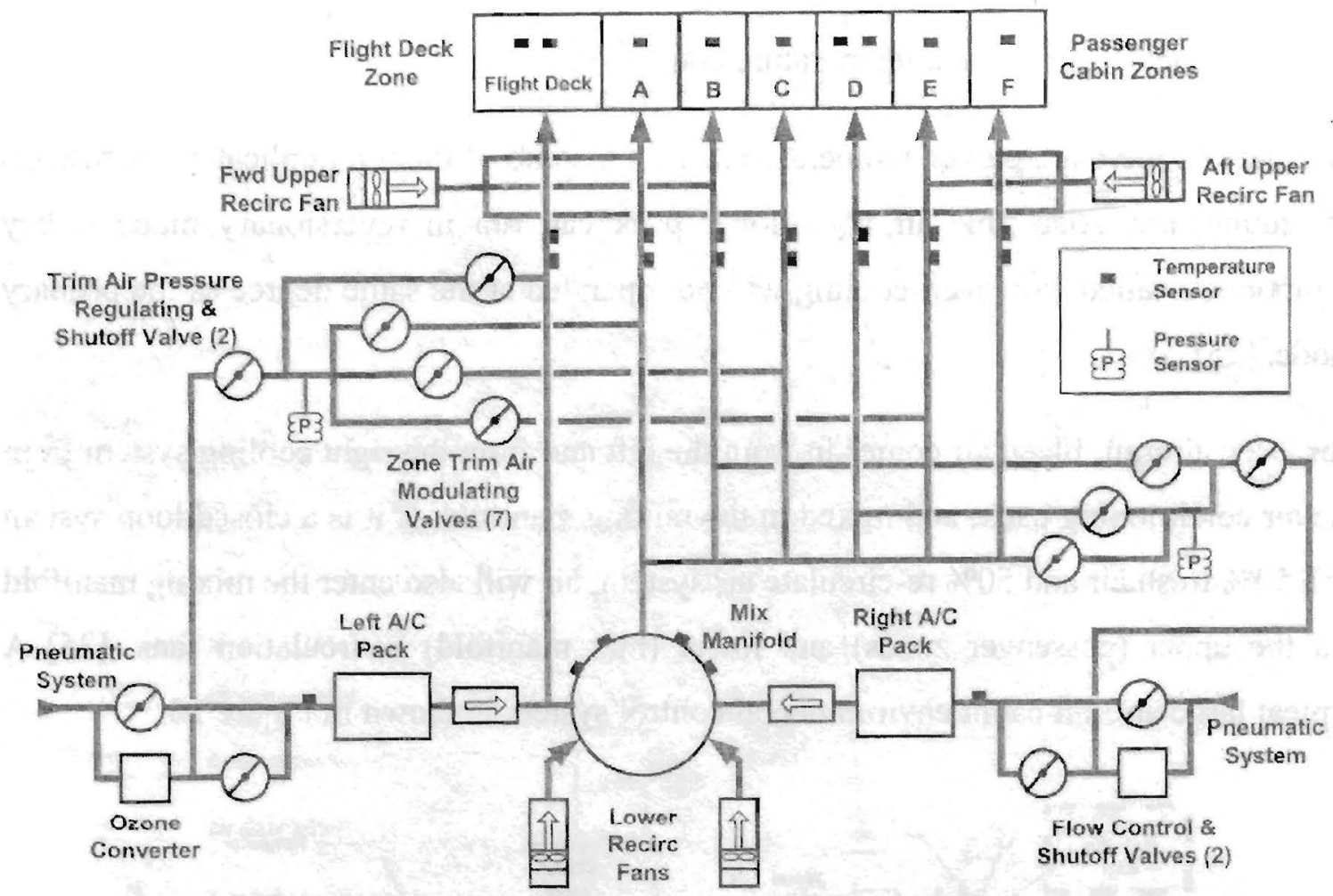

Figure 10: ECS of large airplane cabin temperature control [25]

\subsection{Cabin Pressurization}

Flying at high altitudes can save airline operating costs because air is less dense and has a lower viscosity which means less drag. [4] Base on Boyle's Law, at high altitude, air pressure is lower, which leads to fewer molecules present in a give volume of air [18]. Even though there is still $21 \%$ oxygen in the air, however, thinner air means there are fewer molecules of everything, including oxygen. [6] Table 5 shows at different altitudes, the equivalent percentage of oxygen available at sea level.

Flights above $3,000 \mathrm{~m}(10,000 \mathrm{ft})$ in unpressurized aircraft put crew and passengers at risk from four separate sources, hypoxia, altitude sickness, decompression sickness and barotraumas. [21] Therefore, cabin pressurization systems maintain a cabin altitude lower than the actual flight altitude. This allows for flight at high altitude without the need to wear oxygen masks. 


\begin{tabular}{|c|c|c|}
\hline Altitude & $\begin{array}{c}\text { Equivalent \% of Oxygen } \\
\text { available at sea level }\end{array}$ & Pressure $[\mathrm{kPa}]$ \\
\hline $0 \mathrm{~km}(0 \mathrm{ft})$ & 100 & 101 \\
\hline $1 \mathrm{~km}(3,280 \mathrm{ft})$ & 89 & 90 \\
\hline $5 \mathrm{~km}(16,403 \mathrm{ft})$ & 54 & 55 \\
\hline $10 \mathrm{~km}(32,807 \mathrm{ft})$ & 27 & 28 \\
\hline
\end{tabular}

Table 5: Altitude vs. Oxygen concentration [6]

The aircraft fuselage is designed with a pressure vessel encompassing all areas of the aircraft to be pressurized. This pressure vessel is subjected to the stresses of pressure differential (outside pressure versus inside pressure), and expansion and contraction due to changes in cabin pressure. [25] In Figure 11, the pressure vessel receives a continuous flow of compressed air from the engines. The outflow valves regulate the amount of air which leaves the pressure vessel to maintain selected cabin altitude. Outflow valve position is a product of cabin pressure, suction source, and ambient pressure and the valve is held closed by springs and open by suction. [34]

Normally internal pressure would be around normal atmosphere pressure at $2.4384 \mathrm{~km}$ $(8,000 \mathrm{ft})$ altitude, around $77.22 \mathrm{kPa}(11.2 \mathrm{psia})$, the cabin to outside pressure can have a difference of $59.29 \mathrm{kPa}(8.6 \mathrm{psi})$ when it is $12.19 \mathrm{~km}(40,000 \mathrm{ft})$ above sea level. [40] There is more than a $70 \%$ drop in pressure across the fuselage panel. 


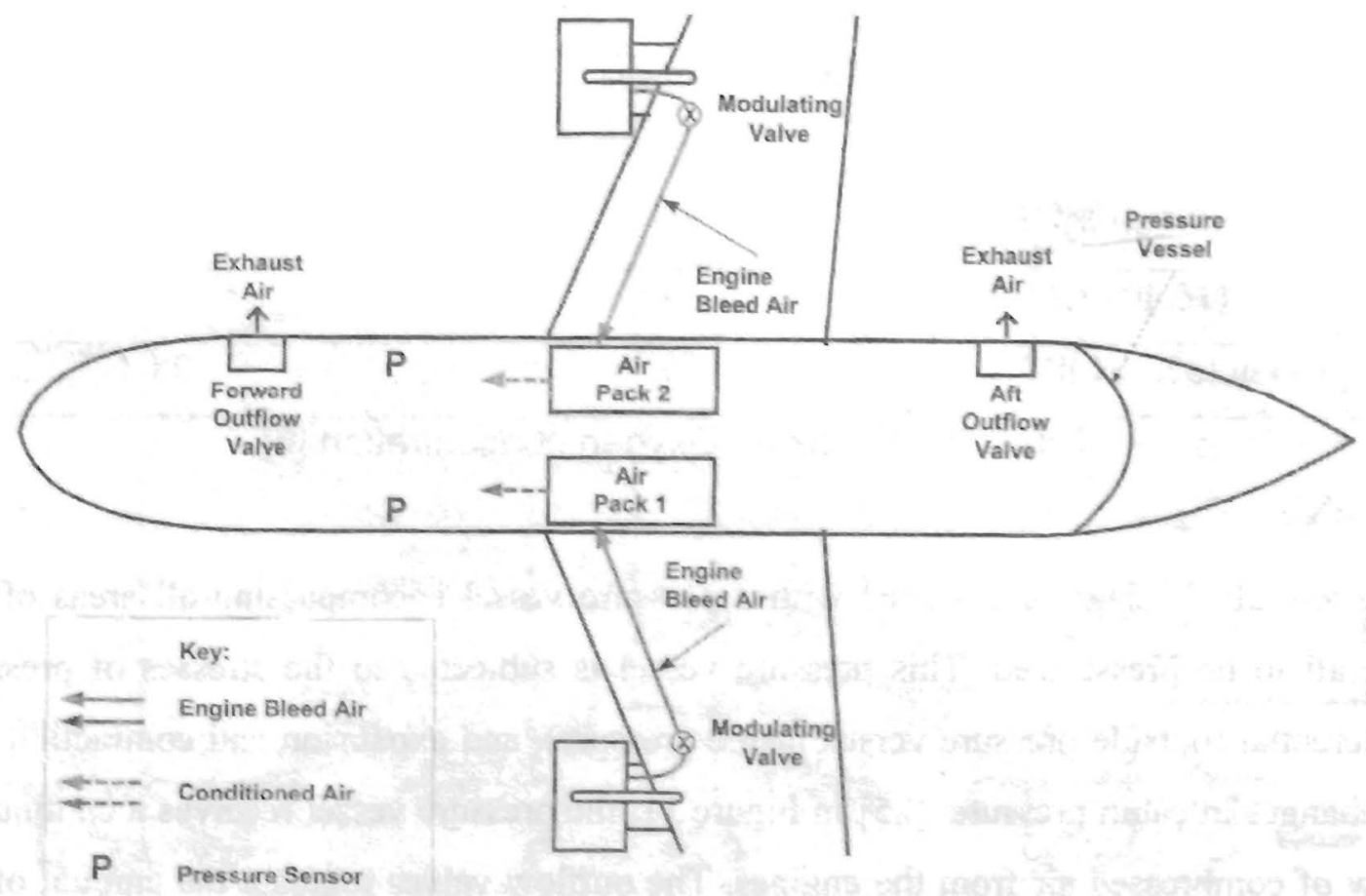

Figure 11: ECS Overview (pressurization system) [25]

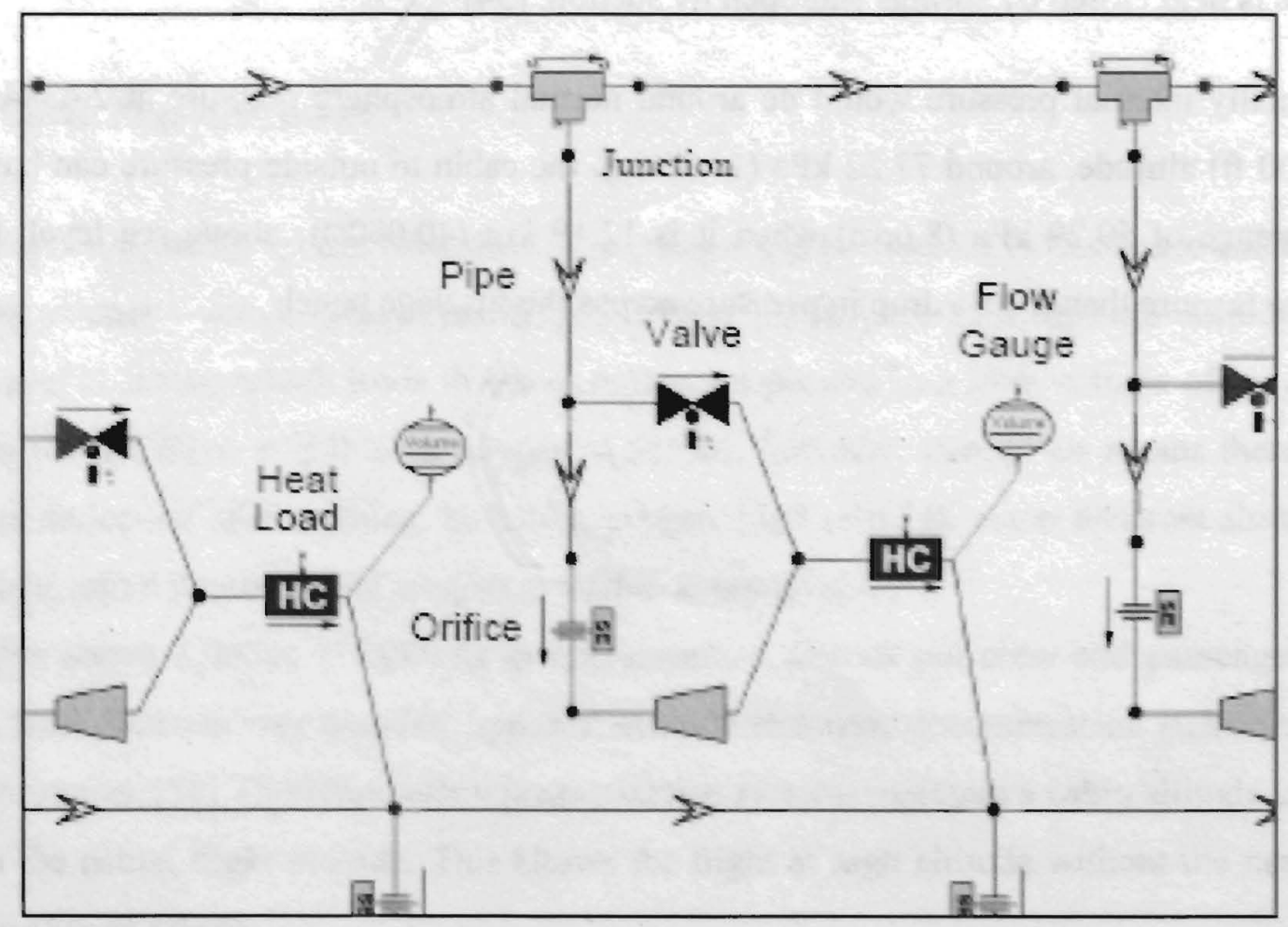

Figure 12: Single section of an ECS [26] 
Figure 13 is a schematic view of a section of the fuselage. There are many numbers of pipes, orifice plates and valves within a small sub system as shown in Figure 13. The best and simple way to model the climate control system is to simulate a pipe flow with an orifice plate. Analyzing a simple model as described, it can then be cascaded into a bigger matrix to simulate as sub system then further expanded to the whole environmental control system.

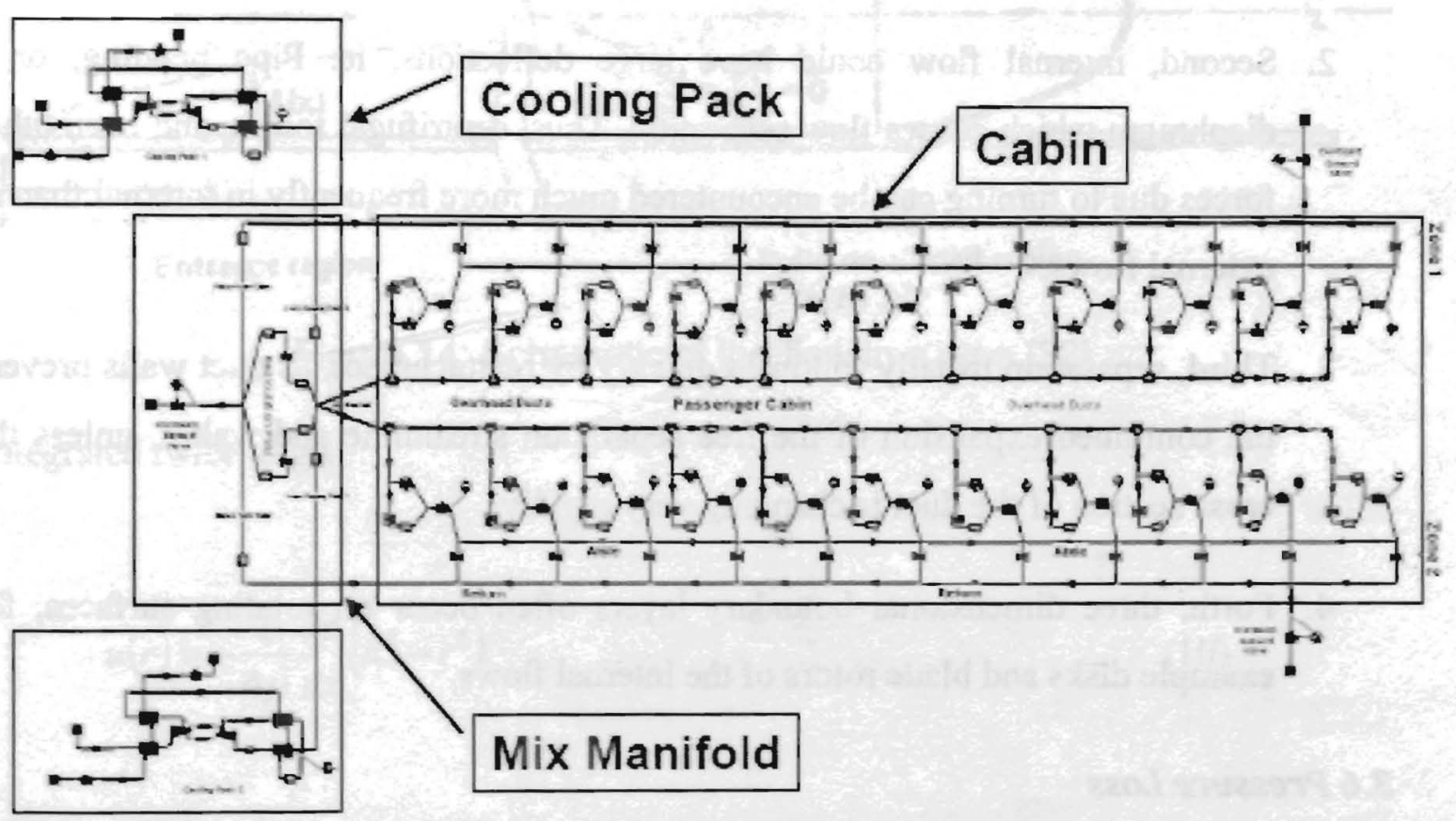

Figure 13: Section of an ECS [26] 


\subsection{Pipe Flow}

Internal flow is flow that are confined by rigid boundaries on all sides and the viscous boundaries are close enough to constrain the flow in important ways. Substance flow through pipe is an example of internal flow. Ackeret defined internal flows with four special features [32]:

1. First, continuity equation must be satisfied. In a long pipe, there are no clear distinction between the inviscid and viscous flow, the boundary layer displacement thickness on the walls effectively narrows the channel and alters the pressure distribution in the centre of the core.

2. Second, internal flow could have large deflections, ie. Pipe bending, or a diaphragm which causes flow separation. Thus, centrifugal forces, and even other forces due to turning can be encountered much more frequently in internal than in external flows.

3. Third, separation usually followed quickly by reattachment, as duct walls prevent the continued expansion of the free separation streamline and wakes, unless the cross section of the duct is changing very rapidly.

4. Forth, three dimensional boundary layers often occur on rotating surfaces, for example disks and blade rotors of the internal flows.

\subsection{Pressure Loss}

Fully developed flow is when the boundary layer growth along the wall completely fills the volume and the flow solution is independent of axial location. Therefore, flow at the inlet of the pipe is not important because boundary layer will change the profile of the flow, as shown in Figure 14, if the pipe is long enough to produce a fully developed flow. Assuming constant properties and steady state situation, combining the continuity equation with momentum equations gives: [32] 


$$
0=-\frac{1}{\rho} \frac{d p}{d x}+\frac{v}{r} \frac{d}{d r}\left(r \frac{d u}{d r}\right)
$$

Or

$$
\frac{v}{r} \frac{d}{d r}\left(r \frac{d u}{d r}\right)=\frac{1}{\rho} \frac{d p}{d x}=\text { constant }
$$

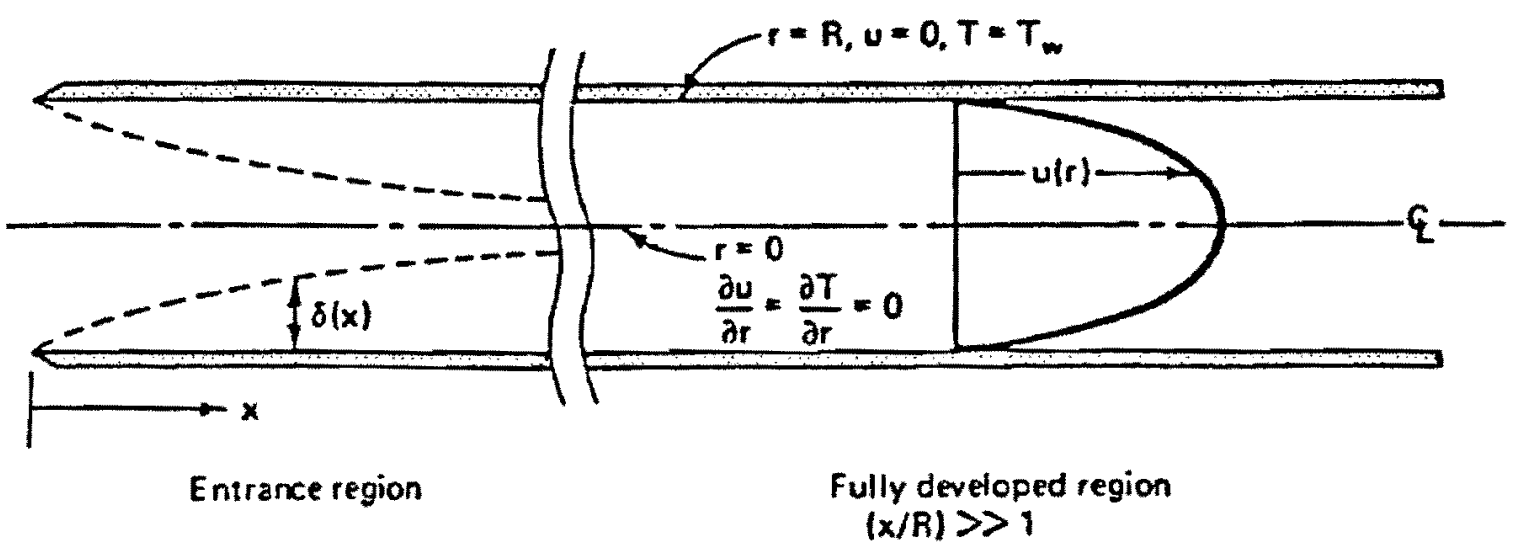

Figure 14: Schematic of the flow in a pipe [32]

Integrated twice to give:

$$
u(r)=-\frac{1}{4 \mu} \frac{d p}{d x}\left(R^{2}-r^{2}\right)
$$

Where $v$ is the kinematic viscosity and $\mu$ is the absolute viscosity

For no slip boundary condition on the wall, velocity is zero and the change in velocity is also zero. [32] As described in the equation, as well as in Figure 14, the velocity profile is parabolic.

A negative sign in equation 8 indicates that there will be a pressure loss along the tube, and that pressure loss is caused by the viscous shear on the pipe wall, which can be calculate via: [32] 


$$
0=-\frac{1}{\rho} \frac{d p}{d x}+\frac{v}{r} \frac{d}{d r}\left(r \frac{d u}{d r}\right)
$$

Or

$$
\frac{v}{r} \frac{d}{d r}\left(r \frac{d u}{d r}\right)=\frac{1}{\rho} \frac{d p}{d x}=\text { constant }
$$

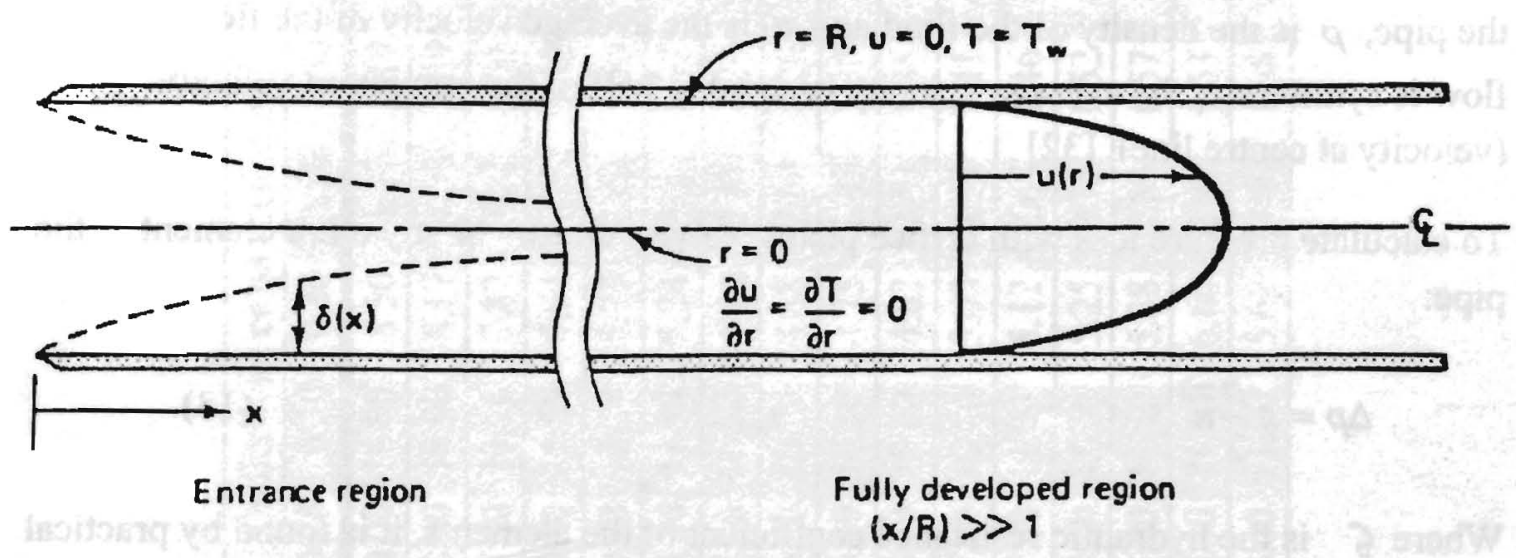

Figure 14: Schematic of the flow in a pipe [32]

Integrated twice to give:

$$
u(r)=-\frac{1}{4 \mu} \frac{d p}{d x}\left(R^{2}-r^{2}\right)
$$

Where $v$ is the kinematic viscosity and $\mu$ is the absolute viscosity

For no slip boundary condition on the wall, velocity is zero and the change in velocity is also zero. [32] As described in the equation, as well as in Figure 14, the velocity profile is parabolic.

A negative sign in equation 8 indicates that there will be a pressure loss along the tube, and that pressure loss is caused by the viscous shear on the pipe wall, which can be calculate via: [32] 


$$
\tau_{w}=-\left.\mu \frac{d u}{d r}\right|_{r=R}=-\frac{R}{2} \frac{d p}{d x}
$$

Or

$$
\Delta p=\lambda \frac{L}{D} \frac{\rho}{2}^{-2}
$$

Where $\lambda$ is the pipe friction coefficient, $\mathrm{L}$ is the length of the pipe, $\mathrm{D}$ is the diameter of the pipe, $\rho$ is the density of the fluid and $\bar{u}$ is the average velocity of the flow. [20] If flow is symmetric, the average velocity is equal to half of the maximum velocity (velocity at centre line). [32]

To calculate pressure loss with orifice plates, valves, elbows or any other element in the pipe:

$$
\Delta p=\varsigma \frac{\rho}{2} u^{-2}
$$

Where $\zeta$ is the hydraulic resistance coefficient of the elements, it is found by practical testing and/or vendor specification. The hydraulic resistance coefficient for a straight orifice plate can be calculated by: [20]

$$
\begin{aligned}
& \varsigma=0.5961+0.0261 \beta^{2}-0.216 \beta^{8}+0.000521\left(\frac{10^{6} \beta}{\operatorname{Re}_{D}}\right)^{0.7}+ \\
& \left(0.0188+0.0063\left(\frac{19000 \beta}{\operatorname{Re}_{D}}\right)^{0.8}\right)\left(\frac{10^{6}}{\operatorname{Re}_{D}}\right)^{0.3} \beta^{3.5}
\end{aligned}
$$

Where $\beta$ is the ratio of the diameter of the hole of the orifice plate to the diameter of the orifice plate, and Reynolds number can be calculate:

$$
\operatorname{Re}_{D}=\frac{V D}{v}=\frac{\rho V D}{\mu}
$$

The hydraulic resistance coefficient for an orifice plate can be found in table 6 : 


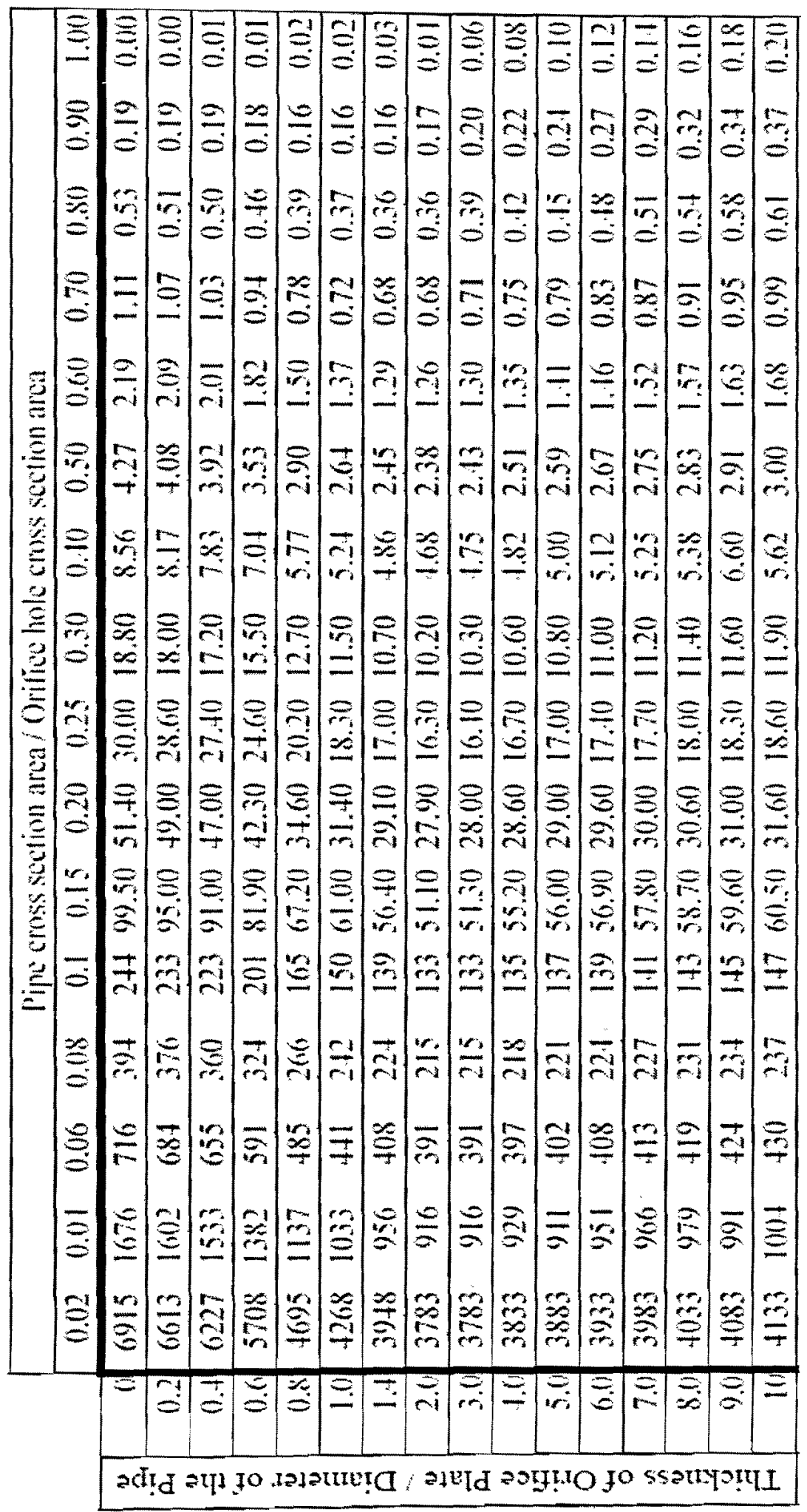

Table 6: Hydraulic Resistance Coefficient [20] 


\section{Chapter 4: Computational Theory}

"A numerical simulation of the flow over an airfoil using the Reynolds averaged Navier Stokes equations can be conducted on today's supercomputers in less than a half hour for less than $\$ 1,000$ cost in computer time. If just one such simulation had been attempted 20 years ago on computers of that time (e.g., the IBM 704 class) and with algorithms then known, the cost in computer time would have amounted to roughly $\$ 10$ million, and the results for that single flow would not be available until 10 years from now, since the computation would have taken about 30 years to complete."

- Dean R. Chapman, NASA, 1977

There are three possible ways to solve fluid dynamic problems. The two traditional ways to solve fluid mechanic problems are through experiments and equations developed by pure theory, and analytical solution. In the late $1990 \mathrm{~s}$, with the rapid increase in computer power available to engineers and scientists, Computational Fluid Dynamic (CFD) programs becoming the third main methods to solve fluid mechanic problems. This newly developed method can provide similar results as traditional experimental method with lower operating cost; it can also provided a faster result than theoretical solution; furthermore, it is capable to provide intractable results for classical analytical methods. That is the reason why computational fluid dynamic is the new revolution for airplane design, and it has changed modern aeronautical research and development. [5] 


\subsection{Theoretical (Analytical) Solution}

The governing equations of aerodynamics, such as the continuity, momentum, and energy equations, represent the basic physical fundamentals of the flow fields.

Continuity equations:

$$
\frac{\partial}{\partial t} \oiiint_{\nu} \rho d v+\oiint_{S} \rho \vec{V} \cdot d \vec{S}=0
$$

Or

$$
\frac{\partial \rho}{\partial t}+\nabla \cdot(\rho \vec{V})=0
$$

Momentum equations:

$$
\frac{\partial}{\partial t} \oiiint_{v} \rho \vec{V} d v+\oiiint_{S}(\rho \vec{V} \cdot d \vec{S}) \vec{V}=-\oiiint_{S} p d \vec{S}+\oiiint_{v} \rho \overrightarrow{f f} d v+\vec{F}_{v i s c o u s}
$$

Or

$$
\begin{aligned}
& \frac{\partial(\rho u)}{\partial t}+\nabla \cdot(\rho u \vec{V})=-\frac{\partial p}{\partial x}+\rho f_{x}+\left(F_{x}\right)_{v i s c o u s} \\
& \frac{\partial(\rho v)}{\partial t}+\nabla \cdot(\rho v \vec{V})=-\frac{\partial p}{\partial y}+\rho f_{y}+\left(F_{y}\right)_{v i s c o u s} \\
& \frac{\partial(\rho w)}{\partial t}+\nabla \cdot(\rho w \vec{V})=-\frac{\partial p}{\partial z}+\rho f_{z}+\left(F_{z}\right)_{v i s c o u s}
\end{aligned}
$$

Energy equations:

$$
\begin{aligned}
\frac{\partial}{\partial t} \oiiint_{v} \rho\left(e+\frac{V^{2}}{2}\right) d v+\oiint_{S} \rho\left(e+\frac{V^{2}}{2}\right) \vec{V} \bullet d \vec{S}= \\
\oiiint_{v} \dot{q} \rho d v+\dot{Q}_{v i s c o u s}-\oiiint_{S} p \vec{V} \bullet d \vec{S}+\oiiint_{v} \rho(\vec{f} \cdot \vec{V}) d v+\dot{w}_{\text {viscons }}
\end{aligned}
$$

Or 


$$
\frac{\partial}{\partial t}\left[\rho\left(e+\frac{V^{2}}{2}\right)\right]+\nabla \cdot\left[\rho\left(e+\frac{V^{2}}{2}\right) \vec{V}\right]=\rho \dot{q}-\nabla \cdot(\rho \vec{V})+\rho(\vec{f} \cdot \vec{V})+\dot{Q}_{\text {viscous }}^{\prime}+\dot{W}_{\text {viscous }}^{\prime}
$$

These equations are highly non-linear, coupled set of partial differential equations, which, to date, no general analytical closed-form solution. These equations are very powerful and by themselves represent a sophisticated intellectual construct of the understanding of the fundamentals of a fluid flow. However, assumptions have to be made in order to solve and then to obtain the actual flow fields over specific body shapes with specific flow conditions. [5]

For example, flow properties change only in the direction of the flow when crossing a normal shock wave, therefore, for the above governing equations, if flow is in $\mathrm{x}$ direction, which means the derivatives term for the $\mathrm{y}$ and $\mathrm{z}$ direction will be identical to zero. [5] Equations will be simplified and reduced to a one dimensional equation which can be solved with the developed mathematical techniques. And indeed this one dimensional solution is an exact solution because assumptions were made according to the exact value of the flow conditions. There are other cases that the actual flow is not one dimensional but the derivative of the $y$ and $\mathrm{z}$ terms were assumed to be zero, since the change in the other dimensions ( $y$ and $z$ directions) is small enough to be neglected, compared with the flow direction ( $x$ direction). [5] This analytical solution is called an approximate solution.

\subsection{Computational Fluid Dynamic (Numerical) Solution}

Computational Fluid Dynamic program makes use of mathematic numerical analysis to solve the aerodynamic governing equations listed above. The continuity, momentum and energy equation are solved either in integral equation or partial differential form. To solve these non-linear equations by using numerical analysis, the continuous flow problem would be discretized algebraically, which in turn are solved to obtain numbers for the flow field values at discrete points in time and/or space. [5] Numerical analysis generates massive amount of data. Before computer power was advanced, numbers are calculated by hands, large books were produced with formulas and tables of data such as 
interpolation points and function coefficients. Using these tables, often calculated out to 16 decimal places or more for some functions, one could look up values to plug into the formulas given and achieve very good numerical estimates of some functions. [9] In the last third of the twentieth century, high speed digital computers advanced, leading numerical analysis to be more common. When compared with the closed form analytical solution, although the output of the computational fluid dynamics program is an approximation to the solution of the governing equations, the objective of most engineering analyses is just a quantitative description of the problem. [5]

\subsection{Grid/Meshing}

In order to get a result from computational fluid dynamic program that will agree with the actual experimental result, obviously, both setups have to be near as identical as possible. The flow geometry and boundary conditions in computational fluid dynamic program has to be model in the same way as the conditions of the flow in the experiment. However, in addition to setting the right boundary conditions, a fine grid is needed in order to get a accurate result from the computational fluid dynamic programs.

The beauty of CFD is that it can deal with the full non-linear equations of continuity, momentum, and energy. CFD programs would divide the flow field into a number of discrete points, with lines connect these points to form a grid. The discrete points are called grid points. In different cases, different grids would be used to retrieve flow properties at user point of interest. For example, when modeling a flow field around an airfoil, if viscous flow near the boundary is the main concern, the space between grid points will be formed closely together near the body while the grid uses a wider spacing in the far field. The flow field properties, such as pressure, density, velocity will only be calculated at the discrete grid points and nowhere else, and the partial derivatives or the integrals in the governing equations are approximated using the flow-field variables at grid point only. [5]

In general the process of using a CFD program is to solve an aerodynamic problem is: 
1. Geometries would be drawn with Computer Aided Three dimensional Interactive Application (CATIA) program.

2. Mesh would be generated by grid generator software. The grid generator that was used in this project is CentaurSoft.

3. Geometries with discrete grid point will be submitted to CFD program to complete the analysis.

\subsection{CentaurSoft}

CentaurSoft provides a complete grid generation package that can be used in all phases of computational engineering. CENTAUR ${ }^{\mathrm{TM}}$ grid generator use hybrid grids with minimal user interaction to produces meshes composed of unstructured prismatic (wedge), hexahedral, pyramidal and/or tetrahedral elements. [13]

Traditional grid generator used block-structured, usually composed of hexahedral, or unstructured, usually tetrahedral, techniques to generate mesh for the input geometry. Hybrid grid generators use prismatic element, for viscous regions of the flow, and tetrahedral elements for inviscid regions of the flow to improve the spatial accuracy of the solution while minimizing the number of grid points. [28] Hybrid grids also couple the $3 \mathrm{D}$ isotropic division of tetrahedral and $2 \mathrm{D}$ directional division of prisms to refine the grid. [28] CENTAUR ${ }^{\mathrm{TM}}$ grid generator combines both traditional and hybrid techniques, using prismatic and hexahedral elements for high solution gradients regions, and tetrahedral with pyramids for transition location between prisms/hexahedra and the tetrahedral. [13] The 2D and 3D elements that were used in CENTAUR ${ }^{\mathrm{TM}}$ are displayed in Figure 15. 


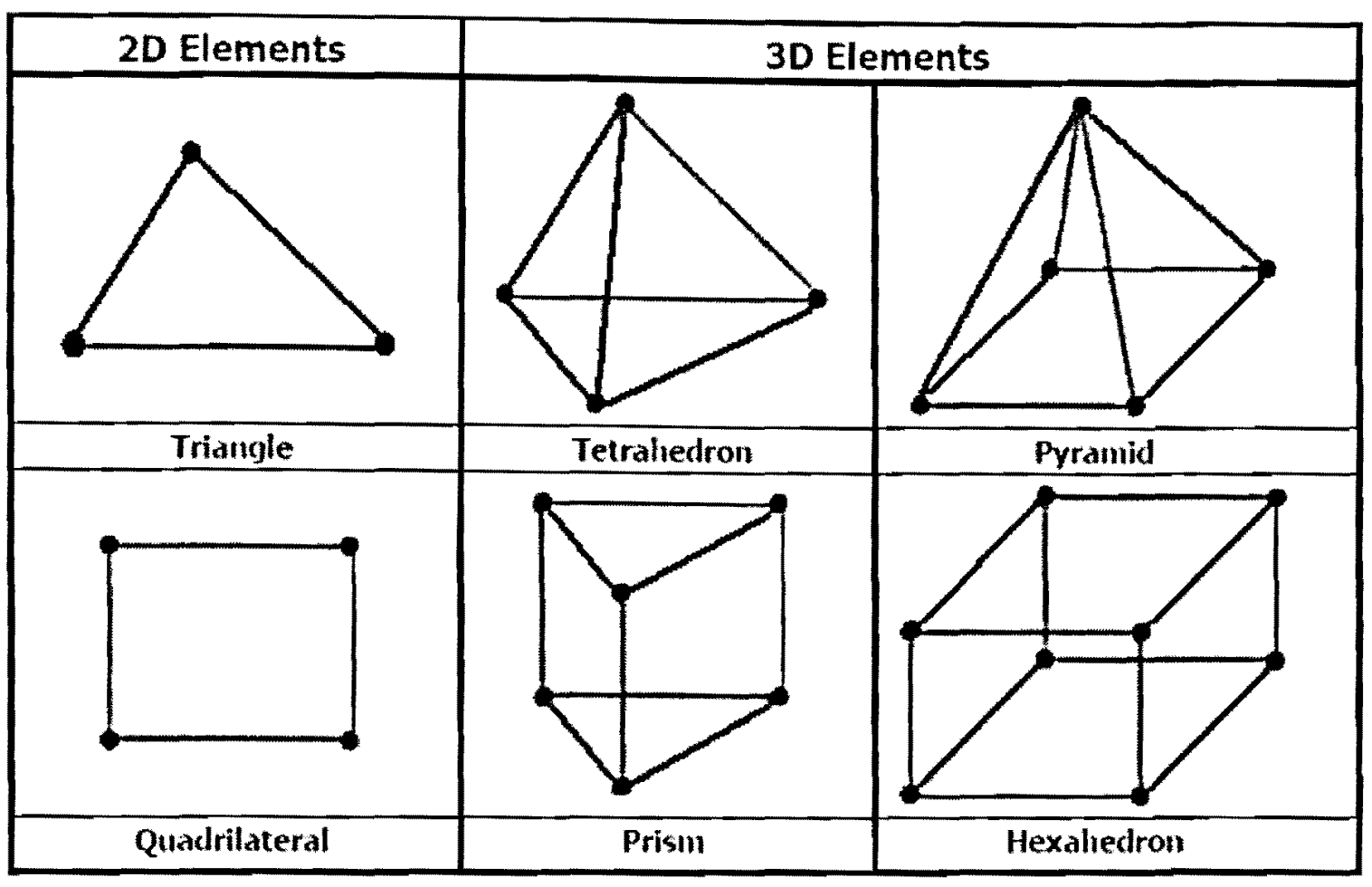

Figure 15: 2D and 3D Elements [13]

CentaurSoft believes the main advantages of the hybrid system that they use are: [13]

1. The prismatic or hexahedral layers close to wall surfaces exhibit good orthogonality and clustering capabilities characteristic of structured mesh generation approaches.

2. The structured nature allows for the implementation of multi-grid convergence acceleration schemes, implicit methods, and also results in memory savings.

3. The use of tetrahedral elements to fill the rest of the domain allows single-block generation for extremely complex geometries since the tetrahedron is the simplex element in 3-D.

4. The unstructured tetrahedral elements are well suited for cell adaptation, thus allowing the resolution of active features in the domain.

5. The flexibility of the hybrid mesh generation approach automates an otherwise highly interactive procedure. 
6. The hybrid prismatic/hexahedral/tetrahedral strategy requires no solution interpolation or grid interfacing techniques as in the traditional blockstructured approach.

7. The prismatic and hexahedral portions of the grid reduces the memory requirements when compared with an all tetrahedral grid of the same resolution, and also reduces grid generation time substantially.

\subsection{Procedure}

The CENTAUR ${ }^{\mathrm{TM}}$ grid generator that was used in this project is Centaur IGES Converter (setupgrid) CAD Conversion Engine Version 7.0.1.2.

The CENTAUR ${ }^{\mathrm{TM}}$ mesh generation process can be split into 4 stages. After importing the CATIA IGES file into Centaur IGES Converter,

First run a CAD diagnostics and cleaning to convert CAD data into CENTAUR ${ }^{\text {TM }}$ format, setting boundary conditions that are specified in the original input file and set the types for the basic cell element. CAD converter has the capability to identify potential problems with the incoming geometry and to fix most of them prior to mesh generation. During data conversion, the converter will add simple geometric features like bounding boxes and missing surfaces to an existing geometry to avoid discretizing error.

Second, when cleaning is done, unstructured triangles or quadrilaterals are generated to discretize the surface mesh.

Third, boundary layer surfaces are covered with thin elements for prismatic and hexahedral mesh, i.e. triangles are extruded to form layers of prisms, and quadrilaterals are extruded to form layers of hexahedra.

Forth, the remainder of the computational domain is then automatically filled with tetrahedral elements, and the tetrahedral elements will automatically match local prismatic and hexahedral thickness to form the tetrahedral mesh. 
Due to the topic of this research project, the main interest is noise generation in a pipe flow in the flow separation behind the orifice plate, therefore, a function in CENTAUR ${ }^{\mathrm{TM}}$ gird generator called "source" was used. The CENTAUR ${ }^{\mathrm{TM}}$ grid generator allows the user the ability to specify mesh clustering in regions where the mesh would not automatically cluster due to geometric features or in areas where the user would like additional mesh clustering. Both geometric (line, sphere, cylinder, hexahedron) and CAD-based (curve, panel, group) types of sources are supported. These sources control the clustering either by specifying a length scale in the source region or by specifying an additional amount of clustering relative to the pre-existing clustering. Relative sources can also be used to locally coarsen the mesh. Figure 16 shows the difference the use of a "source" function provides. An example of a wing was shown in Figure 16. The wing geometry show in the bottom of Figure 16 has two cylindrical sources which is represented by the shaded part on the top view of the wing.

A cylindrical source is placed behind the orifice plate for this research. In Figure 17, the black region behind the orifice plate and near the top and bottom of the pipe is simply the computer graphics way of showing a very large number of closely spaced grid points. Detailed flow properties at these regions will be collected in the result. 


\section{(Isotropic Elements)}

Normal Surface Mesh with No Sources

9640 faces

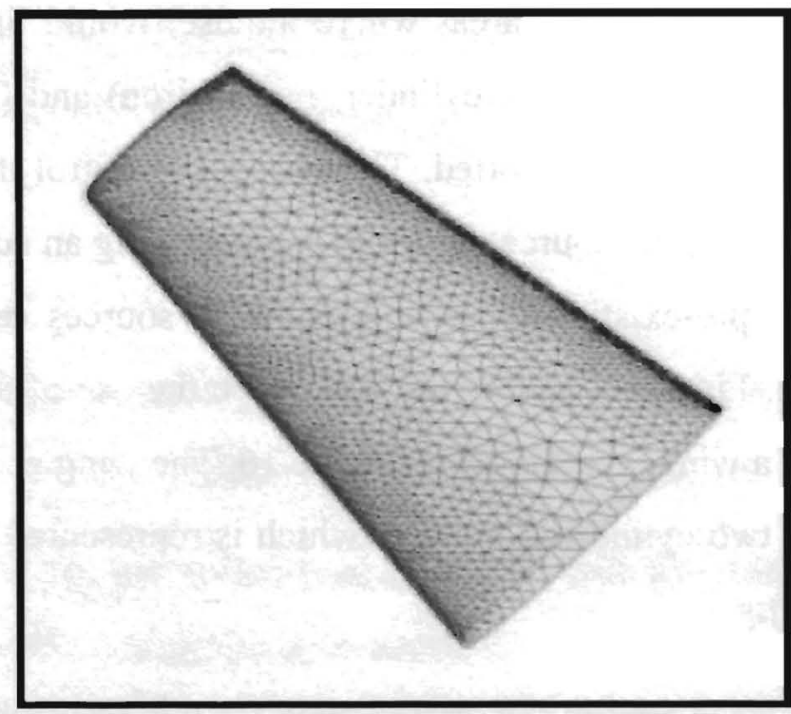

Surface Mesh with Two Cylindrical Sources 13830 faces

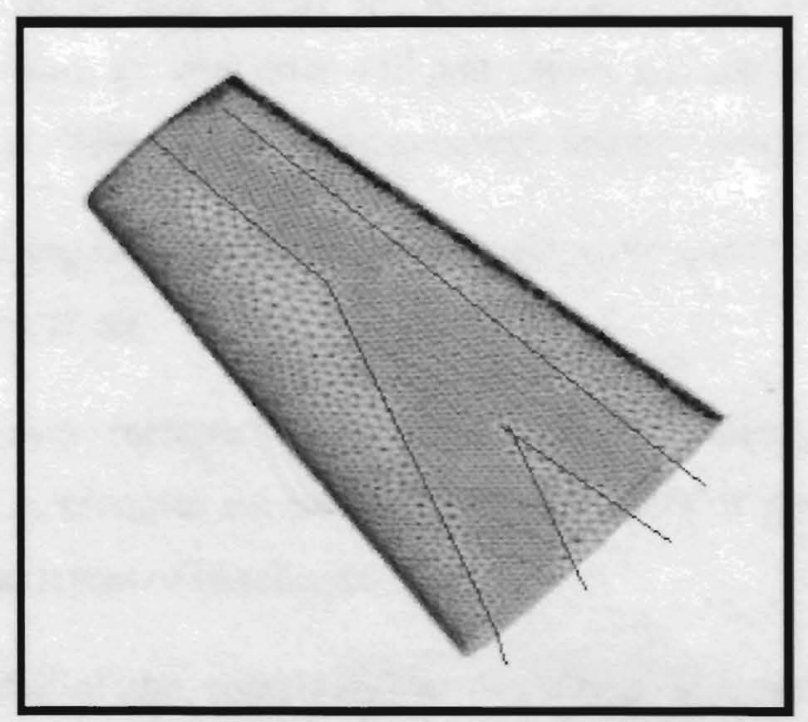

Figure 16: Use of source function [13] 


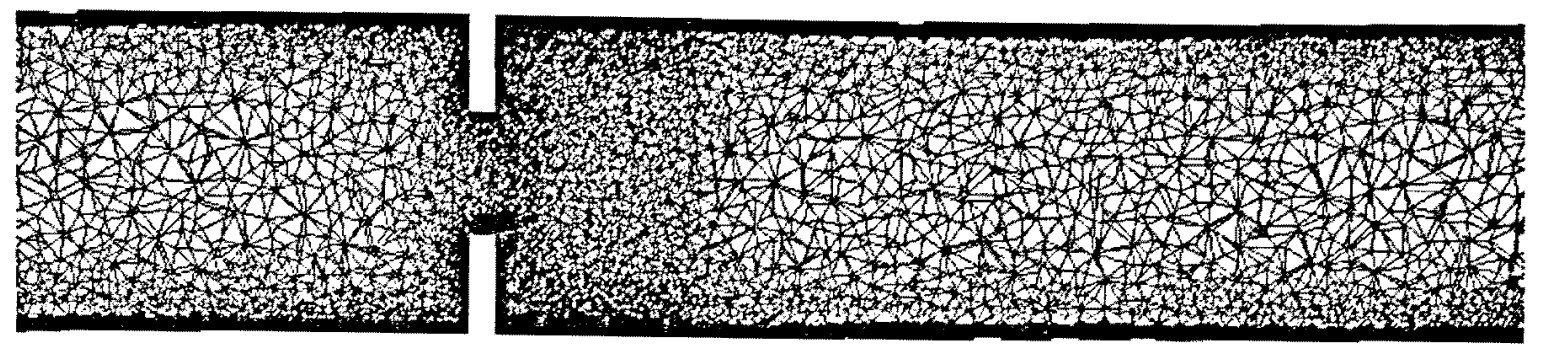

Figure 17: Source function is used behind the orifice plate

There are three output files from CENTAUR ${ }^{\mathrm{TM}}$ grid generator which were edited before inputting in a CFD program: the Prismatic INput (PIN) file, Tetrahedral INput (TIN) file and Surface INput (SIN) file.

The maximum tetrahedral size was limited in the tetrahedral input file, so that each tetrahedral cell is smaller which will increase the total number of cells and increase the spatial accuracy of the results.

The automatic curve pull back angle from prismatic input file is used in all geometries with sharp corners so that every curve does not need to be identified for local pullback separately. This maintains good quality cells at these sharp corners. An example is illustrated in Figure 18 and shows the different setting for the pull back angle on an example geometry. Figure 19 is the result for the sharp corners at the orifice in the pipe flow geometry. As can be seen the cell size is uniform throughout the corners. After adjusting all the setting in the input files corresponding to these research required, the final mesh for the pipe is shown as in Figure 20, 21 and 22. 


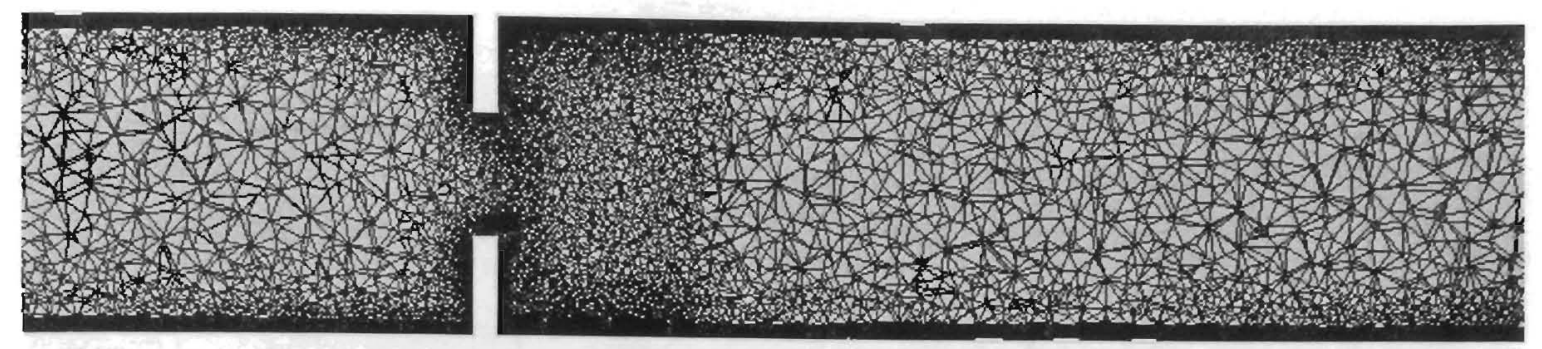

Figure 17: Source function is used behind the orifice plate

There are three output files from CENTAUR ${ }^{\mathrm{TM}}$ grid generator which were edited before inputting in a CFD program: the Prismatic INput (PIN) file, Tetrahedral INput (TIN) file and Surface INput (SIN) file.

The maximum tetrahedral size was limited in the tetrahedral input file, so that each tetrahedral cell is smaller which will increase the total number of cells and increase the spatial accuracy of the results.

The automatic curve pull back angle from prismatic input file is used in all geometries with sharp corners so that every curve does not need to be identified for local pullback separately. This maintains good quality cells at these sharp corners. An example is illustrated in Figure 18 and shows the different setting for the pull back angle on an example geometry. Figure 19 is the result for the sharp corners at the orifice in the pipe flow geometry. As can be seen the cell size is uniform throughout the corners. After adjusting all the setting in the input files corresponding to these research required, the final mesh for the pipe is shown as in Figure 20, 21 and 22. 
Typical Range: $0.05-0.50$

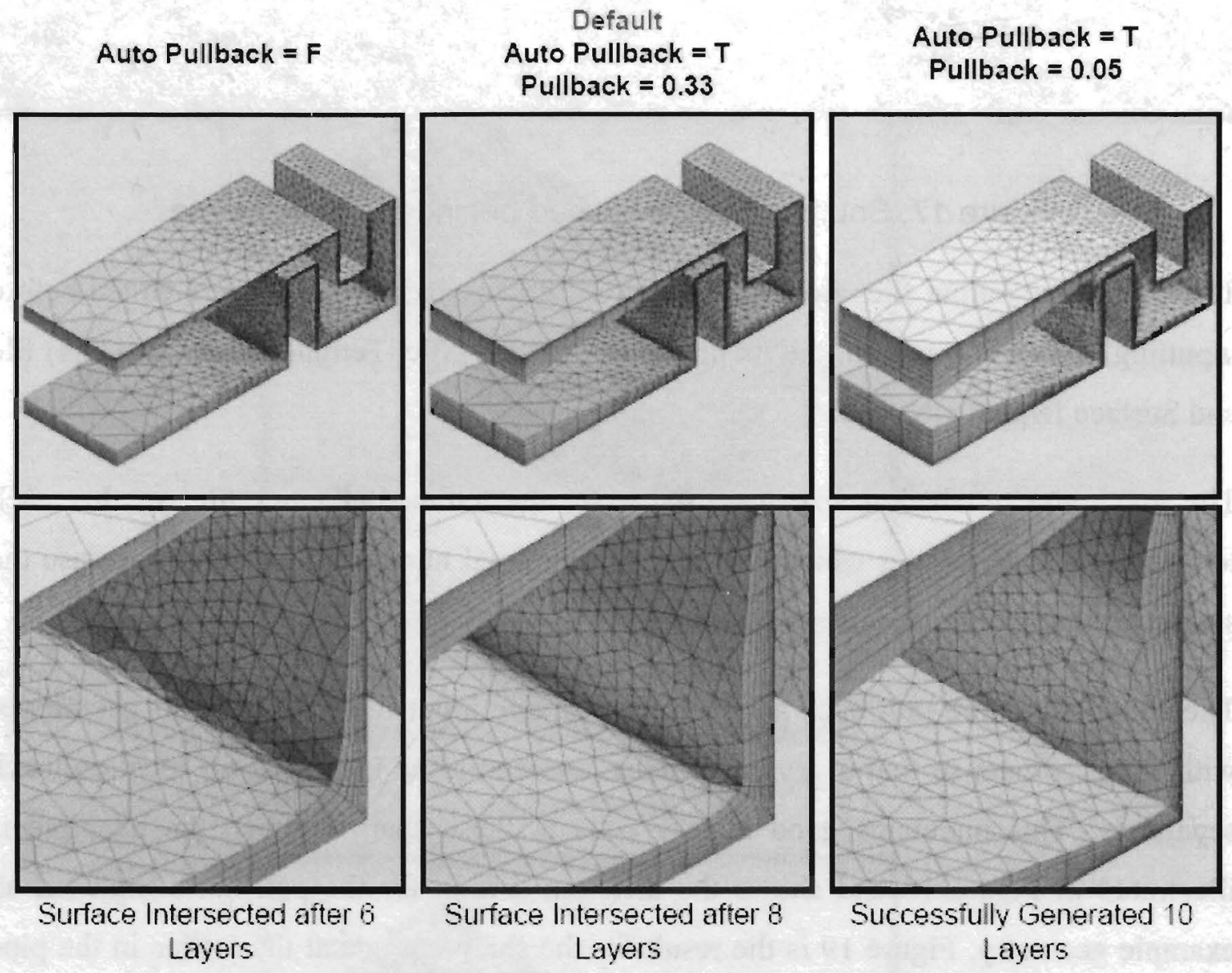

Figure 18: Curved Pull Back example [13] 


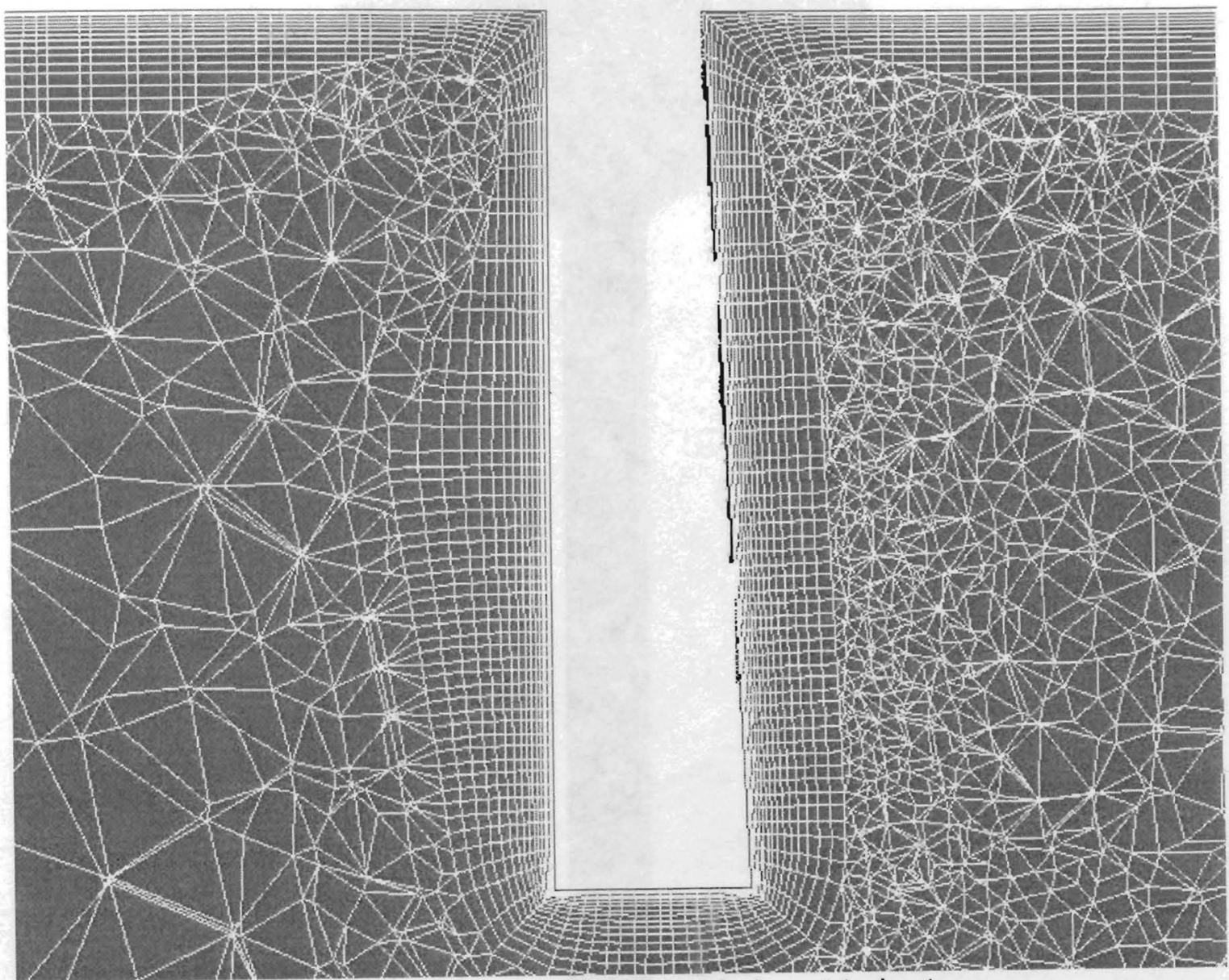

Figure 19: Curve pull back angle is set to be true 


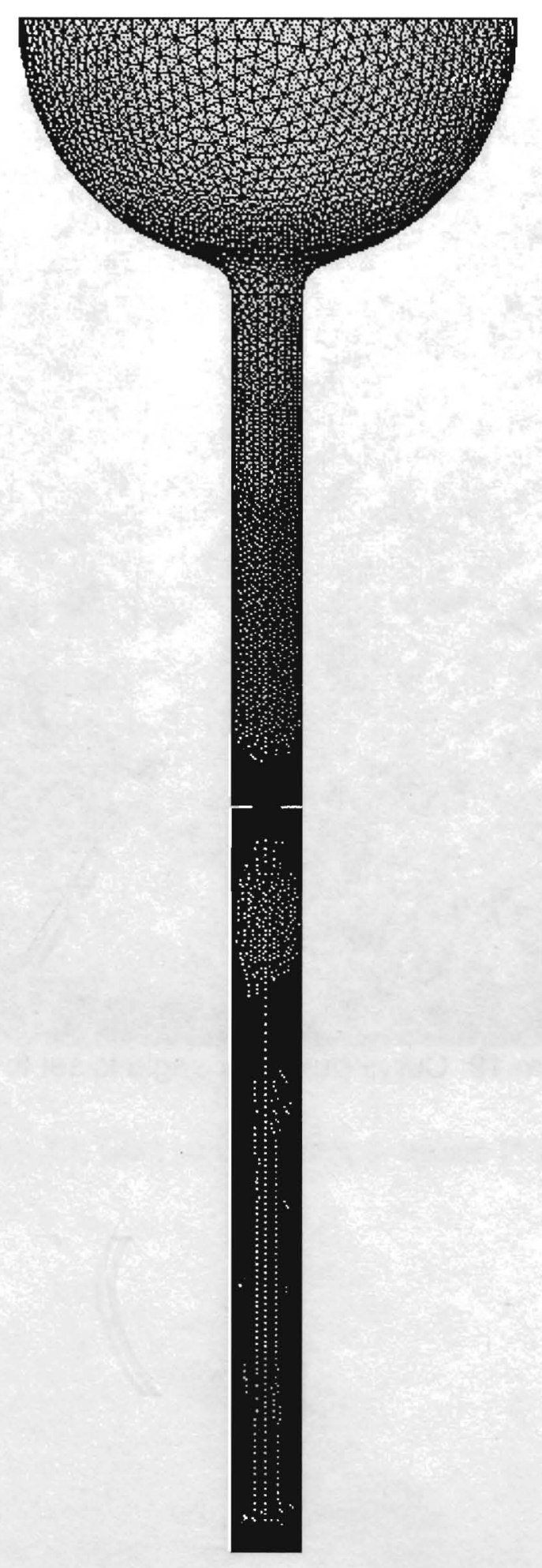

Figure 20: Grid (Surface view) 


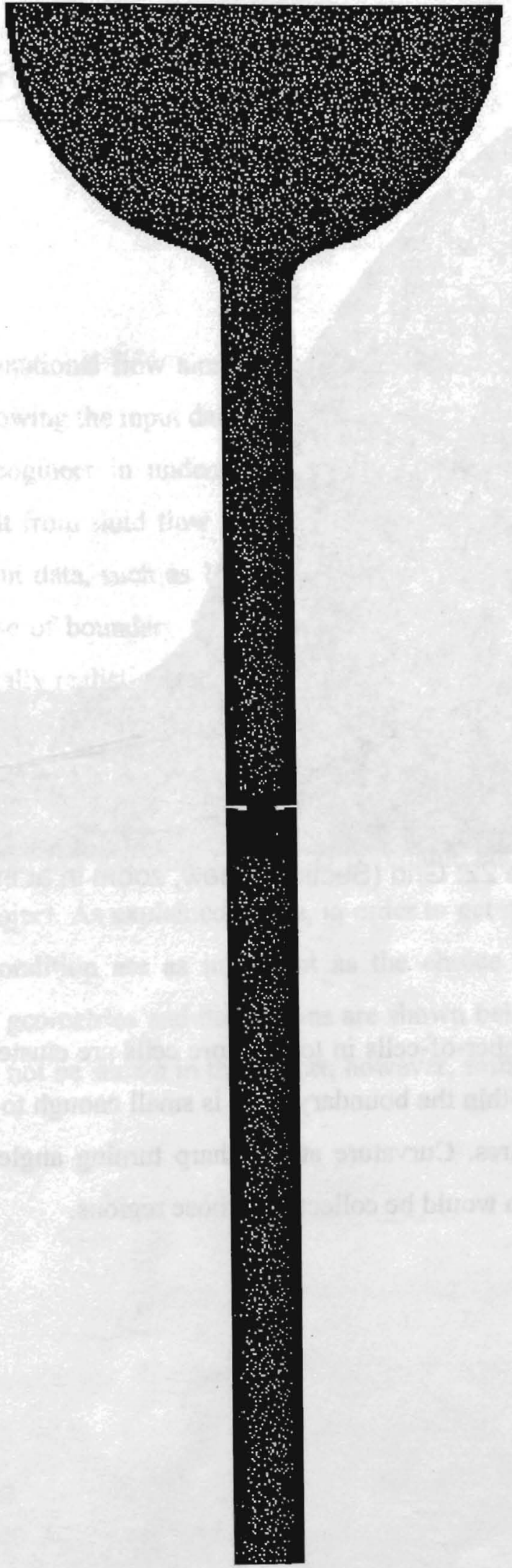

Figure 21: Grid (Sectional view) 


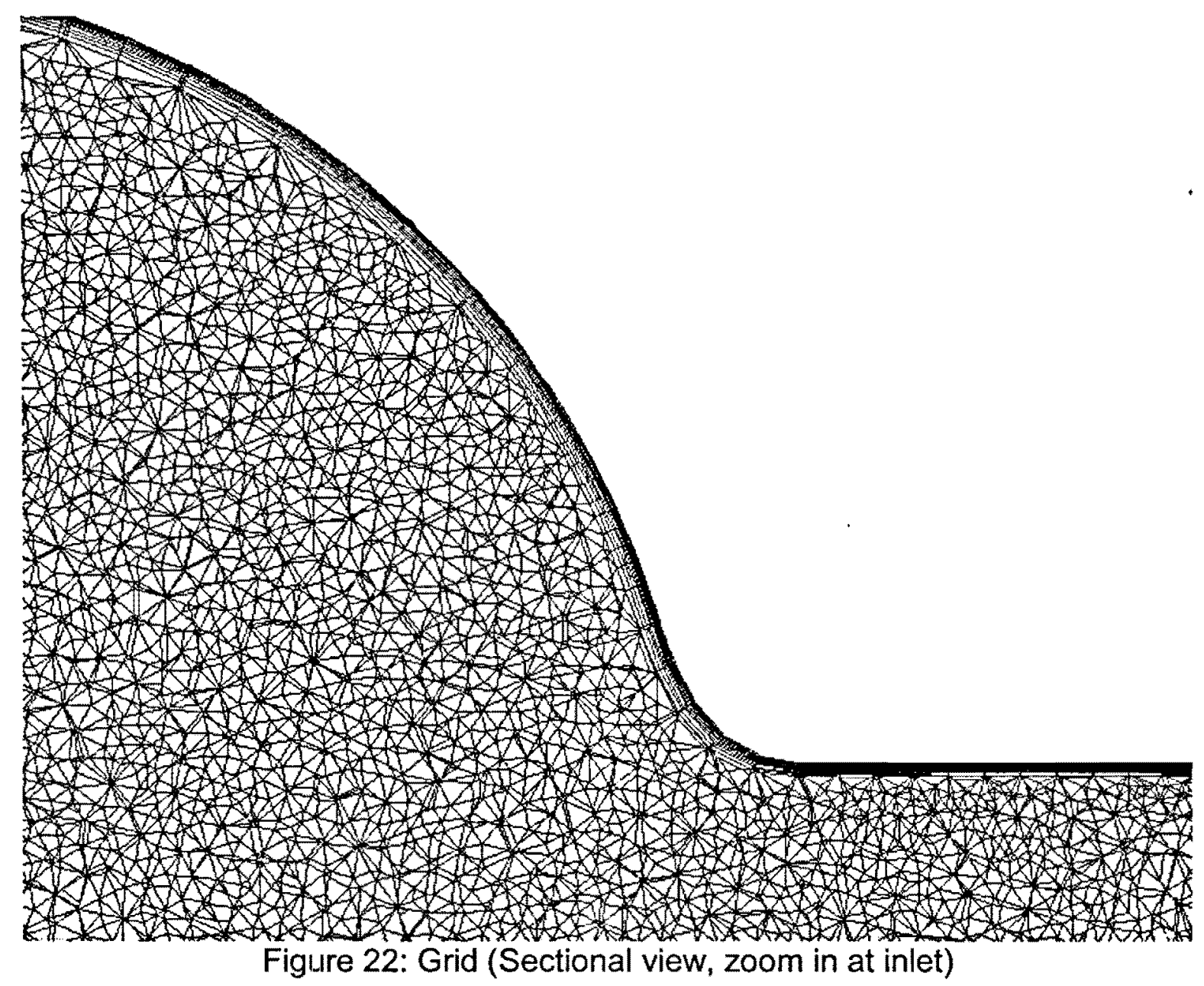

There are 3,588,989 number-of-cells in total. More cells are clustered behind the orifice plate and grid spacing within the boundary layer is small enough to reflect as much detail as this experiment requires. Curvature at the sharp turning angle is smooth, therefore more flow properties data would be collected at those regions. 


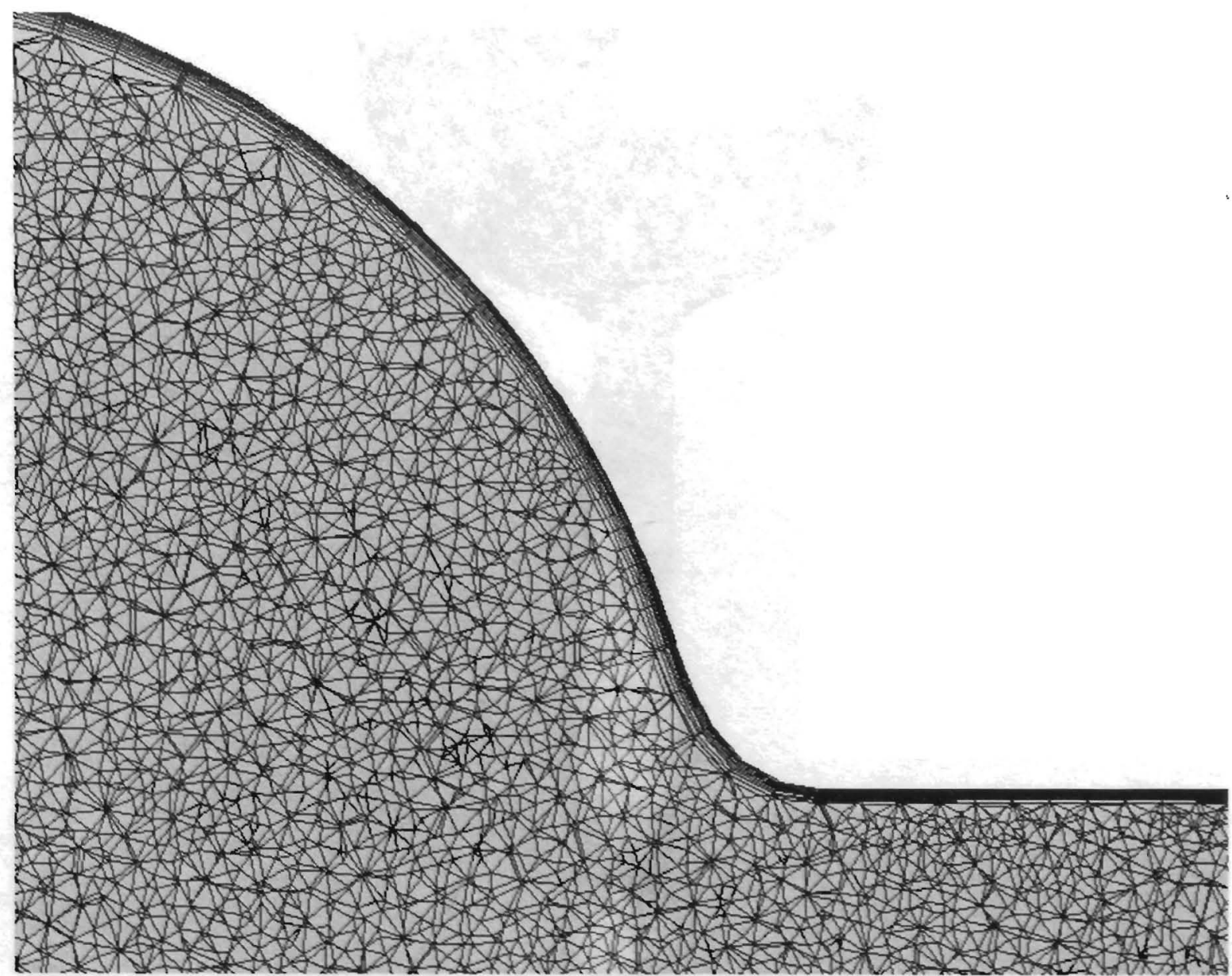

Figure 22: Grid (Sectional view, zoom in at inlet)

There are 3,588,989 number-of-cells in total. More cells are clustered behind the orifice plate and grid spacing within the boundary layer is small enough to reflect as much detail as this experiment requires. Curvature at the sharp turning angle is smooth, therefore more flow properties data would be collected at those regions. 


\section{Chapter 5: CFD Result}

\subsection{Star-CD}

The process of computational flow simulation should not start with the direct use of a CFD code without knowing the input data. Star-CD as well as any other CFD programs is a tool to assist the engineer in understanding physical phenomena. The accuracy or reliability of the result from fluid flow simulation depends not just on the CFD coding, but also upon the input data, such as 1) geometry of the flow domain, 2) setting of the fluid properties, 3) use of boundary conditions and 4) solution control parameters. The model must be physically realistic and correctly presented to the analysis code in order to have any chance of success in the simulation. Star-CD version 3.24 .000 was used in this research project.

As provided by Bombardier Aerospace, Star-CD is reliable enough to perform the flow simulation for this project. As explained above, in order to get realistic results from Star$\mathrm{CD}$, the boundary condition are as important as the choice of CFD code. Both the experiment and CFD geometries and dimensions are shown below in Figures 23 and 24. Detailed settings will not be shown in this report; however, some key information will be listed below. 


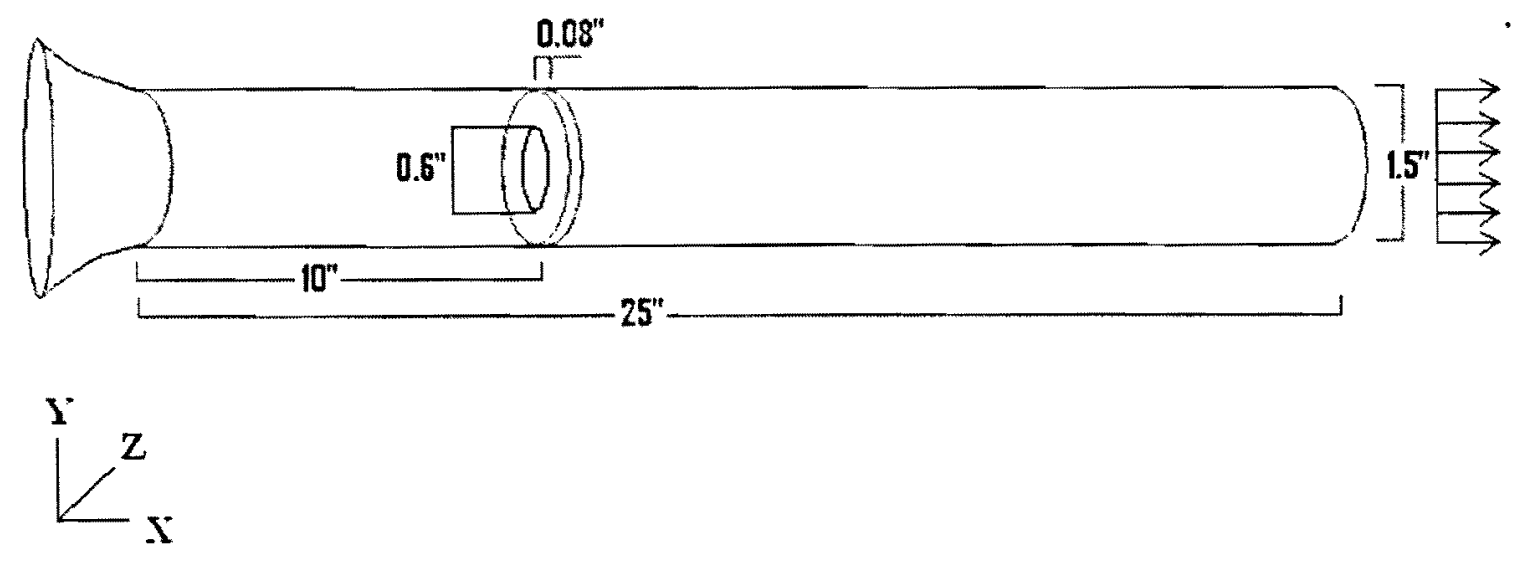

Figure 23: Experiment Geometry
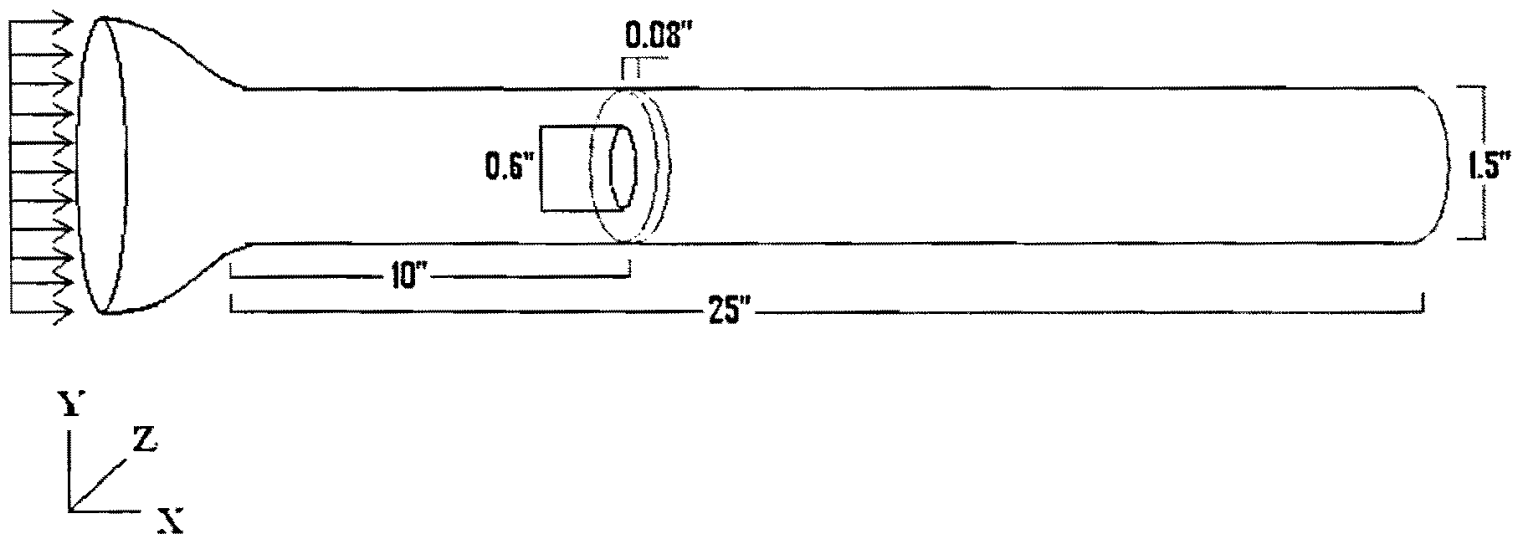

Figure 24: CFD Geometry

\subsection{Boundary Conditions and Flow Properties}

As seen in the experiment geometry, the experiment will be performed starting with flow vacuumed in from the far right side of the pipe. The length of the pipe behind the orifice plate is long enough to let boundary layer grow to produce a fully developed flow. The bell mouth inlet is specially design to avoid flow separation at the inlet as well as simplify the modeling process for CFD simulation. 

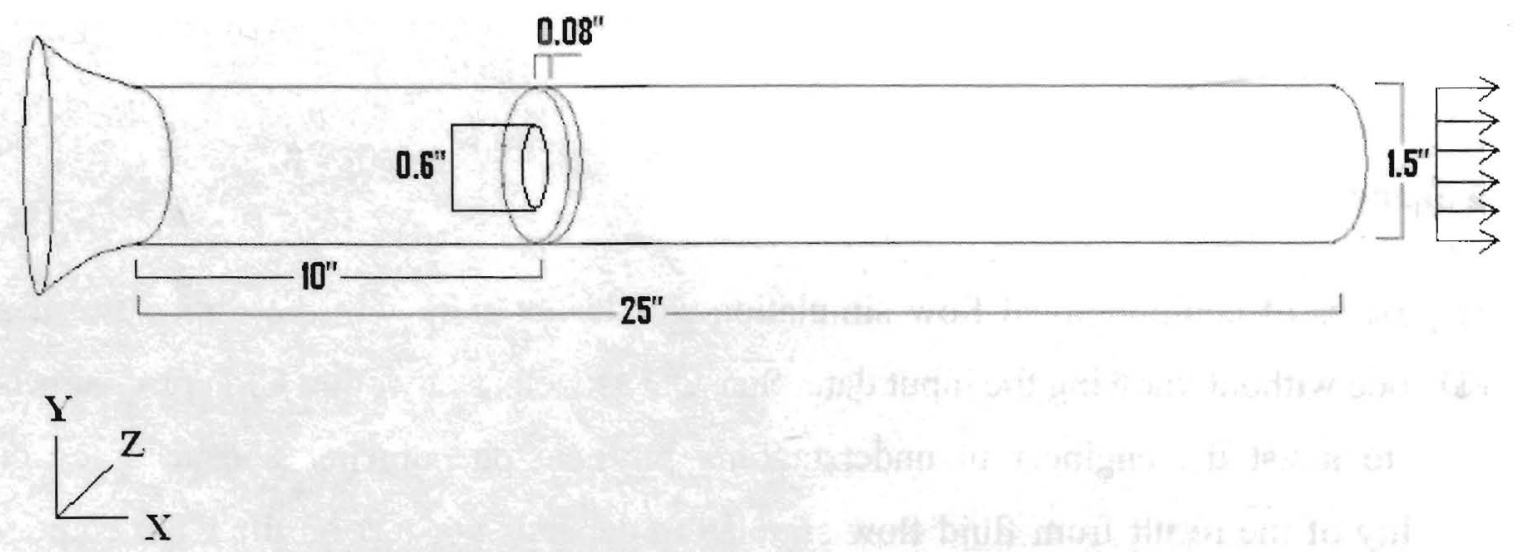

Figure 23: Experiment Geometry
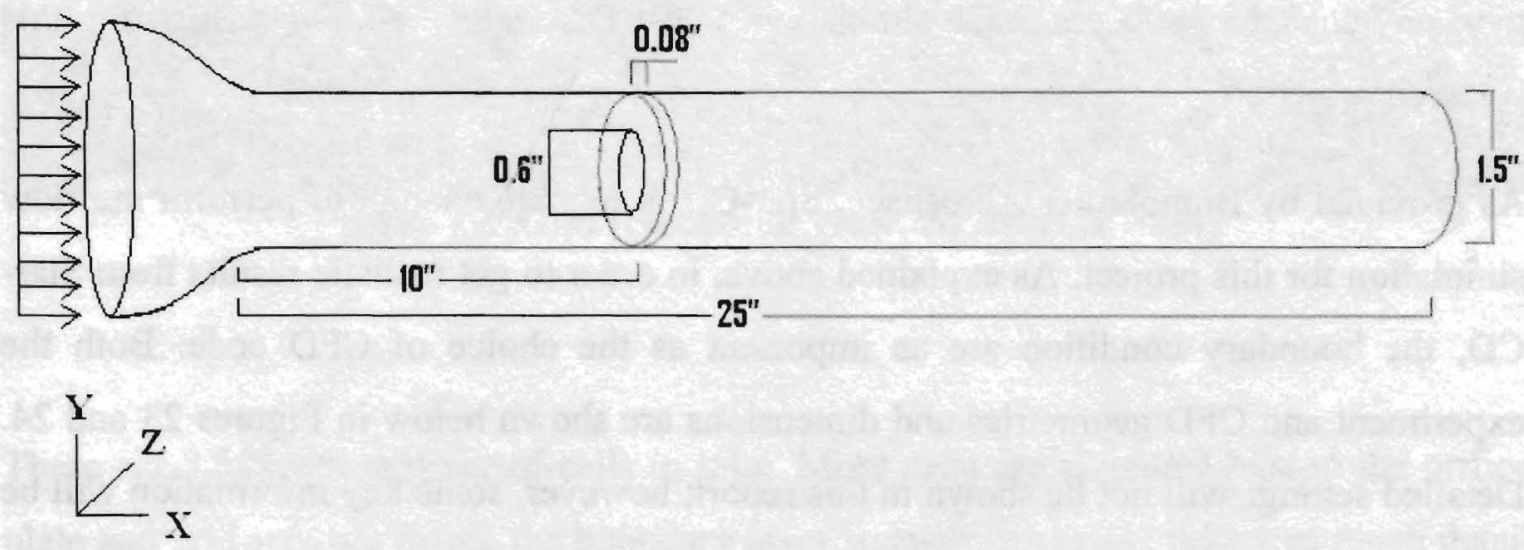

Figure 24: CFD Geometry

\subsection{Boundary Conditions and Flow Properties}

As seen in the experiment geometry, the experiment will be performed starting with flow vacuumed in from the far right side of the pipe. The length of the pipe behind the orifice plate is long enough to let boundary layer grow to produce a fully developed flow. The bell mouth inlet is specially design to avoid flow separation at the inlet as well as simplify the modeling process for CFD simulation. 
Due to the setup constrains of the computational fluid dynamic program, the simulation cannot match the experimental setup exactly. However, the flow conditions and the physical boundary conditions of the flow will be model exactly the same, therefore, the result will be realistic and matched to the experimental data.

For an inlet without a bell mouth, when flow is vacuumed in from the outlet, air will come in at all directions at the inlet, producing vortices which reduce the effective inlet area and create more noise than expected. CFD analysis showing random velocity vector build up at the inlet of a pipe without the bell mouth is shown in Figure 25.

The bell mouth design in the experimental setup helped to eliminate flow separation by reducing the flow turning at the inlet, which also reduces the noise from the inlet. Instead of modeling flow coming in at all direction at the inlet in the CFD simulation, a half sphere geometry is added in front of the bell mouth to simulate that flow coming in straight in farfield and curving at the bell mouth inlet. A schematic is shown in Figure 26.

The simulation can be simplified as a one-dimensional flow. Flow enters at the inlet, the left side in CFD geometry, at an average velocity of $0.28485 \mathrm{~m} / \mathrm{s}$ in axial direction and exits at the right hand side of CFD geometry. In order to match the physical experiment, the outlet is set to match the ambient pressure. As seen below in Figure 27, flow separation is avoided at the inlet. 


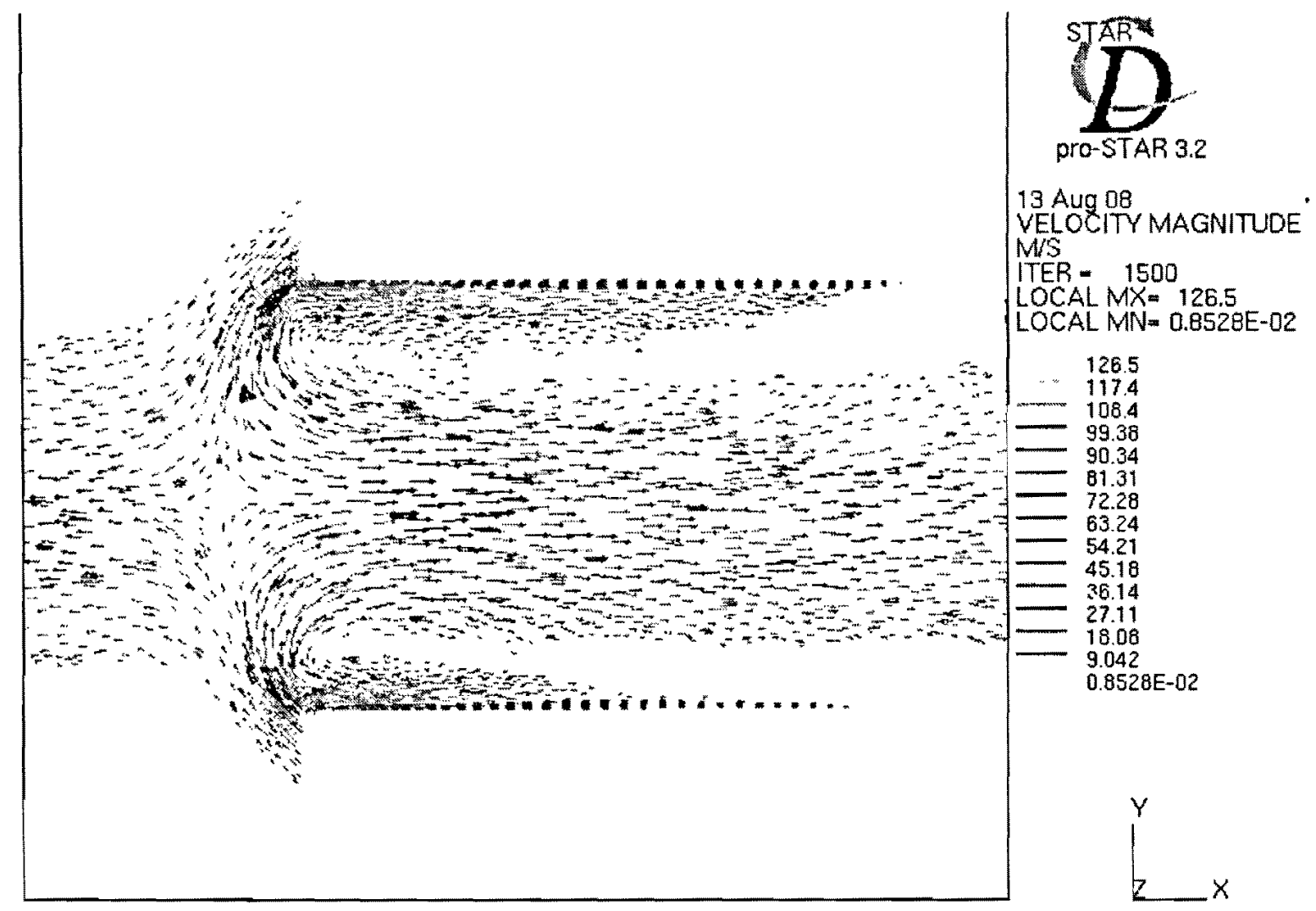

Figure 25: Flow coming in at all direction, flow separation at inlet

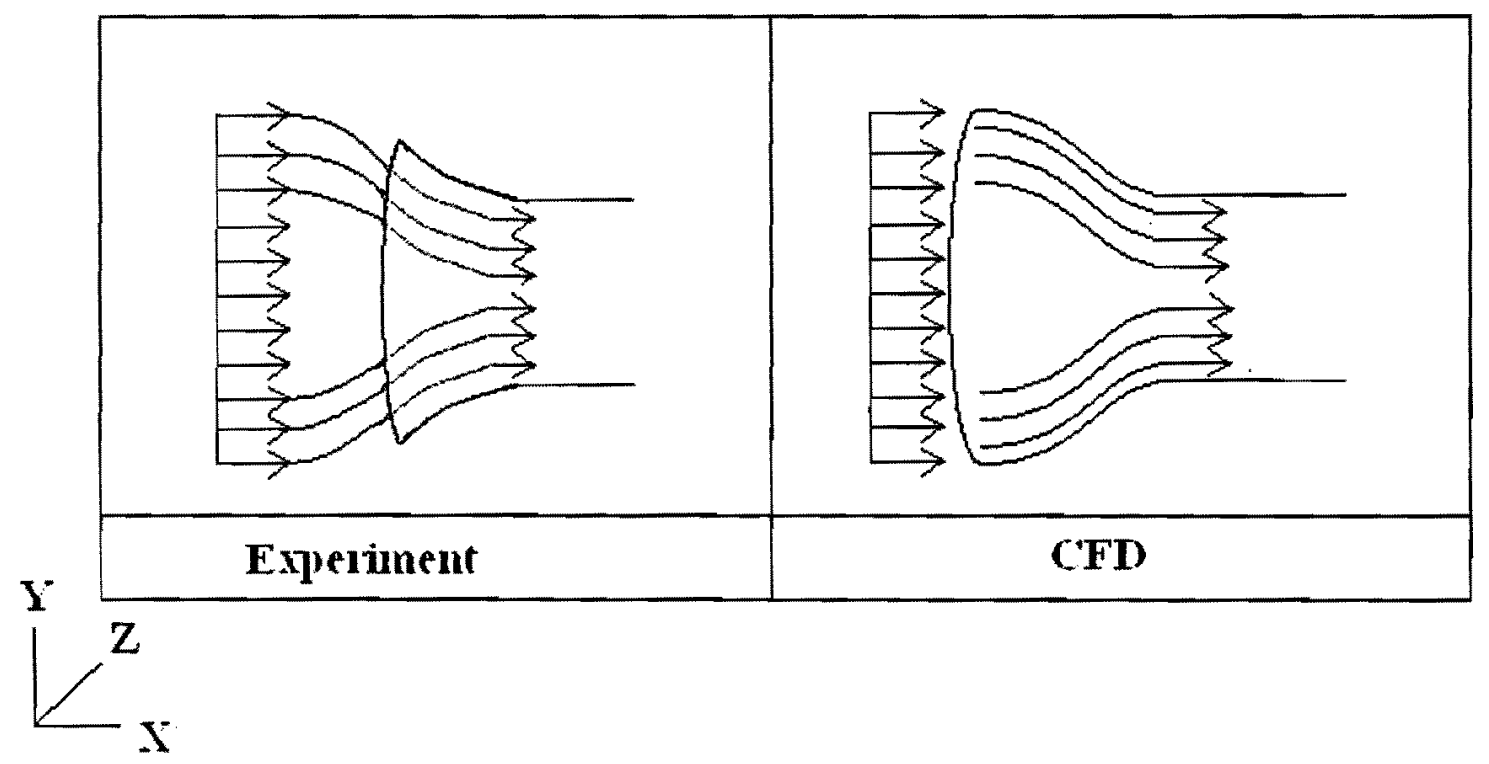

Figure 26: CFD inlet is setup similar to the experiment 


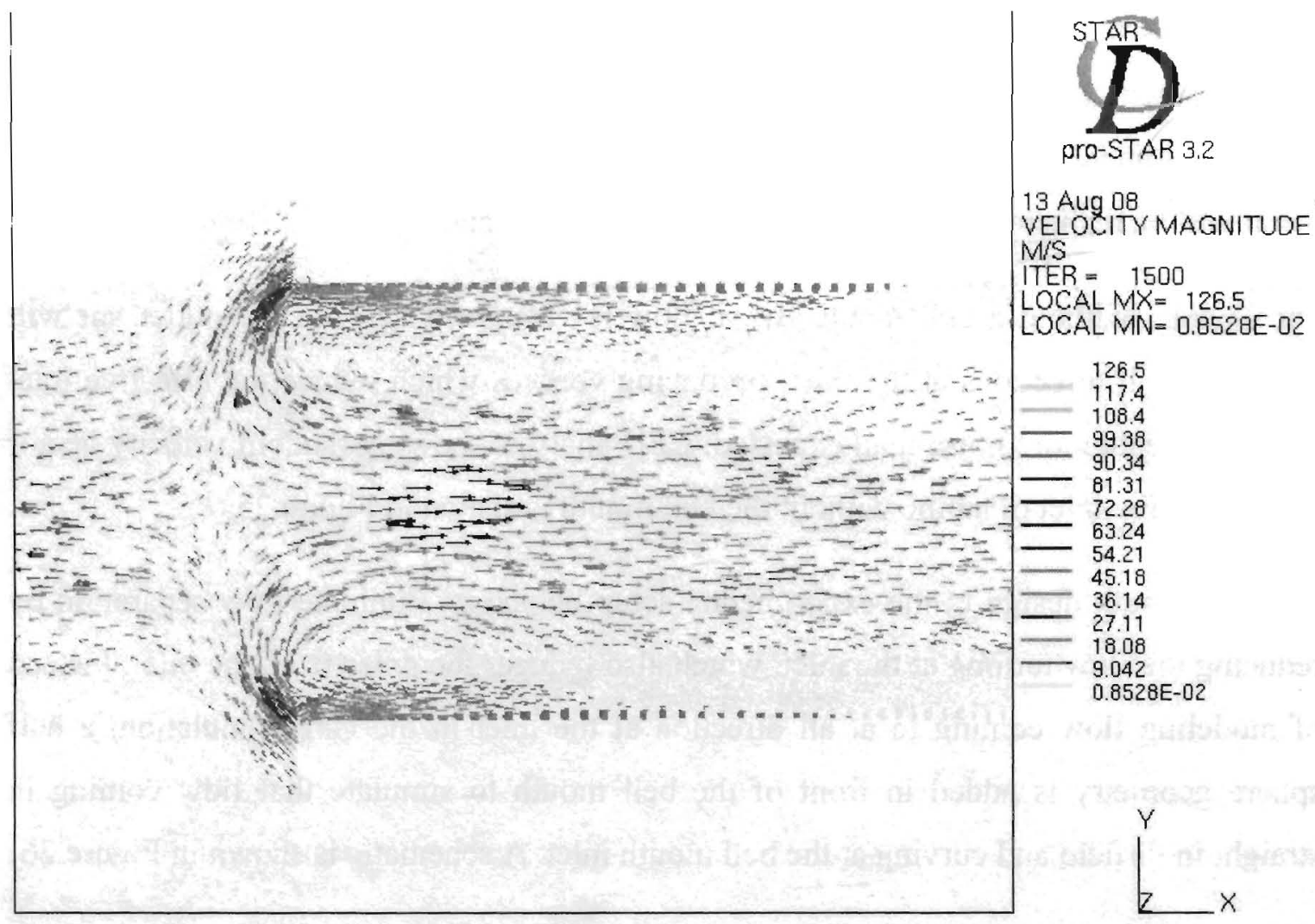

Figure 25: Flow coming in at all direction, flow separation at inlet

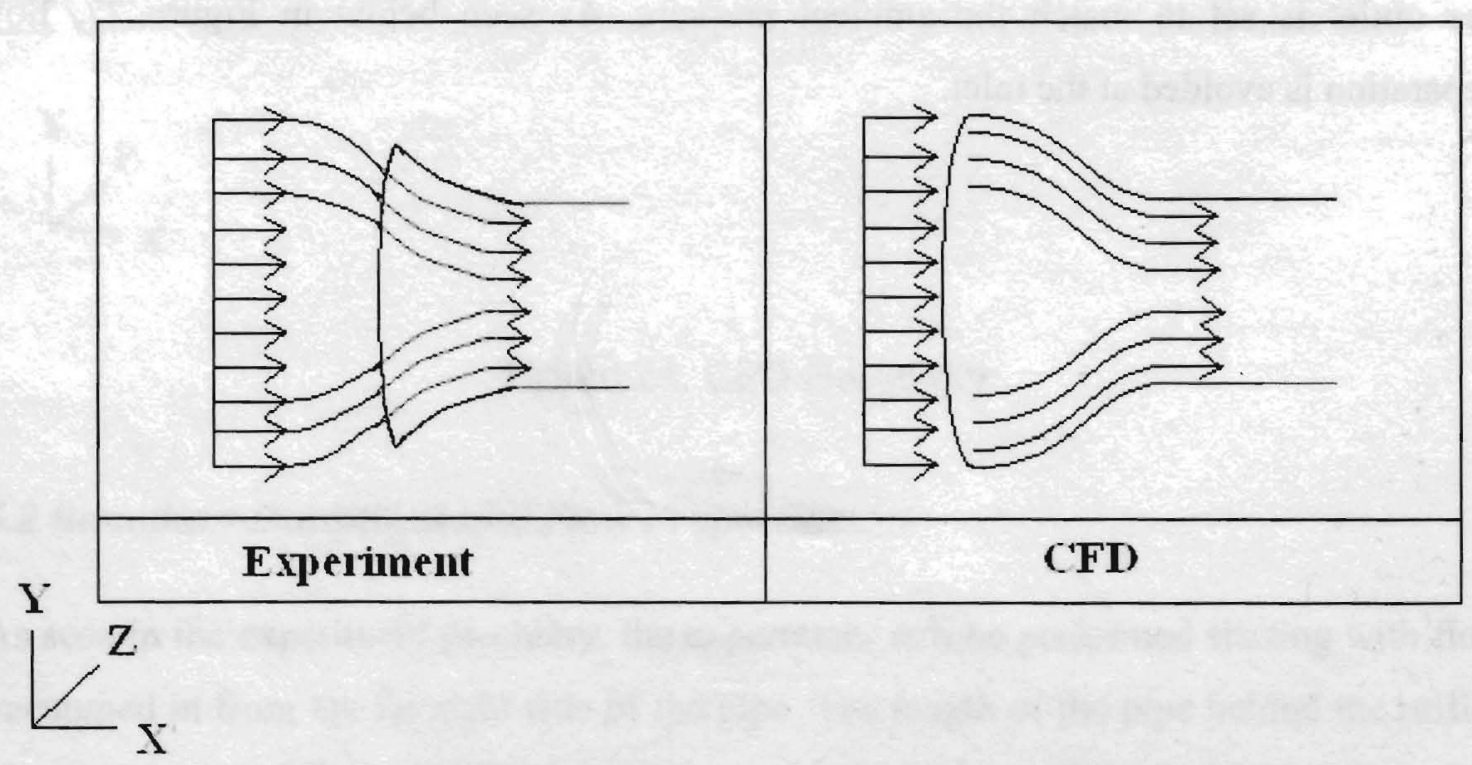

Figure 26: CFD inlet is setup similar to the experiment 


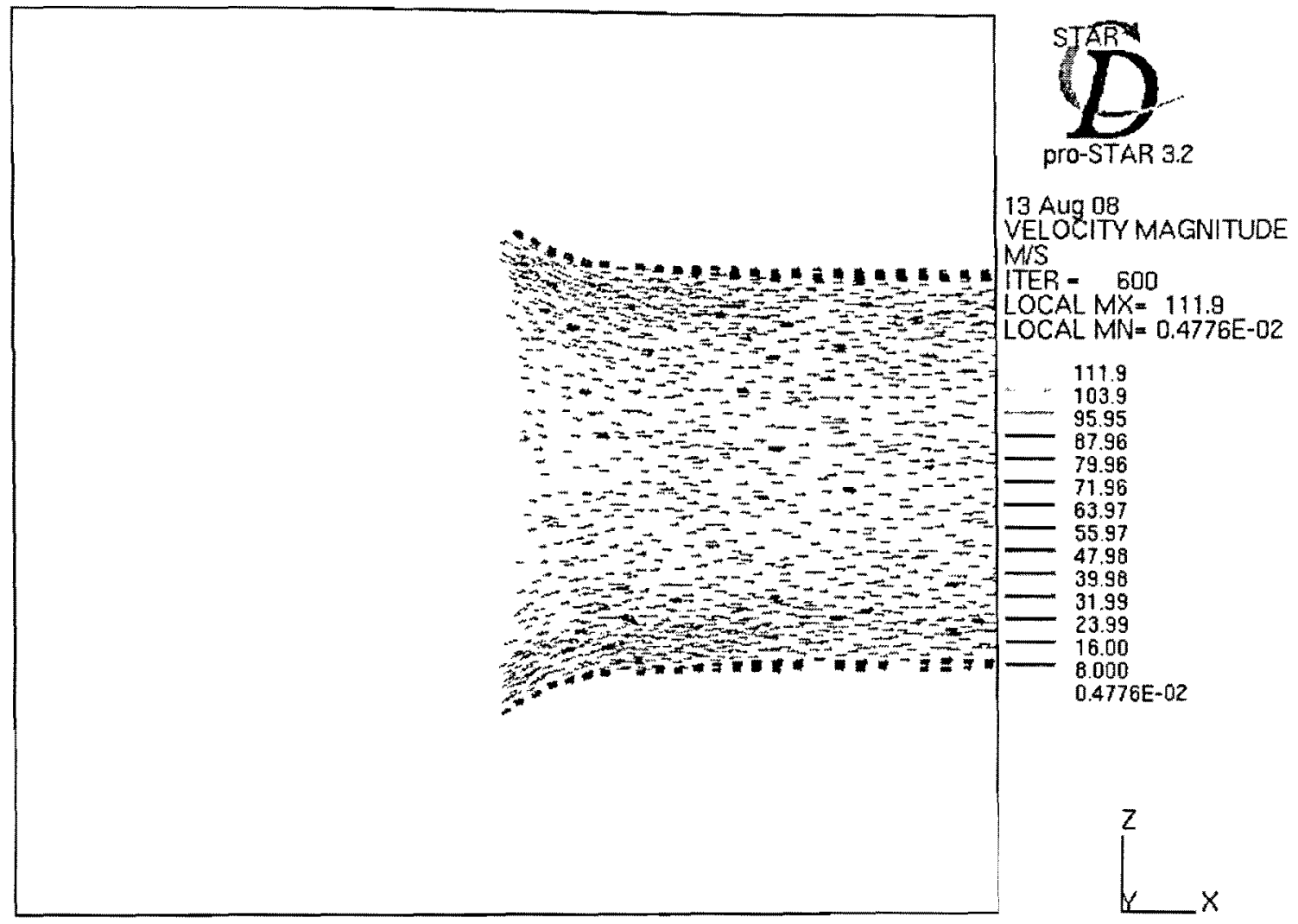

Figure 27: Flow coming in smoothly with no flow separation at inlet

The Spalart-Allmaras model is a one-equation model that solves a modeled transport equation for the kinematic eddy (turbulent) viscosity. This model was designed specifically for low-Reynolds-number aerospace applications involving wall-bounded flows and has been shown to give good results for boundary layers subjected to adverse pressure gradients. [35] The Spalart-Allmaras model required the viscous-affected region of the boundary layer to be properly resolved. This may make it the best choice for relatively crude simulations on coarse meshes where accurate turbulent flow computations are not critical. Furthermore, the near-wall gradients of the transported variable in the model are much smaller than the gradients of the transported variables in the $k$ - $\epsilon$ energy equation models. [35] This can make the model less sensitive to numerical error when non-layered meshes are used near walls. As suggested by George Waller, senior of advanced aerodynamics engineering and product development at Bombardier Aerospace, in personal communication, the Spalart-Allmaras / Low Reynolds turbulence model is suitable for this project. 


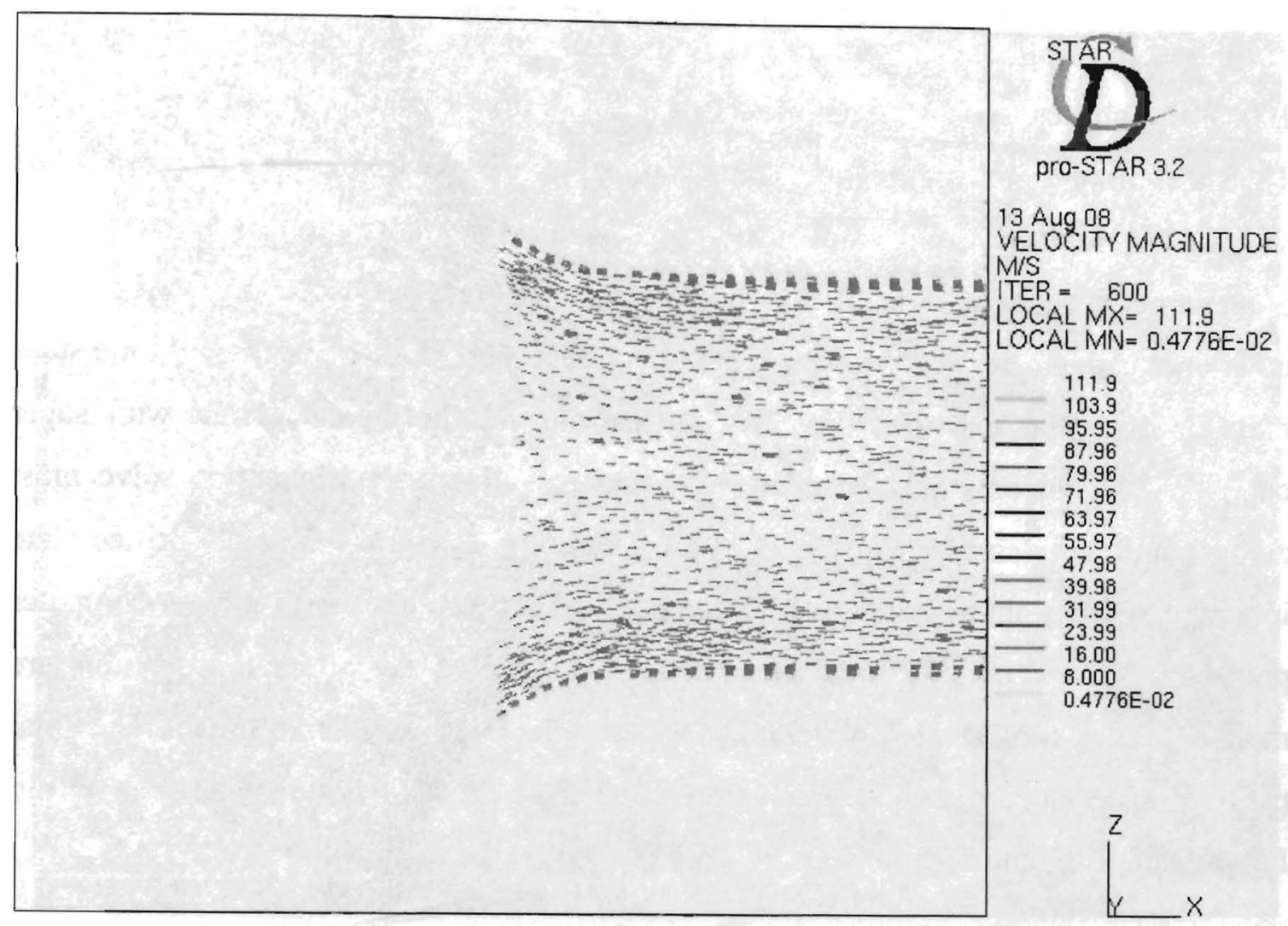

Figure 27: Flow coming in smoothly with no flow separation at inlet

The Spalart-Allmaras model is a one-equation model that solves a modeled transport equation for the kinematic eddy (turbulent) viscosity. This model was designed specifically for low-Reynolds-number aerospace applications involving wall-bounded flows and has been shown to give good results for boundary layers subjected to adverse pressure gradients. [35] The Spalart-Allmaras model required the viscous-affected region of the boundary layer to be properly resolved. This may make it the best choice for relatively crude simulations on coarse meshes where accurate turbulent flow computations are not critical. Furthermore, the near-wall gradients of the transported variable in the model are much smaller than the gradients of the transported variables in the $k$ - $\epsilon$ energy equation models. [35] This can make the model less sensitive to numerical error when non-layered meshes are used near walls. As suggested by George Waller, senior of advanced aerodynamics engineering and product development at Bombardier Aerospace, in personal communication, the Spalart-Allmaras / Low Reynolds turbulence model is suitable for this project. 
For output control, 10,000 iterations were used, and the output frequency was set to be 100. The time step was set at a constant 0.1 millionth of a second for the entire simulation The smaller the time step, the more computational time is required to get a result from the simulation. However, from an acoustic point of view, a small time step is required in order to get accurate and detail flow properties as the flow passes the orifice plate. For other applications, i.e. CFD analysis for flap or other high lift device, a bigger time steps may be used. For example, normal CFD analysis for the whole aircraft with super computers would only take two hours to get result that are sufficient to solve most aerodynamic problems.[5] For this simple geometry, transient flow through orifice plate in a pipe, it takes almost three days to complete 10,000 iterations with 8 super computer processors. To prepare for post process noise analysis, a set of reference points are monitored in Star-CD during iteration and air pressure value is recorded. The total pressure and velocity contour graph from CFD transient flow simulation are shown in Figure 28, 29, 30 and 31 .

The main focus of this research is to determine the noise generation due to flow passing through orifice plate. Total pressure is constant at the inlet which demonstrates that there is no significant pressure fluctuation creating noise at this region. Total pressure dropped when crossing the orifice plate which matched with the pipe flow theory. Total pressure is constant at outlet as well, which is equivalent to the experiment setup.

Figure 29 shows that there are no vortices before the flow passes the orifice plate. Velocity in the half sphere is low, which is best simulating constant velocity entering the pipe from far field. The transient velocity profile indicates that boundary layer is fully developed before it entered the orifice plate. After flow separation due to the orifice plate, the velocity goes back to uniform at the exit of the pipe. These boundary conditions matched the experimental setup. Figure 30 shows a clearer view of the velocity profile as well as the flow separation generation due to the orifice plate. 


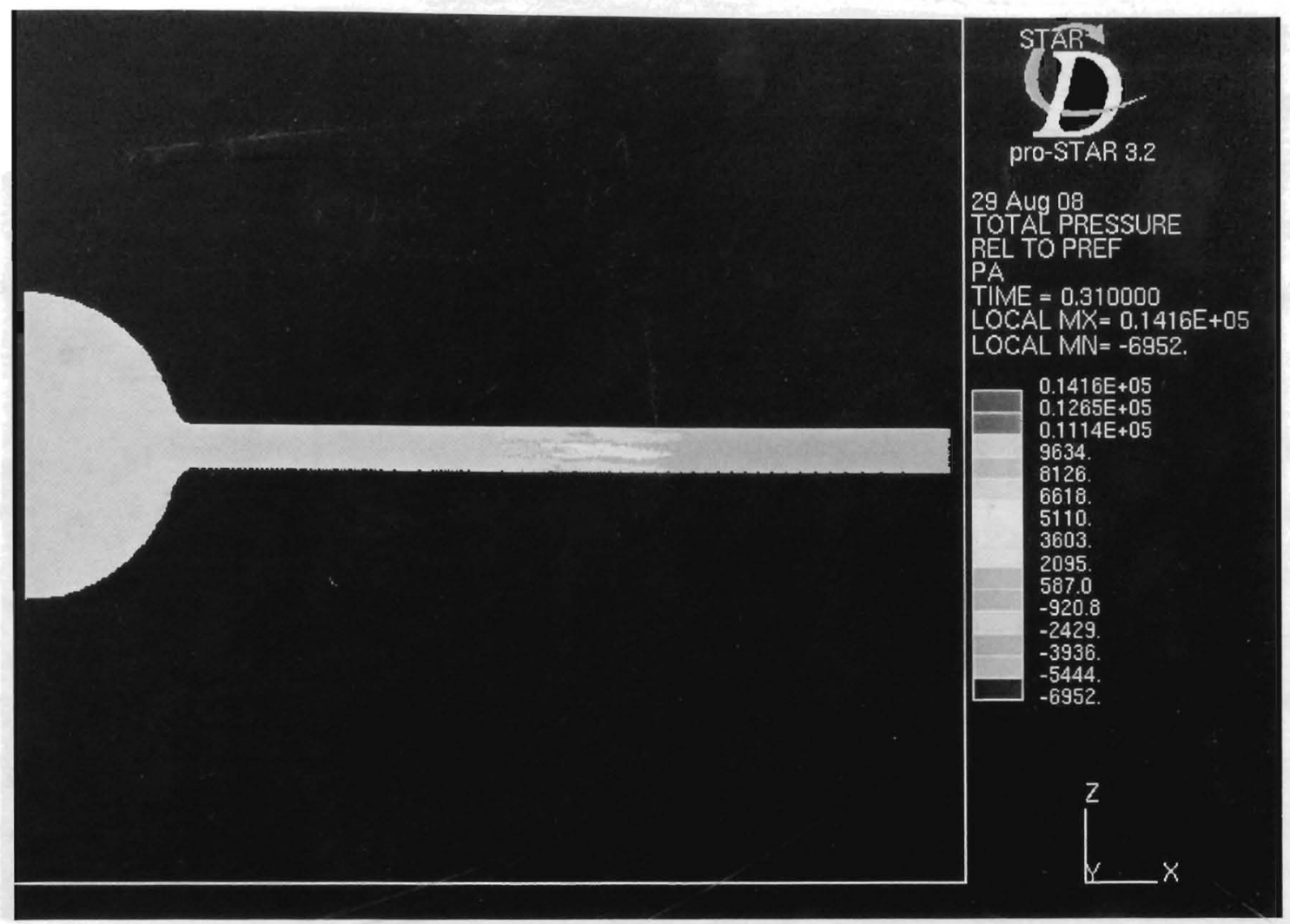

Figure 28: Total pressure contour graph

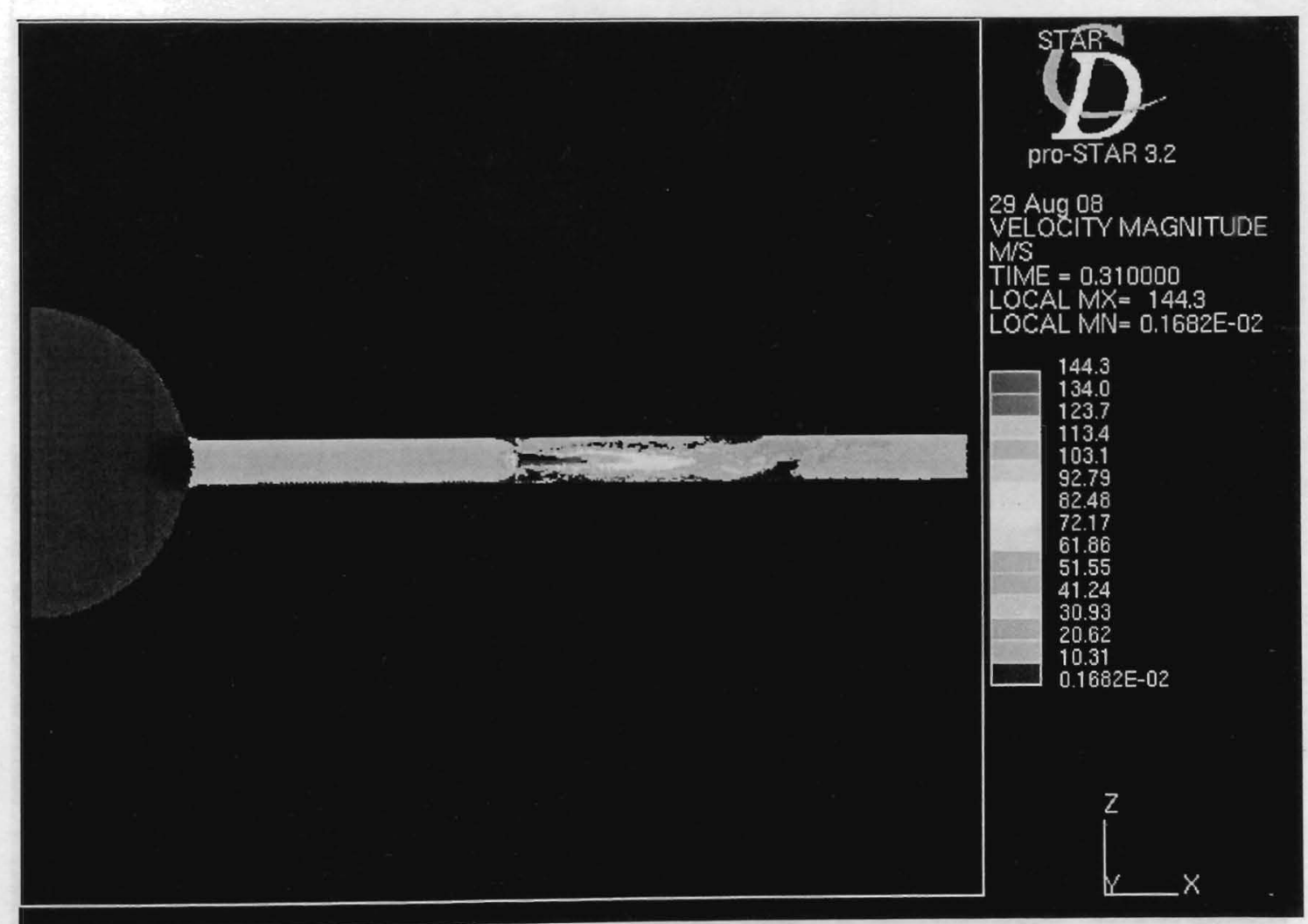

Figure 29: Velocity contour graph 


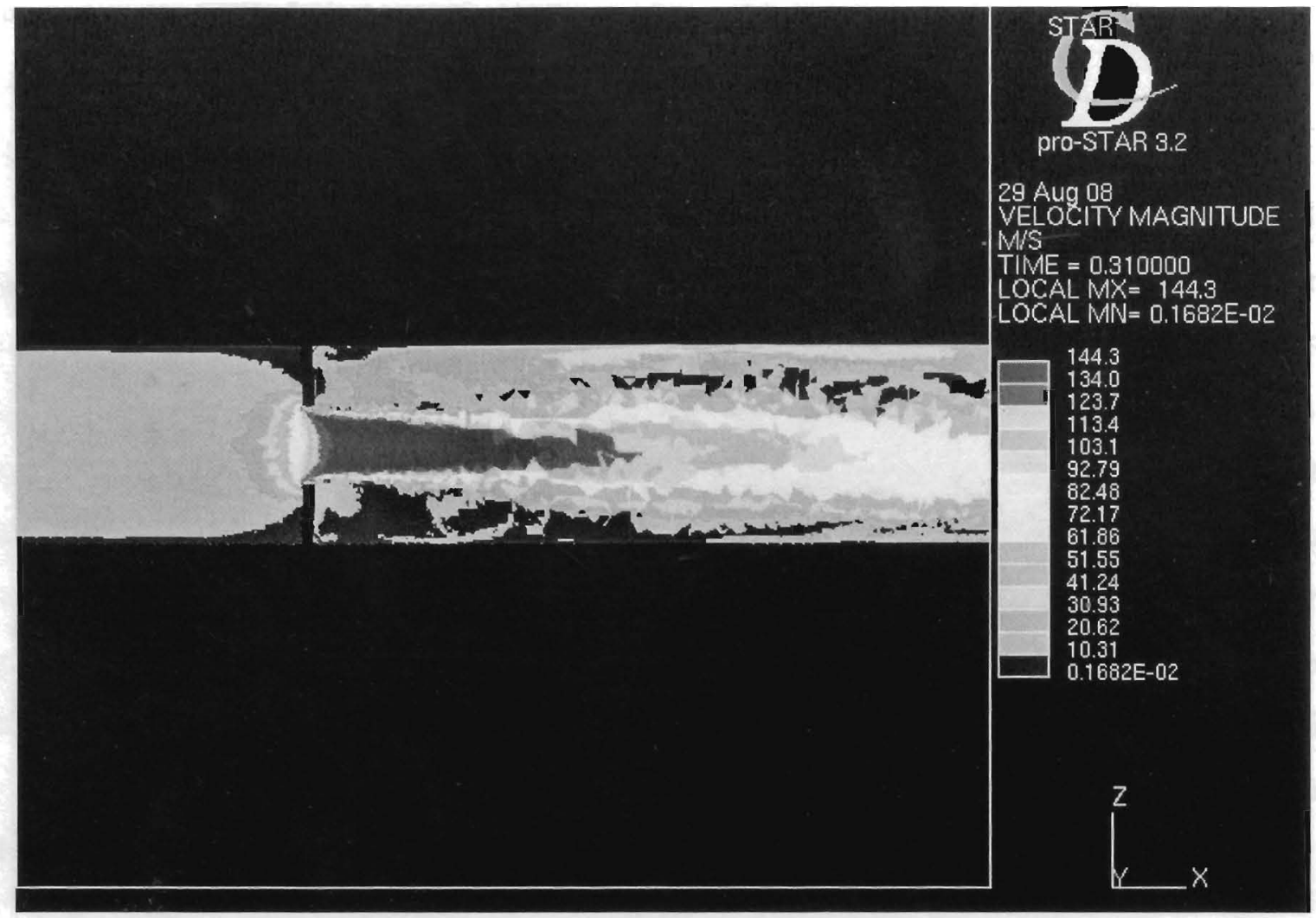

Figure 30: Velocity contour graph behind orifice plate

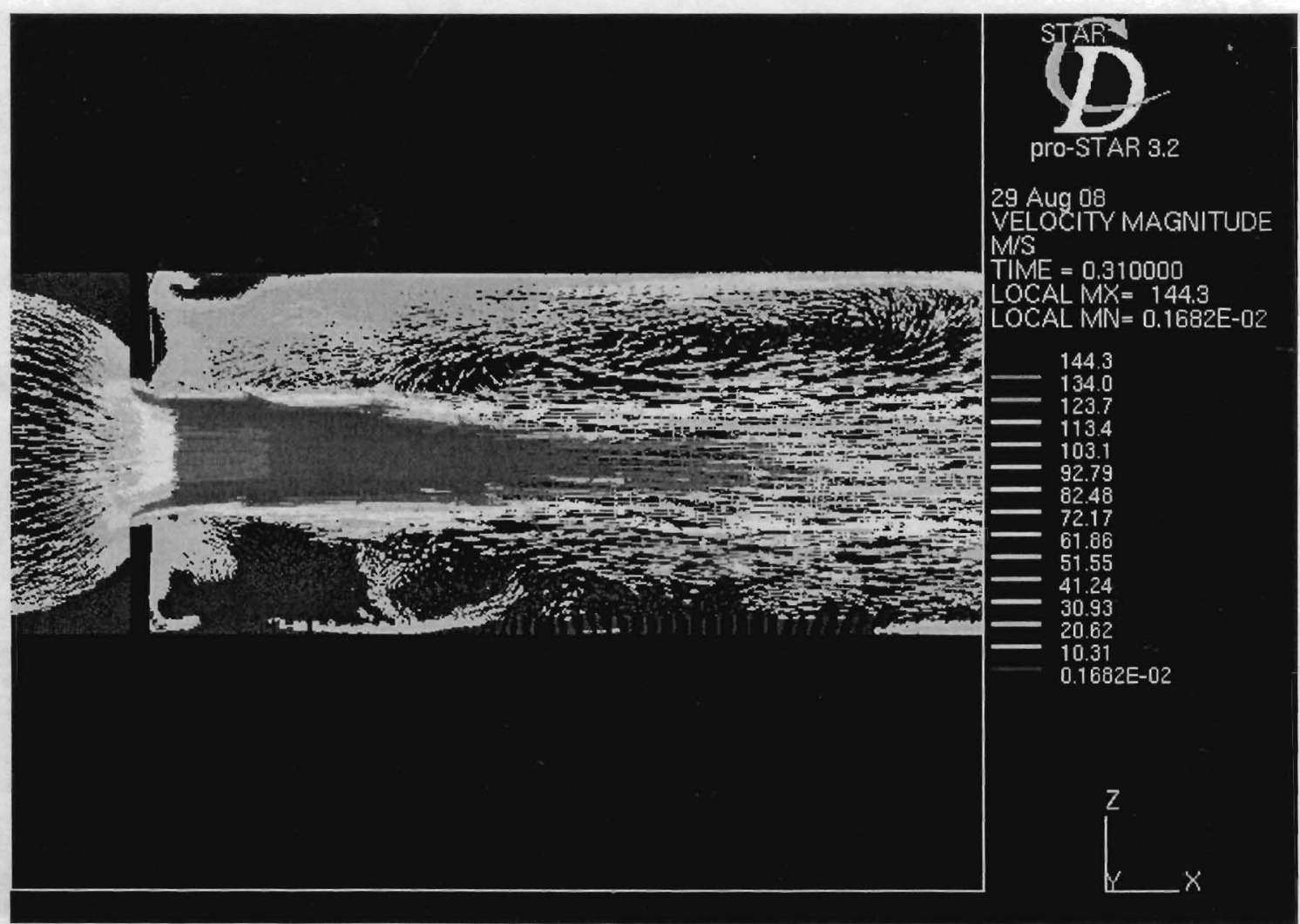

Figure 31: Velocity vector graph behind orifice plate 
Figure 31 gives a clearer view of where the vortices are and how they developed. High velocity air coming out from the small diameter orifice hole, expands to fill a big diameter pipe, created a reversal flow at the top and bottom boundary layer. This reversal flow caused the formation of the vortices at the corners and areas between the jet stream and the boundary. As explain in the previous chapters, large vortices will generate low frequency noise and broadband noise is as expected.

With the flow properties calculated from Star- $C D$, the Ffowcs Williams-Hawkings (FWH) equation and Discrete Fourier Transform (DFT) is applied to convert air pressure into sound pressure, and then transform sound pressure to a noise signal. With FWH and DFT one can propagate the source of the sound pressure to any location which in this simulation is the location of the microphone in the experiment. In-house developed code was provided by Bombardier to perform this transformation. Therefore, the noise signal can be compared with noise collected from experiment numerically, which is at the inlet of the pipe, and is given in Figure 32. The average percent error is less than 10\%.

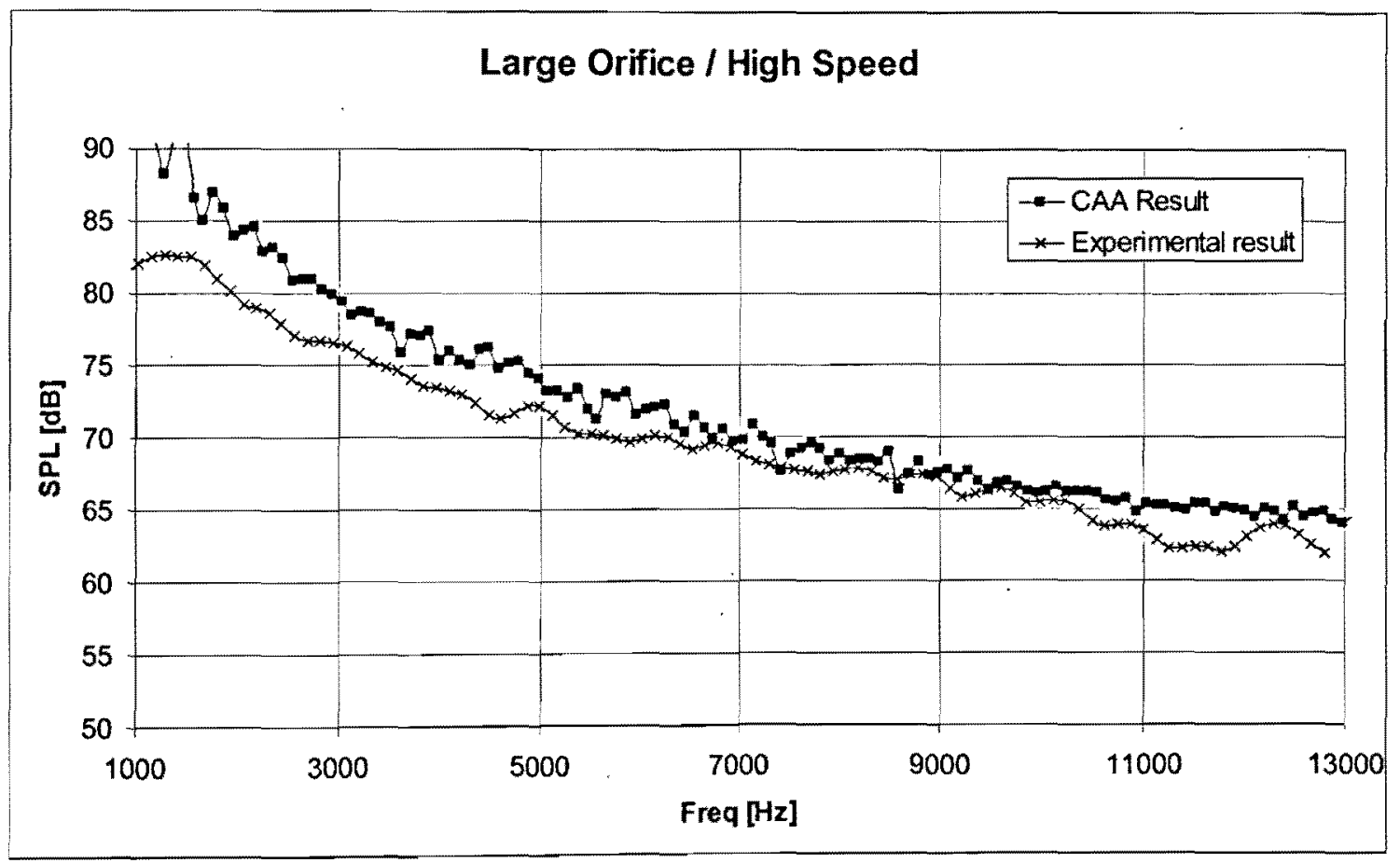

Figure 32: Result from CAA and Experiment 
Bombardier had run an experiment with different flow speeds with different sized orifice plates. Large orifice plate with high speed is what being model in the computational simulation.

Microphone sensitivity and background noise caused the actual measured sound pressure to be lower than the computed aero-acoustic value. As explained before, sound pressure fluctuated across a wide range of frequencies and it is almost impossible to measure the actual pressure level, at least at the time of this writing. Loss in signal is hard to avoid during measurement, which leads to a higher computational $\mathrm{dB}$. However, the percent error is low and it is within an acceptable range. [39]

\subsection{Grid Refinement and Accuracy Check}

These comparisons, shown in Figure 32, indicated that the lowest percent error in the average sound pressure levels could be achieved when a few critical flow parameters were met. Our results showed that the fully developed velocity profile entering the orifice region and the total pressure drop across the actual orifice plate were the two most important parameters to be controlled. These can be achieved by refining the gird and adjusting the inlet and outlet conditions.

\subsection{Tonal noise}

When flow passes through an orifice plate or a corner of a turning pipe, flow separation can occur. Large vortices generate low frequency noise, therefore, sound pressure level at low frequency is high and sound pressure level is low at high frequency. [39] Therefore, when air flow though an orifice plate inside a pipe, broad band noise tends to be produced.

The octave band was used to measure the noise in the experiment, however the results were not as detail as expected, therefore the experiment was repeated again with onethird octave band. In the experimental data collect from the one-third octave band, a high 
frequency tonal noise was detected at high speed flow with a small diameter orifice hole. These experimental results are shown in Figure 33.

It is believed that when the mass flow rate of the internal flow reached its critical speed, a jet stream is coming out from the exit of the orifice plate. [24] This jet stream effect may be the cause of the high frequency tonal noise, generated by the shear of the jet stream. For example, tonal or discrete frequency sound might be emitted in flow through a pipe in a similar way to most musical wind instruments. However, further study is needed to confirm this information, and it is beyond the scope of this research topic.

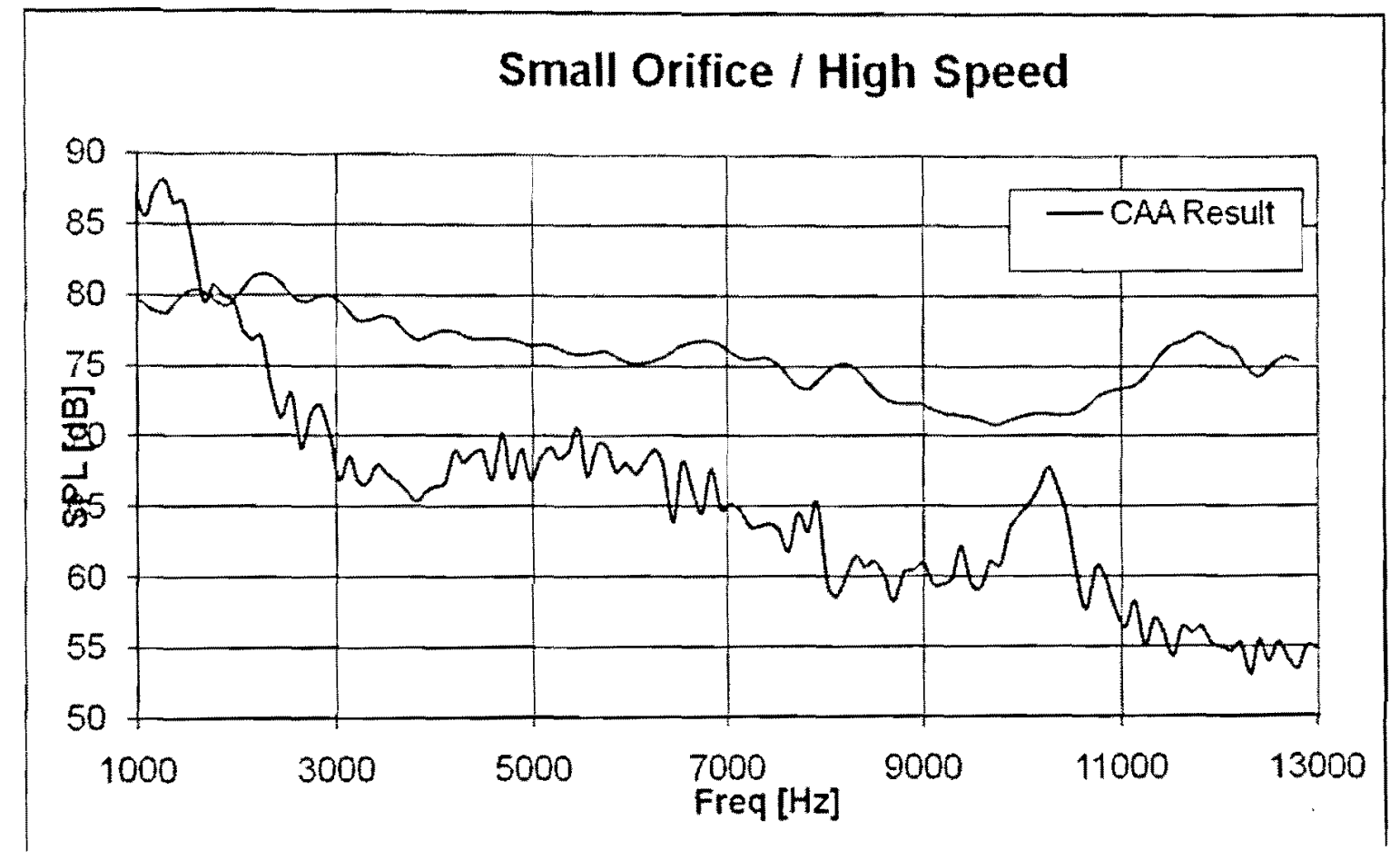

Figure 33: Result from CAA and Experiment 


\section{Chapter 6: Summary and conclusions}

\subsection{Summary of accomplishments}

This goal of this work was to simulate flows through ducts and orifice plates of an aircraft environmental control system and to compare the results with experimental data. As our focus was to investigate broadband rather than tonal noise, the percent error of the average sound pressure level was calculated over a range of frequencies and used to determine the reliability of the computational aero acoustics analysis that was performed in this work. With CATIA generated geometry, both steady and transient flows were simulated with the Star-CD computational fluid dynamic program provided by Bombardier Aerospace.

In this work a simple orifice plate in a pipe was used to model a single sub-configuration within a larger aircraft climate control system. Numerical simulations of this single subconfiguration were compared to experimental data. These comparisons showed that the lowest percent error in the average sound pressure levels could be achieved when a few critical flow parameters were met. Our results showed that the fully developed velocity profile entering the orifice region and the total pressure drop across the actual orifice plate were the two most important parameters to be controlled. With the experience and knowledge gain from simulating this single sub-configuration, the hope is that this success could extend, ultimately, to the full aircraft climate control system.

\subsubsection{Computational Aero Acoustics}

First, steady state simulations were conducted to verify appropriate grid resolution, to obtain the correct inflow boundary conditions needed to produce the required velocity profile crossing the orifice plate, and to ensure that the average pressure drop across the orifice plate matched experimentally verified values.

In this work, the computational inflow velocities and the exit pressures were adjust to obtain a fully developed flow entering the orifice plate region and to ensure the accuracy 
of the total pressure drop across the orifice plate. Since a significant region of flow separation and vorticity was found immediately behind the orifice plate, a grid resolution study was conducted to optimize the accuracy of our results. The error in the total pressure drop across the orifice plate was found to be within $6.63 \%$.

Then, transient simulations were conducted to obtain total pressure distributions at various locations behind the orifice plate. These total pressure values were then processed through a Discrete Fourier Transform to obtain sound pressures which were then plotted versus sound frequency.

Total pressures were recorded at one- and ten- diameter-length behind the orifice plate during the 10,000 iterations needed to achieve time periodicity. Given these results, the Ffowcs Williams-Hawkings Equation was used to transform these total pressures into sound pressures at the inlet.

\subsubsection{Experiment}

Based on our initial computation simulations, it was shown that a bell mouth inlet would be required to minimize any flow separation at the entrance to the pipe and orifice plate configuration. Preliminary simulations showed that without this inlet, flow separation would occur and thus the noise measured at the inlet would no longer be just the noise generate by the orifice plate.

With this new experimental setup, a microphone was placed at the center of the bell shaped inlet to record the noise propagated upstream from the orifice plat.

This experiment was performed for 3 different mass flow rates and 2 different orifice plate diameters. However, in this work numerical simulation was only compared to the results obtained from the largest orifice plate diameter. While experimental results were obtained for a smaller diameter orifice plate, these flows contain significant amount of tonal noise and thus were not included in our broadband noise investigation. 


\subsubsection{Comparison between computation and experimental result}

The computational predictions compared well with the experimental data. Because sound pressure waves travel in all directions, and with constant expansion and contraction, there will always be some variation in the sound measurements that cannot be avoided. In this. work the differences between the experimental and numerical results were found to be less than $10 \%$, and given the variations that are sure to exist in the experimental data, these numerical results were consider acceptable.

\subsection{Future research}

In this work a simple orifice plate in a pipe was used to model a single sub-configuration within a larger aircraft climate control system. With the success of these simulations, the next step would be to extend these results to the simulation of the full aircraft climate control system. However, within the full aircraft climate control system, both broadband and tonal noises are likely to exist.

Further study is needed to optimize flow simulations and acoustic calculations for the tonal noise that is likely to be produced by small diameter orifices. In fact an understanding of both broadband and tonal noise, and their ultimate effect on passenger comfort, may lead to an optimization of the sizes and shapes of the orifice plates found in future aircraft environmental control systems. 


\section{Reference}

[1] Abdelhamid, Yahia A and Lian L Ng. "Fan Broadband Noise Generation and Propagation." AlAA 2006-215 (2006).

[2] Abom, Mats, Sabry Allam and Susann Boij. "Aero-Acoustics of Flow Duct Singularities." AIAA 2006-2687 (2006).

[3] Acoustical Consultants Noise Management. "Acoustical Consultants Noise Handbook." 9 November 2008. Acoustical Consultants. 19 November 2008 $<$ http://www.atcoacoustical.com/NOISE_HANDBOOK.pdf>.

[4] Anderson, John D. Jr. Aircraft Performance and Design. United State of America: Thomas Casson, 1999.

[5] -. Fundamentals of Aerodynamics 3rd Ed. New York: Thomas E. Casson, 2001.

[6] Baillie, Kenneth, et al. Barometric Pressure Calculator. 19 January 2008. November 2008 <http://www.altitude.org/calculators/airpressure.htm>.

[7] Bell, Lewis H. Fundamentals of Industrial Noise Control. Trumbull: Harmony, 1973.

[8] Bombardier. "Fundamentals and Interior Noise." Acoustics Fundamentals. Toronto: Aero acoustic team, 2008.

[9] Burden, Richard L and Douglas J Faires. Numerical Analysis 8th Ed. Thomson Learning Emea, n.d.

[10] CAFE Foundation \& The GAT Challenge. Enabling Technologies - Noise Technologies. 2008. 1 November 2008

<http://cafefoundation.org/v2/pav_enablingtech_noisetech.php>.

[11] Carlson, Robert W. "What You Don't Know Might Kill You." Supplemental Oxygen for the General Aviation Pilot (1998).

[12] CD-adapco STAR-CD. StarCD Version 3.20 Manual. CD-adapco, n.d.

[13] Centaur Soft. Centaur IGES Convertor Tutorial. 2008. November 2008 $<w w w . c e n t a u r s o f t . c o m>$.

[14] Climate Action Network Europe. "Response to the European Commision Consutlation Paper: How to Considerably Reduce Greenhouse Gas Emissions Due to Mobile Air 
Conditioners." March 2003. Climate Action Network Europe Web site. 28 November 2008 <http://www.climent.org/EUenergy/position_papers_FGases.html>.

[15] Everest, Alton F. The Master Handbook of Acoustics. 3rd. New York: Tab Books, 1994.

[16] Federal Aviation Administration. "Hearing and Noise in Aviation." Federal Aviation Adminstration (2008).

[17] Federal Aviation Regulation. FAA Regulations. USA: Federal Aviation Adminstration, 2008.

[18] Glenn Research Center. National Aeronautics and Space Administration. 11 July 2008. 2008 <http://www.grc.nasa.gov/WWW/K-12/airplane/boyle.html>.

[19] Hogan, Michael C. and Jorgen Ravnkilde. "Design of Acoustical Insulation for Existing Residences in the Vicinity of San Jose Municipal Airport." Transportation Research Board, 1985. 54-59.

[20] Idelchik. Handbook of Hydraulic Resistance 3rd Ed. Connecticut: Begell House, 2001.

[21] Laming, J. "Helios Out Of Oxygen." Flight Safety Australia Magazine (2005): 27-33.

[22] Lassaline, Jason V. "Heat and Mass Transfer." Toronto: Ryerson University, 2005.

[23] Liu, Guanjun. "Avionic System Lecture." Toronto: Ryerson Univerity, 2006.

[24] Lyrintzis, A S and A Uzun. "Integral Techniques for Jet Aeroacoustics Calculations." AlAA 2001-2253 (2001).

[25] Moir, lan and Allan Seabridge. "Civil Avionics Systems." Przemieniecki, John S. AlAA Education Series. Ohio: Education Series, 2003. 293-98.

[26] Nise, Norman S. Control Systems Engineering 4th Ed. Danvers: John Wiley \& Sons, 2004.

[27] Pang, Benny. "Introduction to Aircraft Community Noise." Community Noise. Toronto: Aero acoustic team, 2008.

[28] Parthasarathy, V, Y Kallinderis and K Nakajima. "Hybrid Adaptation Method and Directional Viscous Multigrid with Prismatic-Tetrahedral Meshes." AlAA $95-0670$ (1995).

[29] Physikalisch-Technische Bundesanstalt. "Music As Noise: When the Fortissimo Causes One's Ears To Ring." 17 November 2008. Science Daily. 30 November 2008 <http://www.sciencedaily.com/releases/2008/11/081111093924.htm>.

[30] Poon, C. "Manufacturing Management Lecture Note." Ryerson University. 2007.

[31] Ripka, LV. "Glossary." Plumbing Design and Installation 3rd Ed. Amer Technical Pub, 2002. Glossary. 
[32] Schetz, Joseph A. Boundary Laver Analysis. New Jersey: Prentice-Hall, 1993.

[33] Shivashankara, Belur, et al. "Future Looks Quiet." 777-200LR Flight Test Journal: Archieves (2005).

[34] Silkirk College. Professional Pilot. 2008. November 2008 <http://selair.selkirk.bc.ca/index.html>.

[35] Spalart, P and S Allmaras. "A One-Equation Turbulence Model for Aerodynamic Flows." AIAA 92-0439 (1992).

[36] Spehr, C, et al. "Simulation of Flow-Induced Noise Generation on Orifice Plates in Airconditioning Ducts." AIAA 2008-3022 (2008).

[37] Tanaka, Susan Reed and Sandra Lougheed. H-Series Subway Car. 17 December 2006. 28 November $2008<$ http://transit.toronto.on.ca/spare/0008.shtmil.

[38] Vainchtein, Mike. Diesel City Bus, Toronto Transit Commission. 10 November 2006. 28 November 2008 <http://transit.toronto.on.ca/bus/8509.shtmls.

[39] Waller, George. Interview. Arthur Lin. 2008.

[40] Ziegler, Shayne and Steven Shapiro. "Computer Simulation of an Aircraft Environmental Control System." Flowmaster International Ltd. USA, 2003. 